\title{
Longitudinal Patterns and Economic Consequences of Emergency Department Visits among Medicaid Enrollees
}

\author{
Parul Agarwal
}

Follow this and additional works at: https://researchrepository.wvu.edu/etd

\section{Recommended Citation}

Agarwal, Parul, "Longitudinal Patterns and Economic Consequences of Emergency Department Visits among Medicaid Enrollees" (2015). Graduate Theses, Dissertations, and Problem Reports. 5032.

https://researchrepository.wvu.edu/etd/5032

This Dissertation is protected by copyright and/or related rights. It has been brought to you by the The Research Repository @ WVU with permission from the rights-holder(s). You are free to use this Dissertation in any way that is permitted by the copyright and related rights legislation that applies to your use. For other uses you must obtain permission from the rights-holder(s) directly, unless additional rights are indicated by a Creative Commons license in the record and/ or on the work itself. This Dissertation has been accepted for inclusion in WVU Graduate Theses, Dissertations, and Problem Reports collection by an authorized administrator of The Research Repository @ WVU.

For more information, please contact researchrepository@mail.wvu.edu. 


\title{
Longitudinal Patterns and Economic Consequences of Emergency Department Visits among Medicaid Enrollees
}

\author{
Parul Agarwal, MPhil MPH
}

Dissertation Submitted to School of Pharmacy at West Virginia University in partial fulfillment of the requirements for the degree

\author{
Doctor of Philosophy \\ in \\ Pharmaceutical \& Pharmacological Sciences (Health Outcomes Research Pathway)
}

Thomas K Bias, PhD, Co-chair

Usha Sambamoorthi, $\mathrm{PhD}$, Co-chair

Suresh Madhavan, $\mathrm{PhD}$

Stephanie Frisbee, $\mathrm{PhD}$

Nethra Sambamoorthi, PhD

Department of Pharmaceutical Systems and Policy

Morgantown, West Virginia, USA

2015

Keywords: medicaid, emergency department, healthcare expenditures, health services utilization, health outcomes

Copyright 2015 Parul Agarwal 


\title{
ABSTRACT \\ Longitudinal Patterns and Economic Consequences of Emergency Department Visits among Medicaid Enrollees
}

\author{
Parul Agarwal, MPhil, MPH.
}

\section{Objective}

The objective of the dissertation was to examine the patient- and county-level factors associated with the Emergency Department (ED) visits and economic consequences associated with persistent ED use among adult fee-for-service (FFS) Medicaid beneficiaries. The first study examined the patient- and county-level factors associated with the number of ED visits and the second study examined the longitudinal patterns of ED visits among FFS Medicaid beneficiaries. Further, in both the studies ED visits due to primary care sensitive conditions were also examined. The third study examined the patient- and county- level factors associated with persistent ED use followed by an estimation of the excess healthcare expenditures associated with persistent ED use.

\section{Methods}

Both cross-sectional and longitudinal study designs were implemented using a retrospective observational claims data of Medicaid beneficiaries residing in Maryland, Ohio, and West Virginia. Study population included adult, alive, FFS, not dually enrolled in Medicare, nonpregnant and continuously enrolled Medicaid beneficiaries. Data on patient-level factors were obtained from the Medicaid Analytic eXtract (MAX) files for the years 2006-2010. MAX files consisted of personal summary, other therapy, inpatient and prescription drugs claims. The personal summary file included demographics, Medicaid eligibility, county federal information processing standard (FIPS) codes, Medicaid managed care enrollment, and Medicare eligibility status. The inpatient claims file included information related to hospital stays, dates of service, Medicaid payment, and the International Classification of Disease, Ninth Revision, Clinical Modification codes (ICD-9-CM) and ICD-9-CM procedure codes. The other therapy claims file included information on dates of service, types of service, Medicaid payment, ICD-9-CM, and Current Procedural Terminology (CPT) codes. The prescription drugs claims file included information on the date of prescription filled, days supplied, Medicaid payment and national drug code (NDC). All these files were linked using encrypted identification numbers. Data on county-level factors such as socio economic status, healthcare resources, and obesity rates were obtained from the Area health resource and county health ranking files. Frequencies, means, inter-quartile range, and $90^{\text {th }}$ percentile were used to examine the characteristics of the study population and distribution of ED visits. In the first study, unadjusted and adjusted negative 
binomial regressions (NBR) were conducted to examine the patient- and county-level factors associated with the number of ED visits. In the second study, multivariable hurdle models with logistic and NBRs were used to analyze ED visits over time, after adjusting for all other independent variables. In the third study, chi-square tests and logistic regression was conducted to examine the patient- and county-level factors associated with persistent ED use. Further, adjusted generalized linear models with log link function and gamma distribution were conducted to examine the excess expenditures. All analyses were conducted using STATA version 14.0.

\section{Findings}

In the first study, it was observed that more than half of the study population had one or more ED visit. Patient-level factors such as complex chronic illness, fragmented primary care use, polypharmacy, and tobacco use were associated with higher number of ED visits. Residents in counties with higher number of urgent care centers had lower number of ED visits. Almost, half of the ED visits were preventable. In the second study, the likelihood of ED use did not change from year to year. However, among ED users, the estimated number of ED visits increased over time with a small magnitude. More than half of the ED visits were primary care sensitive in each panel year. In the third study, one in ten Medicaid beneficiary had persistent ED use i.e. they had 4 or more ED visits in both index and follow-up years. There were significant differences between persistent ED users and non-users in patient- and county-level characteristics. Individuals with complex chronic illnesses, fragmented primary care use, poly-pharmacy and tobacco use were more likely to be persistent ED users. In multivariable regression, persistent ED users had significantly higher total healthcare expenditures as compared to non-users.

\section{Conclusions}

Adult FFS Medicaid beneficiaries with complex healthcare needs had higher number of ED visits. The number of ED visits increased over time with a small magnitude. Almost, half of the ED visits are preventable with timely care. Medicaid beneficiaries also had persistent ED use and had higher excess healthcare expenditures associated with persistent ED use. Taken together, these findings suggest that only access to primary care may not reduce ED visits. There is a need to have targeted interventions focused on this particular subgroup of the population who is consuming higher healthcare resources as compared to others. Cost containment may be achieved by providing comprehensive care management to individuals with complex healthcare needs. Access to county-level resources such as urgent care centers may contribute in reducing the number of ED visits and cost containment as care provided in these settings is less expensive as compared to ED. 


\section{ACKNOWLEDGEMENTS}

I am grateful to my mentors Drs. Thomas K Bias and Usha Sambamoorthi for their continuous support and guidance in completing this dissertation. I feel blessed for getting their mentorship. I appreciate the flexibility that both of them provided in scheduling joint meetings and also the resources that were required to complete this dissertation. Thank you both for meticulously going over multiple revisions of my dissertation drafts and providing insightful comments and suggestions. I am also thankful to my other dissertation committee members for providing consistent feedback to improve my dissertation research.

I want to pay regards to my grandparents, parents, in-laws, brothers - Praful and Abhinav, and sisters - Surabhi and Khushboo. I know you have waited long to get my full attention back. I want to thank you for your unconditional love and support. I also want to thank my husband Abhishek for continuous love and support. Abhishek, without you this dissertation was impossible. Thank you for not letting me do $\mathrm{PhD}$ from any institution in India or any other country. It was tough as we took the decision to do $\mathrm{PhD}$ after our wedding. But definitely this decision was worth taking. Thank you for always encouraging to do good research. My niece Yashanshi and nephew Annanya have always motivated me to work harder whenever they mentioned me in front of their friends.

I want to acknowledge my funding sources - West Virginia University School of Pharmacy, Health Research Center, West Virginia Office of Insurance Commissioner, and Claude Worthington Benedum Foundation.

I am thankful to God and my brother Sameer Sharma for always showing right path in life and inspiring to be good. 


\section{$\underline{\text { Table of Contents }}$}

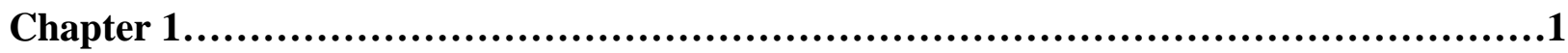

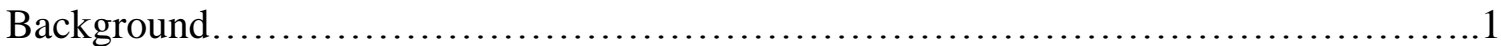

Significance of the study................................................... 10

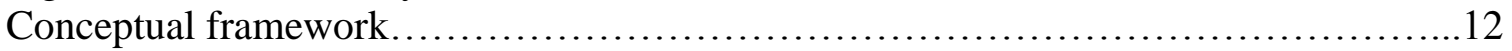

Specific Aims.............................................................

Methods......................................................................... 16

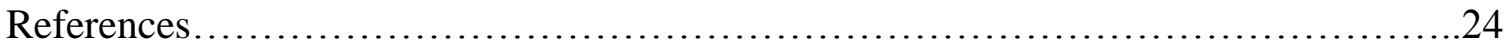

Chapter 2..............................................................................30

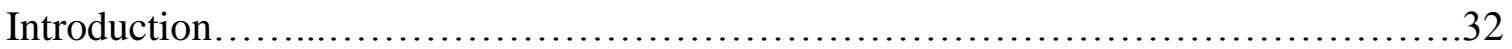

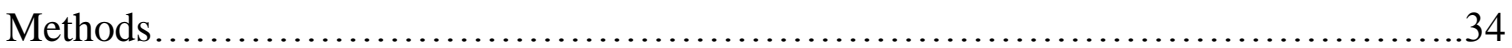

Results...................................................................... 40

Discussion........................................................................ 42

Tables........................................................................... 48

Appendix................................................................56

References................................................................. 57

Chapter 3....................................................................................61

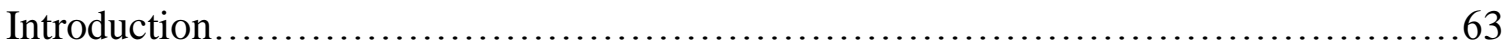

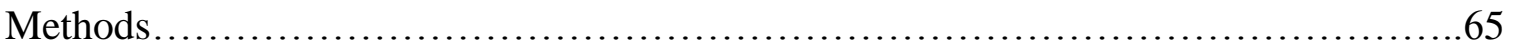

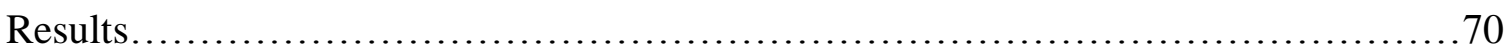

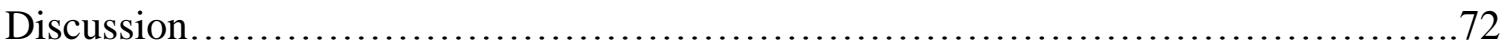

Tables........................................................................... 76

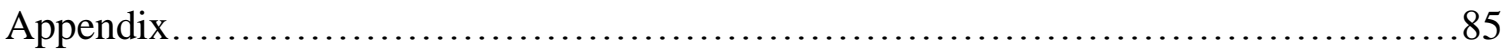

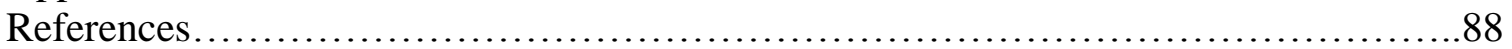

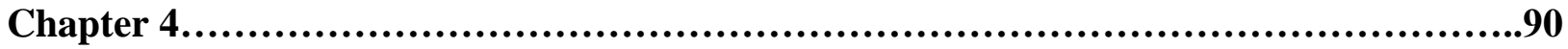

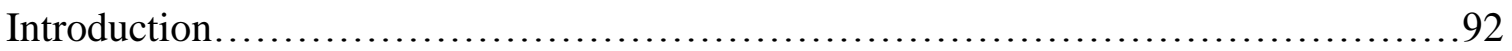

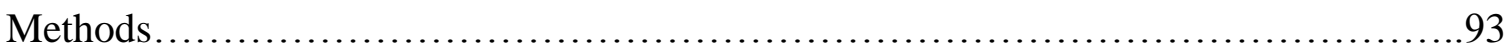

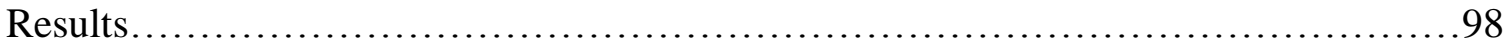

Discussion...................................................................... 101

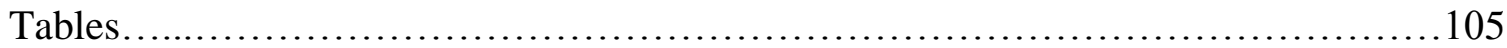

Appendix................................................................ 111

References............................................................ 119

Chapter 5...................................................................................122

Overall findings......................................................... 122 


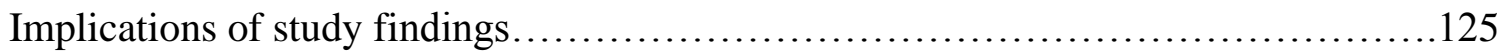

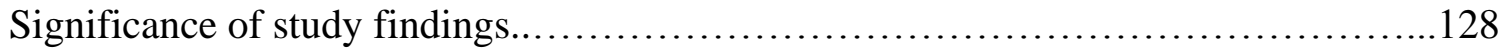

Strengths and limitations........................................................... 130

Future research.....................................................................

References........................................................... 132 


\section{CHAPTER 1}

\section{Background}

Traditionally Emergency Departments' (EDs) were mostly used for medical emergencies; however its role is now evolving with it being considered as an essential part of the healthcare system safety net for both uninsured and insured patients. The Emergency Medical Treatment and Labor Act (EMTALA) law mandates EDs to provide care to individuals residing in the United States (US) regardless of their ability to pay. There is a common misperception that ED users who have preventable conditions or are frequent ED utilizers are uninsured. ${ }^{3}$ However, these ED users often have public or private health insurance. ${ }^{3}$ EDs are used by uninsured as these settings are the last medical resort for them to obtain healthcare. However, insured individuals visit ED due to lack of access to primary care. Therefore, EDs are increasingly used by both insured and uninsured patients for treatment of their non-urgent and preventable healthcare conditions due to limited access to primary care. ${ }^{1,4}$ Increased ED use results in fragmented care, and higher healthcare expenditures. There is evidence that fragmented care leads to negative economic consequences and reductions in quality of care. ${ }^{5}$

With the recent implementation of the Patient Protection and Affordable Care Act (ACA) in 2010, there is a growing concern among policy-makers that the ED use will lead to increased healthcare expenditures. This is more relevant to Medicaid program because 31 US states expanded Medicaid under ACA. Medicaid enrollees already rely on the EDs due to lack of access to primary care, and inadequate coordination among healthcare providers. Increased provision of health insurance coverage without corresponding increase in the primary care availability may lead to increased ED visits for non-emergent care. ED visits for non-urgent and preventable healthcare conditions by insured are a financial strain on the healthcare system, on the individuals and the community. 


\section{ED use for emergent and non-emergent care}

Most of the ED visits are preventable with the availability of a primary care provider or timely provision of healthcare in any other type of setting. ${ }^{1,4}$ Identification of preventable ED visits is critical in reducing the financial burden on the healthcare system. The Centers for Medicare and Medicaid Services (CMS) encourages states to identify the emergent and nonemergent ED visits and vary the payments to providers accordingly. ${ }^{6}$ The New York University (NYU) Center for Health and Public Service Research and the United Hospital Fund of New York developed an algorithm for identifying and quantifying the non-emergent, emergent/primary care treatable, preventable/avoidable ED care, and not preventable/avoidable care visits to the EDs known as "the Emergency Department Algorithm (EDA)"., 1,8 Detailed description of the EDA algorithm is provided in the methods section of the chapter.

Using EDA algorithm, McWilliams et al. classified approximately three-fourth of the ED visits in Carolinas Healthcare System as those for Ambulatory Care Sensitive Conditions $(\mathrm{ACSCs})^{9}$. Notably, for approximately $70 \%$ of ACSCs related visits, Medicaid was the primary payer. ${ }^{9}$ A report that utilized Medicaid data for all 50 states documented that West Virginia had higher ED utilization rate as compared to other states, and approximately 30-40\% of these visits were preventable. ${ }^{10}$ Another report by Florida Center for Health Information and Policy Analysis on ED utilization and associated expenditures, documented that among adult ED users approximately half of the ED visits were preventable. ${ }^{11}$ The total charges attributable to all the ED visits were around $\$ 10.7$ billion half of which were for preventable ED visits. ${ }^{11}$ Similarities were observed in the characteristics of the individuals using ED for ACSCs and frequent users of the ED. ${ }^{12}$ A systematic review of 26 US based studies reported that the rate for non-urgent visits to the ED varied anywhere between $8-62 \%$ depending upon the definition used of the non-urgent visits. ${ }^{13}$ The definitions were based on factors such as diagnoses, triage evaluation by the physician or nurse, and prescribed procedures and tests at the time of ED care. 
From the above discussion, it can be summarized that EDs are used by individuals for both preventable and non-preventable causes. Therefore, it is critical to examine reasons for ED visits as increased ED use results in fragmented and reduced quality of care, and higher healthcare expenditures.

\section{ED utilization among Medicaid enrollees}

It is evident in the literature that Medicaid enrollees had higher ED visits as compared to those with Medicare, private insurance and uninsured. ${ }^{14-18}$ Tang et al. reported that among adult Medicaid enrollees ED visits increased from 9.6 million to 17.7 million between 1997 and 2007, whereas nonsignificant increase in ED visits was observed for those with private insurance, Medicare and among uninsured. ${ }^{17}$ For adults covered with private insurance and Medicare,

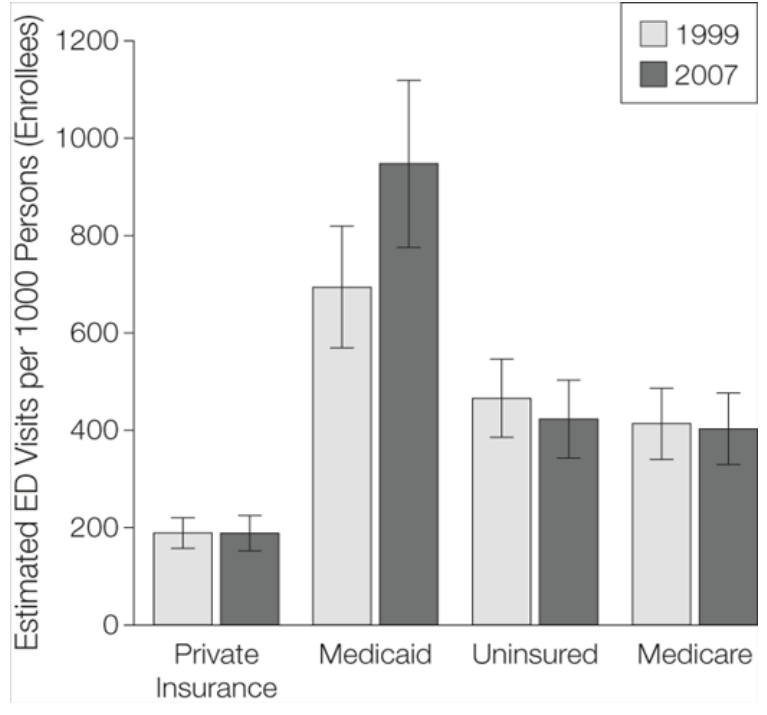

Source: Tang N, Stein J, Hsia RY, Maselli JH, Gonzales R. Trends and Characteristics of US Emergency Department Visits, 19972007. JAMA. 2010; 304(6):664-670.

doi:10.1001/iama.2010.1112.

ED visits increased from 1.4 to 1.6 million. ${ }^{17}$

Cheung et al. also observed similar findings. ${ }^{18}$ The author noted that greater proportion of Medicaid enrollees (39.6\%) used ED as compared to those with private insurance $(17.7 \%)$. Taken together, findings from above mentioned studies suggest that it is important to conduct research on Medicaid enrollees to examine the factors that contribute to increased ED visits.

\section{Impact of Medicaid expansion on ED utilization}

Medicaid's importance has increased as more low-income individuals are getting enrolled into the program with income up to $138 \%$ of the federal poverty line. ${ }^{19}$ In 2015,72 million 
individuals were enrolled in Medicaid program. ${ }^{20}$ The increased use of the ED by Medicaid enrollees is a matter of concern for the policymakers as Medicaid is an important source of health insurance coverage in the US for low-income families and children, and disabled Medicare beneficiaries. Expanded health insurance coverage may have a significant impact on the utilization of EDs. The literature presents ambiguous findings related to the utilization of the ED after provision of health insurance coverage. An examination of increased health insurance coverage in Massachusetts after implementation of their insurance marketplace, the Health Connector, found little or no change in the ED utilization. ${ }^{21,22}$ Results noted by Oregon's more recent health insurance experiment found that Medicaid expansion significantly increased the ED utilization, including visits related to both preventable and non-preventable causes. ${ }^{23}$ Research indicates there are many unknowns related to the association between expanded health insurance coverage and ED Utilization.

\section{Factors associated with ED use among Medicaid enrollees}

It is evident from the literature that due to several patient- and county-level factors Medicaid enrollees visit ED repeatedly. The Center for Studying Health System Change noted that increase in ED visits among Medicaid enrollees is due to non-urgent conditions and higher burden of chronic illnesses. ${ }^{24}$ Billings et al. noted that among Medicaid beneficiaries in New York city ED users had higher prevalence of chronic conditions and it increased with the number

of ED visits. ${ }^{25}$ Capp et al. noted that among Medicaid beneficiaries, ED users had following most common chronic conditions: chronic obstructive pulmonary disease (COPD)/asthma, hypertension, and diabetes. ${ }^{26}$ They also suffer from mental illnesses such as depression and anxiety. $^{26}$

Weinicik et al. noted that approximately $13.7 \%$ to $27.1 \%$ of the ED visits can be prevented with the use of urgent care centers. ${ }^{27}$ Rothkopf et al. observed that Medicaid enrollees visiting federally qualified health centers (FQHCs) were less likely to have ED visits as 
compared to those visiting healthcare providers with private practice. ${ }^{28}$ Similarly, Falik et al. found that Medicaid enrollees seeking care in FQHCs were less likely to visit EDs for treatment of ACSCs as compared to those seeking care from other healthcare providers. ${ }^{29}$ Cunningham et al. noted that geographical areas with less number of outpatient service providers had higher number of ED visits as compared to other communities. ${ }^{30}$ Lowe et al. also noted similar findings. ${ }^{31}$

Cheung et al. noted that a greater proportion of Medicaid enrollees faced barriers in accessing timely primary care as compared to individuals with private insurance. ${ }^{18}$ These barriers included limited access of physician's on telephone, delays in getting an appointment, long waiting time in physician's office, lack of transportation, and trouble in getting after hour care. Lowe et al. reported that among Medicaid enrollees ED visits decreased if after hour care was available to the patients. ${ }^{32}$

Willingness of physician's to accept Medicaid patient for providing healthcare may also impact ED visits. Willingness of the physicians to provide treatment is affected by the reimbursements rates for their services. For example, Decker et al. observed that with a decrease in physician's fees Medicaid enrollees were more likely to have increased ED visits. ${ }^{33}$ In another study by same author, it was noted that there were state level differences ranging from $8 \%$ to $54 \%$ in the acceptance rates of primary care physicians to provide treatment to new Medicaid enrollees. ${ }^{34}$ The differences in the acceptance rates were related to the size, and location of the organization in which the physician was working. ${ }^{35}$ A report by Government Accountability Office documented that states faced challenges in getting access to primary care providers due to their limited numbers and low reimbursement rates. ${ }^{36}$ Although findings from the above mentioned studies revealed that lower physician fees may increase ED visits, other studies in literature found that physician reimbursements may have little or no impact on access to healthcare. ${ }^{37,38}$ 
Taken together, findings from the above mentioned studies suggest that both patient- and county-level factors may affect ED use and thus it is important to examine these factors for individuals residing in different communities. Identification of patient- and county-level factors may contribute in formulating strategies for improved healthcare delivery.

\section{ED utilization over time}

Several studies in the literature documented that ED visits have increased in the US in past two decades. ${ }^{16,17,39-41}$ Tang et al. reported that ED visits increased from 94.9 to 116.8 million between 1997 and 2007. ${ }^{17}$ More than 130 million ED visits were reported in 2011 that outpaced the population growth. ${ }^{16}$ The Center for Disease Control and Prevention (CDC) estimated 129.8 million visits using 2010 data of National Hospital Ambulatory Medical Care Survey. ${ }^{40}$ Xu et al. found that the number of ED users increased from 34.2 to 40.8 million between 1996 and $2005 .{ }^{41}$ It is also noted in the literature that out of 354 million visits for acute care in the US, approximately one-third are treated in $\mathrm{EDs}^{3}$. It is noteworthy that all the studies mentioned above used visit level or several years of survey data to estimate the increase in ED visits. Visit level data limits identification of individuals who repeatedly visit ED and may provide an over estimation of the number of ED visits. Moreover, it is not possible to conduct longitudinal studies using visit level or survey data i.e. following an individual over time. Therefore, in this dissertation patient-level Medicaid claims data were used to study the longitudinal patterns of ED visits and persistent ED use over time.

\section{Frequent ED use over time}

Frequent ED users have "complex physical, behavioral, and social needs" that were not met "by the current fragmented health care system" 42 ; are often medically high-need individuals, ${ }^{43-48}$ with chronic physical and/or mental health conditions, ${ }^{4,49,17-23}$ have higher healthcare utilization, ${ }^{49,50}$ incur higher expenditures,${ }^{51}$ and have higher rates of mortality ${ }^{52}$ as 
compared to less frequent ED users. There is some evidence that frequent ED use may be persistent with some individuals visiting EDs frequently every year (i.e. persistent ED users). Among all ED users, the percentage of persistent ED users ranged from $0.5 \%$ to $38 \%$ depending on the definition of frequent ED use, settings, and region. ${ }^{48,53-56}$ There is no consensus on the annual number of visits that define frequent ED use and the definition ranges from 3 to $10 \mathrm{ED}$ visits annually. ${ }^{54,56-58}$ In a recently published study, Hwang et al. defined individuals who had $\geq$ 4 ED visits every year (for a period of two years) as persistent ED users using data from a primary academic center and found that $0.5 \%$ had persistent ED use. ${ }^{56}$ Knee et at defined individuals who had $\geq 10$ ED visits every year (over a period of 4 years) and found that $17 \%$ had persistent ED use. ${ }^{54}$ Fuda et al. defined individuals who had $\geq 5$ ED visits every year (for a period of two years) using data from acute-care hospital and found that $28 \%$ had persistent ED use. $^{58}$

Studying persistent ED use is important because they account for a larger portion of ED visits annually. ${ }^{26}$ Additionally, frequent ED users are often covered with public insurance such as Medicaid $^{3,59}$; they have complex healthcare needs and higher healthcare expenditures. ${ }^{25}$ However, except for one study, ${ }^{56}$ comprehensive research on subgroup differences among persistent ED users is lacking.

\section{Persistent ED use and economic consequences}

Frequent visits to the ED are associated with increased overall healthcare expenditures and lower quality of care, ${ }^{60,61}$ The primary reasons for high healthcare expenditures among frequent ED users are presence of multiple chronic conditions ${ }^{43-45}$ and use of other healthcare resources such as inpatient hospitalizations, primary and specialist care.$^{49,50,58,62-66}$ McWilliams et al. reported that the majority of these expenditures, calculated from the payer's perspective, can be attributable to ED visits due to the ACSCs and can be prevented with access to the primary care settings. ${ }^{9}$ 
To date, no study has analyzed the economic consequences associated with persistent ED use. A recent study by billings et al. analyzed the longitudinal healthcare expenditures from the patient perspective and reported that frequent visits to the ED results in higher healthcare expenditures particularly due to inpatient hospitalizations. ${ }^{25}$ On the contrary, another study reported that those with 20 or more visits annually to the ED had lower healthcare expenditures as compared to those with 3-20 ED visits. ${ }^{51}$ Notably, those with 20 or more visits to ED were a smaller group of patients $(n=23)$ and were less "sick" as compared to other frequent users. ${ }^{51}$ It is unclear from the study whether those with 20 or more visits had health insurance coverage. Identification of frequent visitors to the ED stimulated the implementation of policies and interventions in different settings and thereby reduced overall healthcare expenditures ${ }^{67,68}$ For example, since 2005 implementation of health information exchange (HIE) in several healthcare organizations in Memphis, Tennessee reduced the overall healthcare expenditures by 1.9 million from a societal perspective.

Frequent ED use also affects utilization of other healthcare services such as inpatient use. The Center for Disease Control and Prevention (CDC) estimated 129.8 million visits using 2010 National Hospital Ambulatory Medical Care Survey. ${ }^{40}$ Out of these visits, $13.3 \%$ resulted in a hospital admission. ${ }^{40}$ Patients utilizing the ED more frequently are documented to be "at a greater risk" for inpatient hospitalization. A study reported that inpatient hospitalizations had grown approximately 50\% (from 11.5-17.3 million) from 1993-2006 and there is also a growth in these hospitalizations for patients visiting the ED first $(33.5 \%$ to $43.8 \%) .{ }^{69}$ Sun et al. in a cross-sectional study, reported that the frequent users of the ED are six times more likely to be hospitalized in the preceding three months of their ED visit as compared to less frequent users of the ED. ${ }^{62}$ Mandelberg et al. reported that approximately $50 \%$ of the frequent users are hospitalized in the same year of their ED visit. ${ }^{50}$ Another study conducted on the Massachusetts EDs reported that $18 \%$ of the ED visits by frequent users resulted in an inpatient 
hospitalization. ${ }^{58}$ A recent study by Billings et al., found that among Medicaid beneficiaries rates of inpatient hospitalizations varied (15\%-19\%) depending on the number of ED $15-19 \% .^{25}$ To summarize, it is noteworthy that no study has examined the economic consequences associated with persistent ED use. 


\section{Significance of the Study}

\section{Role of Medicaid}

Medicaid is an important source of health insurance coverage in the US for low-income families and children and disabled Medicare beneficiaries. Under the ACA, due to Medicaid expansion, Medicaid's importance has increased as more low-income individuals are getting enrolled into Medicaid with income up to $138 \%$ of the federal poverty line. ${ }^{19}$ The impact of the Medicaid expansion on ED utilization is yet to be seen. States plan to monitor frequent visits to ED very closely and implement policies to reduce preventable frequent visits and consequent hospitalizations. ${ }^{6}$ This initiative has been undertaken to reduce the economic burden and provide better healthcare management to individuals with high medical needs. As most studies in the literature report that the frequent users of ED are covered through Medicaid, it is critical to identify characteristics of the Medicaid beneficiaries who visit ED repeatedly using Medicaid administrative claims data..$^{3,59}$

\section{Unique Contributions}

Majority of the studies restricted their analysis to adults receiving ED care without including those individuals who did not visit ED. Exclusion of individuals who did not visit ED limited the conclusive evidence about how ED users were different from the non-users. Additionally, although majority of the studies found that Medicaid enrollees had higher number of ED visits as compared to those insured under other programs, a limited number of studies have been conducted using Medicaid claims data. It is critical to examine factors associated with ED visits using claims data as these type of data include detailed information about procedure codes, diagnosis codes, hospital charges, other healthcare services use, and medication use. Previous studies have analyzed ED utilization using National Ambulatory Medical Care Survey (NHAMCS), the HCUP Nationwide, Emergency Department Sample (NEDS), and the Medical Expenditure Panel Survey (MEPS). Although these datasets provide aggregate information about ED visits and factors associated with increased ED visits, however it is not possible to conduct 
longitudinal studies using these datasets i.e. study the patterns of ED visits over time or examine the characteristics of the individuals who visit ED repeatedly. Furthermore, self-reported and visit level nature of these datasets may lead to under/over estimation of the ED visits.

Further, availability of care delivered in other settings such as physicians' offices and other healthcare settings may also impact ED utilization. Use of claims data enables capturing information from those settings and examine their association with ED visits and persistent ED use. Additionally, at patient-level most studies in the literature have been conducted at single site or few ED sites in a state. Therefore, generalizability of the findings from these studies is an issue. It is important to analyze data from multiple sites to capture patient history and health status better. Furthermore, it is important to capture all the visits even if they happen in different ED settings. ${ }^{70}$

Furthermore, a limited number of studies have analyzed the patient- and county-level factors associated with persistent ED use and excess healthcare expenditures associated with persistent ED use. This dissertation examines the characteristics of persistent ED users and estimates the expenditures associated with persistent ED use. Therefore, this dissertation strengthens the evidence for future policy-making related to repeated ED use in the US. 


\section{Conceptual Framework}

The Andersen's behavioral model for healthcare services utilization was adopted to provide a conceptual framework to the dissertation research. ${ }^{71}$ The model was initially developed in 1968 to understand the utilization of healthcare services, and measure the

distribution of access to care. ${ }^{72}$ The initial model only included predisposing, enabling and need factors. The model was further modified in 1970s where health care system factors were also included as determinants of health services utilization. ${ }^{72}$ Phase 3 of the model in 1980 s included external environment factors and perceived health status as the determinants of healthcare services use. ${ }^{72}$ Phase 4 model i.e. the emerging model created a loop where healthcare services use affects the perceived or actual status of an individual. ${ }^{72}$ In this model the healthcare services use also affects predisposing and personal health practices of an individual. The emerging model is used by the current study to provide a conceptual framework. The emerging model also measures consumer satisfaction as an outcome, however as this dissertation used Medicaid claims data it is not possible to measure consumer satisfaction. Also, in this dissertation loops from the emerging model were not measured.

This model has been extensively used to examine the relationship between predisposing, enabling, need, life-style, and external environment factors with healthcare services utilization and expenditures. It includes both individual and contextual factors that may predict healthcare services use. As suggested by Andersen et al., predisposing factors are demographic characteristics such as age, gender; social structure such as race/ethnicity; and health beliefs such as knowledge about the disease. The enabling factors include the means through which an individual can seek care. Need factors are those that define the health status of the individuals. Personal health practices are the health behavior or life-style choices that may affect the healthcare service use by an individual. Environment includes both health system and external healthcare environment factors that may affect healthcare services use. 
The model posits that the healthcare services utilization (in this study it is in the form of visits to the ED, persistent ED use, and healthcare expenditures) can be predicted through individual level factors: 1) predisposing - gender, race/ethnicity, and age; 2) enabling Medicaid eligibility due to cash assistance/poverty, county level education, county-level unemployment, primary care use; 3) need - Presence of complex chronic illness, poly-pharmacy, Medicaid eligibility due to medical needs ; 4) personal health practices - tobacco use and county-level obesity rates, and 5) external environment factors - health professional shortage area, metro status of the county, number of EDs/100,000 population, number of hospitals with psychiatric emergency services/100,000 population, number of rural health centers/100,000 population, number of urgent care centers/100,000 population, number of FQHCs/100,000 population, and number of community mental health centers/100,000 population. 


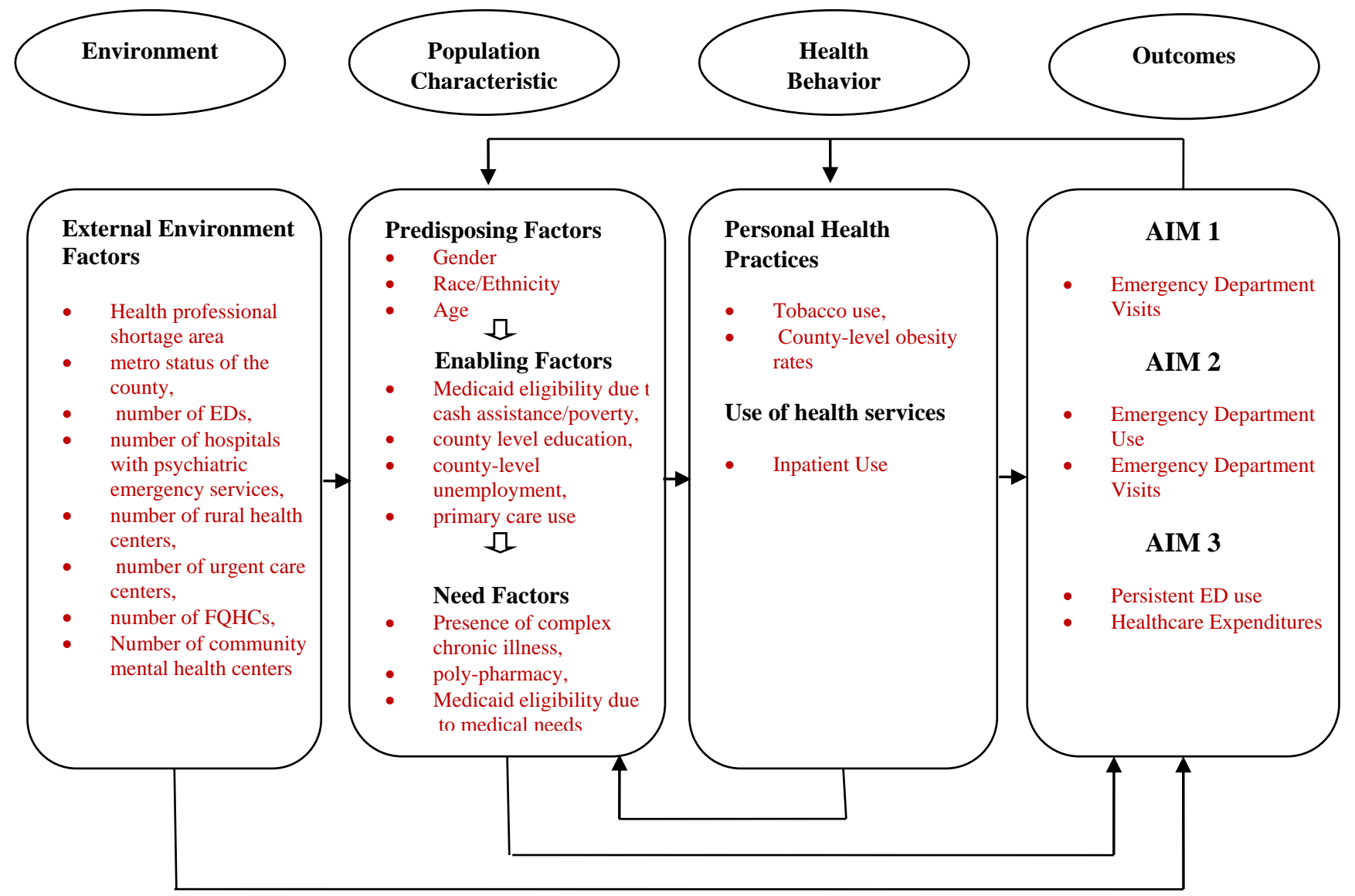

Modified Andersen's Behavioral Model for Health Services Utilization 


\section{Specific Aims}

Aim 1: Examine patient- and county-level characteristics associated with the number of ED visits among adult fee-for-service (FFS) Medicaid beneficiaries; examine the reasons for ED visits among ED users.

Hypothesis: Patient complexity and fragmented primary care use will increase the number of ED visits; Presence of urgent care centers in the counties will decrease the number of ED visits.

Aim 2: Analyze the variation in the number of ED visits over time among adult FFS Medicaid beneficiaries; describe primary care sensitive ED visits over time at the visitlevel.

Hypothesis: ED use and number of ED visits among ED users will increase over time after controlling for predisposing, enabling, need, life-style and external health environment practices.

Aim 3: Examine the patient- and county-level factors associated with persistent ED use and its impact on healthcare expenditures among adult fee-for-service (FFS) Medicaid beneficiaries.

Hypothesis: Adults with persistent ED use will have higher healthcare expenditures (other than ED) compared to non-users of ED. 


\section{Methods}

\section{Study population}

The study population included adult fee-for-service (FFS) Medicaid beneficiaries, continuously enrolled in the Medicaid program, not eligible for Medicaid, not pregnant and alive during the study period residing in Maryland (MD), Ohio (OH), and West Virginia (WV).

\section{Data sources}

\section{Medicaid Analytic Extract (MAX) Files}

For all the specific aims in this dissertation research, MAX files were used. MAX files are prepared and released by CMS in assistance with Research Data Assistance Center (ResDac). States submit patient-level Medicaid data to the Medicaid Statistical Information System (MSIS) system through which MAX files are prepared to be used for research purposes after completing a quality review. A research proposal was submitted to CMS to access Medicaid claims data for MD, OH, and WV for the years 2006-2010. The data were obtained for these states as they have expanded for Medicaid. This dissertation provides baseline findings about ED visits and persistent ED use pre-ACA. Future studies examining the impact of ACA on ED utilization may draw comparisons from this dissertation. The proposal was approved by Institutional Review Board of West Virginia University. MAX files include four different files: 1) Personal summary file, 2) Inpatient claims file, 3) Other therapy file, and 4) Prescription drugs claims file. These files are organized by the calendar year of service. While preparing the files CMS maintains uniformity across variables. All files were linked using a state specific masked encrypted ID.

Personal summary includes enrollment related information of the Medicaid beneficiaries including demographics, eligibility status, county FIPS codes, managed care enrollment, dual eligible, and summary of charges and payments. The outpatient and other therapy claims file 
include information related to the hospital stay, outpatient services used by the beneficiaries, date of service, the International Classification of Disease, Ninth Revision, Clinical Modification codes (ICD-9-CM), and Current Procedural Terminology (CPT) codes. The prescription drugs claims file includes information on date of prescription filled, days of supply, and national drug code (NDC). These files also include some standard variables that appear in all the files.

Table 1 presents the number of Medicaid beneficiaries that are enrolled in the Medicaid program of $\mathrm{MD}, \mathrm{OH}$, and $\mathrm{WV}$. It also provides data on total number of claims that were filed for all the enrollees from 2006-2010.

Table 1

Total Medicaid Enrollees and Type of Claims by Each State Medicaid Analytic eXtract Files 2006-2010

\begin{tabular}{lrrrrr}
\hline State & Year & Total N & $\begin{array}{l}\text { Inpatient } \\
\text { Claims }\end{array}$ & $\begin{array}{l}\text { Other Therapy } \\
\text { Claims }\end{array}$ & $\begin{array}{r}\text { Prescription } \\
\text { Drugs Claims }\end{array}$ \\
\hline Maryland & & & & & \\
\hline & 2006 & 867,649 & 147,034 & $23,613,674$ & $5,666,328$ \\
& 2007 & 856,476 & 146,072 & $23,619,111$ & $6,033,188$ \\
& 2008 & 900,240 & 154,743 & $25,919,545$ & $6,635,036$ \\
& 2009 & 996,018 & 174,777 & $37,631,963$ & $8,092,549$ \\
\hline Ohio & 2010 & $1,091,303$ & 184,961 & $44,385,642$ & $9,212,384$ \\
\hline & & & & & \\
& 2006 & $2,157,415$ & 212,775 & $76,879,452$ & $18,295,922$ \\
& 2007 & $2,173,685$ & 135,360 & $70,955,987$ & $9,776,082$ \\
& 2008 & $2,212,338$ & 126,910 & $75,085,782$ & $8,186,473$ \\
Virginia & 2009 & $2,367,035$ & 131,955 & $79,802,071$ & $8,215,824$ \\
& 2010 & $2,471,701$ & 125,550 & $82,725,278$ & $26,646,535$ \\
\hline & & & & \\
& 2006 & 393,607 & 31,277 & $10,808,744$ & $5,611,527$ \\
& 2007 & 397,462 & 30,855 & $10,922,958$ & $5,781,228$ \\
& 2008 & 404,206 & 30,655 & $11,342,612$ & $5,513,822$ \\
& 2009 & 420,455 & 30,620 & $11,886,687$ & $5,819,155$ \\
& 2010 & 431,717 & 31,230 & $12,194,946$ & $5,972,398$ \\
\hline
\end{tabular}




\section{Area Health Resource File (AHRF)}

This data is released by Health Resources and Services Administration division of U.S. Department of Health and Human Services. It contains national, state, and county level data on approximately 6000 variables. The current data is available for the years 2013-2014. It includes information on variables such as county level education, income, poverty status, health professional shortage area (HPSA), presence of rural and mental health centers, number of federally qualified health centers, community health centers, emergency departments in the county, hospitals with emergency psychiatric services, rural versus urban status of the county, and number of urgent care centers.

\section{County Health Ranking}

The County Health Ranking data provides information on health behaviors, clinical care, social and economic factors, and physical environment for all counties in all states. This information is compiled from various data sources such as Behavioral Risk Factor Surveillance System, National Center for Health Statistics, Census/Current Population Survey, AHRF, Dartmouth Atlas, Medicare claims, Small Area Income and Poverty Estimates, Uniform crime reporting, Federal Bureau of Investigation, and Center for Disease Control and Prevention.

\section{Study measures}

All the measures in this study were selected by conducting a literature review and gaining substantive knowledge about the factors that may affect ED utilization. Study measures were also selected based on conceptual framework.

\section{Non-urgent ED visits}

The New York University (NYU) Center for Health and Public Service Research and the United Hospital Fund of New York developed an algorithm for identifying and quantifying the 


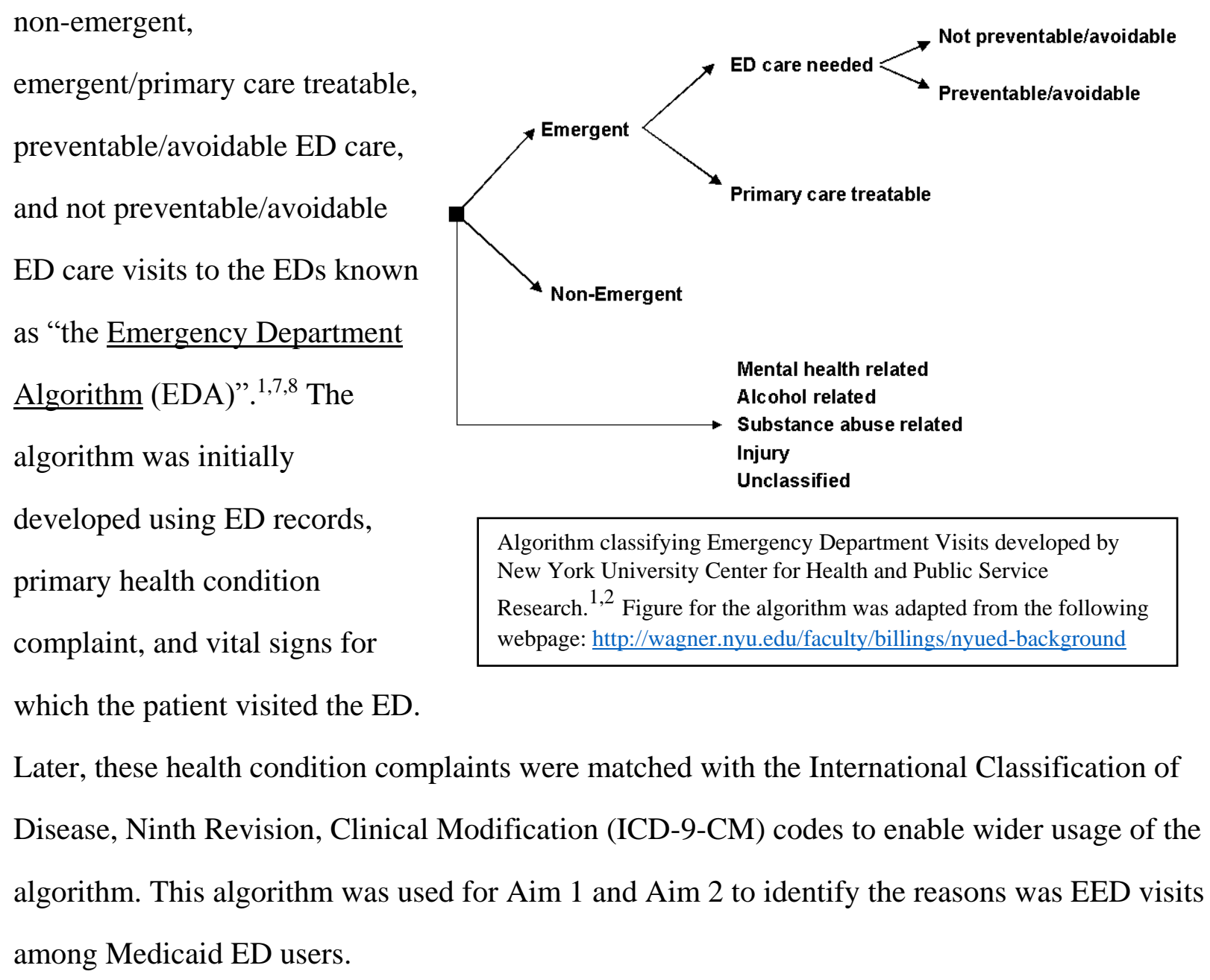

which the patient visited the ED.

Later, these health condition complaints were matched with the International Classification of Disease, Ninth Revision, Clinical Modification (ICD-9-CM) codes to enable wider usage of the algorithm. This algorithm was used for Aim 1 and Aim 2 to identify the reasons was EED visits among Medicaid ED users.

Table 2 presents the information that classifies NYU algorithm into categories as provided by the NYU Center for Health and Public Service Research and the United Hospital Fund of New York. 
Table 2: Defining each category of the algorithm developed by the New York University (NYU) Center for Health and Public Service Research and the United Hospital Fund of New York ${ }^{1,2}$

\begin{tabular}{|l|l|}
\hline $\begin{array}{l}\text { NYU algorithm } \\
\text { categories }\end{array}$ & $\begin{array}{l}\text { "The patient's initial complaint, presenting symptoms, vital signs, } \\
\text { medical history, and age indicated that immediate medical care was } \\
\text { not required within 12 hours;" }\end{array}$ \\
\hline $\begin{array}{l}\text { Emergent/Primary } \\
\text { Care Treatable }\end{array}$ & $\begin{array}{l}\text { "Based on information in the record, treatment was required within } \\
12 \text { hours, but care could have been provided effectively and safely in } \\
\text { a primary care setting. The complaint did not require continuous } \\
\text { observation, and no procedures were performed or resources used } \\
\text { that are not available in a primary care setting (e.g., CAT scan or } \\
\text { certain lab tests);" }\end{array}$ \\
\hline $\begin{array}{l}\text { Emergent - ED Care } \\
\text { Needed - } \\
\text { Preventable/Avoidable }\end{array}$ & $\begin{array}{l}\text { "Emergency department care was required based on the complaint or } \\
\text { procedures performed/resources used, but the emergent nature of the } \\
\text { condition was potentially preventable/avoidable if timely and } \\
\text { effective ambulatory care had been received during the episode of } \\
\text { illness (e.g., the flare-ups of asthma, diabetes, congestive heart } \\
\text { failure, etc.); and" }\end{array}$ \\
\hline $\begin{array}{l}\text { Emergent - ED Care } \\
\text { Needed - Not } \\
\text { Preventable/Avoidable }\end{array}$ & $\begin{array}{l}\text { "Emergency department care was required and ambulatory care } \\
\text { treatment could not have prevented the condition (e.g., trauma, } \\
\text { appendicitis, myocardial infarction, etc.)". }\end{array}$ \\
\hline
\end{tabular}

Note: Text for explaining each category of the algorithm was adapted from the following webpage: http://wagner.nyu.edu/faculty/billings/nyued-background 


\section{Primary Care Use}

It is evident from the literature that primary care use may be associated with the utilization of EDs. Several provider continuity measures are available in the literature to estimate primary care use including Usual provider continuity, ${ }^{73}$ Continuity of care index,${ }^{74}$

Likelihood of continuity, ${ }^{75}$ Known provider continuity index,${ }^{76}$ Modified continuity index,${ }^{77}$ and Modified, modified continuity index. ${ }^{78}$ Some of these measures require information about assigned or referred health care providers. For example, usual provider continuity index measures intensity of physicians visits to his or her self-identified primary care provider. ${ }^{73}$ This measure requires identification of number of patients that are assigned to the primary care provider for treatment. ${ }^{79}$ Continuity of care index has estimation discrepancies where the index decreases sharply with increase in the number of primary care providers ${ }^{78}$ Likelihood of continuity estimates a probability of the actual number of providers that a patient may visit are less than the expected number of providers. This dissertation research adopted Modified, modified continuity index to measure primary care use developed by Magill et al. ${ }^{78}$ Following formula was used to measure primary care use -

\section{MMCI = 1 - (n of providers / [n of visits + 0.1] $/ 1$ - (1/ [n of visits + 0.1)}

MMCI provides a measure ranging from 0 (no continuity) to 1 (perfect continuity). Certain care settings were excluded such as urgent care facility, inpatient hospitals, emergency room hospital, ambulatory surgery center, birthing center, hospice, ambulance - land, ambulance air or water, inpatient psychiatric facility, psychiatric facility partial hospitalization, comprehensive inpatient rehabilitation facility, end stage renal disease treatment facility, independent laboratory, and other. Examples of ambulatory care settings are outpatient hospitals, military treatment facilities, mobile unit, and free standing facilities. Primary care visits were identified using CPT codes. Healthcare providers such as internal medicine specialists, general practitioners, gynecologists and nurse practitioners were considered as primary care providers. 


\section{Complex Chronic Illness}

It is evident from the literature that ED users have both chronic physical and mental health conditions. In general, Medicaid beneficiaries suffer from both chronic and mental health conditions. ${ }^{80,81}$ It is noted that among Medicaid beneficiaries with the presence of each condition there is an increase in the healthcare costs of $\$ 8,400$ annually. ${ }^{80,81}$ Among disabled Medicaid beneficiaries the most prevalent conditions include cardiovascular, psychiatric, central nervous system, pulmonary, and skeletal and connective diseases.

Health and Human Services strategic framework on multiple chronic conditions defined chronic illnesses as "conditions that last a year or more and require ongoing medical attention and /or limit activities of daily living". ${ }^{82,83}$ Co-occurring chronic and mental health conditions can be considered complex based on the definition provided by the Agency for Healthcare Research and Quality (AHRQ). The AHRQ defined "a complex patient is one with two or more chronic conditions where each condition may influence the care of the other condition(s) through limitations of life expectancy, interactions between drug therapies, difficulties in establishing adequate care coordination, and/or direct contraindications to therapy for one condition by other conditions themselves". ${ }^{84}$ Health and Human Services Office of Assistant Secretary of Health used the definition of chronic illnesses and "priority conditions" identified by AHRQ and Quality's effective health care program ${ }^{85}$ to develop a conceptual framework that could specify and define selected chronic conditions. ${ }^{86}$ In this dissertation, selected chronic conditions were used to define the presence of chronic physical and mental health conditions among FFS Medicaid beneficiaries. Each chronic and mental health condition was defined using inpatient or outpatient claims. The algorithm to use inpatient or outpatient claims to define chronic physical and mental health conditions is specified by CMS chronic conditions data warehouse. $^{87}$ 


\section{Presentation of findings}

Findings from each aim are presented as following: Aim 1 presented in Chapter 2, Aim 2 presented in Chapter 3, and Aim 3 presented in Chapter 4. Chapter 2, 3, and 4 are written in manuscript style and each chapter includes: abstract, introduction, methods, results, discussion, tables, appendix, figures, and references. Appendices include study population selection flowchart, and tables from secondary analysis. Overall findings from the dissertation, its unique contribution, consistent and inconsistent findings, overall limitations and future research are summarized in Chapter 5. 


\section{References}

1. Billings J, Parikh N, Mijanovich T. Emergency department use in New York City: a substitute for primary care? Issue brief. Nov 2000(433):1-5.

2. Billings J, Parikh N, Mijanovich T. Emergency department use: the New York Story. Issue brief. Nov 2000(434):1-12.

3. Pitts SR, Carrier ER, Rich EC, Kellermann AL. Where Americans get acute care: increasingly, it's not at their doctor's office. Health Aff (Millwood). Sep 2010;29(9):16201629.

4. Oster A, Bindman AB. Emergency department visits for ambulatory care sensitive conditions: insights into preventable hospitalizations. Medical care. Feb 2003;41(2):198207.

5. Hospital-Based Emergency Care: At the Breaking Point. Washington, DC: The National Academies Press; 2007.

6. Mann C. Targeting Medicaid Super-Utilizers to Decrease Costs and Improve Quality Centers for Medicare \& Medicaid Services; 2013.

7. T BJPNM. Emergency dpertament use in New York City: a survey of Bronx patients. New York: New York University;2000.

8. Ballard DW, Price M, Fung V, et al. Validation of an algorithm for categorizing the severity of hospital emergency department visits. Medical care. Jan 2010;48(1):58-63.

9. McWilliams A, Tapp H, Barker J, Dulin M. Cost analysis of the use of emergency departments for primary care services in Charlotte, North Carolina. North Carolina medical journal. Jul-Aug 2011;72(4):265-271.

10. Evaluating Emergency Department Utilization. The Lewin Group; 9th May 20122012.

11. Emergency Department Utilization Report 2009. Florida: Florida Center for Health Information and Policy Analysis October 20102009.

12. Chukmaitov AS, Tang A, Carretta HJ, Menachemi N, Brooks RG. Characteristics of all, occasional, and frequent emergency department visits due to ambulatory care-sensitive conditions in Florida. The Journal of ambulatory care management. Apr-Jun 2012;35(2):149-158.

13. Uscher-Pines L, Pines J, Kellermann A, Gillen E, Mehrotra A. Emergency department visits for nonurgent conditions: systematic literature review. The American journal of managed care. Jan 2013;19(1):47-59.

14. Pitts SR, Niska RW, Xu J, Burt CW. National Hospital Ambulatory Medical Care Survey: 2006 emergency department summary. Natl Health Stat Report. 2008(7):1-38.

15. Pitts SR, Pines JM, Handrigan MT, Kellermann AL. National trends in emergency department occupancy, 2001 to 2008: effect of inpatient admissions versus emergency department practice intensity. Ann Emerg Med. Dec 2012;60(6):679-686 e673.

16. Weiss AJ, Wier LM, Stocks C, Blanchard J. Overview of Emergency Department Visits in the United States, 2011: Statistical Brief \#174. Healthcare Cost and Utilization Project (HCUP) Statistical Briefs. Rockville (MD)2006.

17. Tang N, Stein J, Hsia RY, Maselli JH, Gonzales R. Trends and characteristics of US emergency department visits, 1997-2007. Jama. Aug 11 2010;304(6):664-670.

18. Cheung PT, Wiler JL, Lowe RA, Ginde AA. National study of barriers to timely primary care and emergency department utilization among Medicaid beneficiaries. Ann Emerg Med. Jul 2012;60(1):4-10 e12. 
19. Centers for M, Medicaid Services HHS. Medicaid program; eligibility changes under the Affordable Care Act of 2010. Final rule, Interim final rule. Federal register. 2012;77(57):17144-17217.

20. CMS. Medicaid \& CHIP: April 2015 Monthly Applications, Eligibility Determinations and Enrollment Report. MD: Department of Health and Human Services Centers for Medicare \& Medicaid Services; 30th Sept 2015.

21. Miller S. The effect of the Massachusetts reform on health care utilization. Inquiry : a journal of medical care organization, provision and financing. Winter 2012;49(4):317326.

22. Smulowitz PB, O'Malley J, Yang X, Landon BE. Increased use of the emergency department after health care reform in Massachusetts. Ann Emerg Med. Aug 2014;64(2):107-115, 115 e101-103.

23. Taubman SL, Allen HL, Wright BJ, Baicker K, Finkelstein AN. Medicaid increases emergency-department use: evidence from Oregon's Health Insurance Experiment. Science. Jan 17 2014;343(6168):263-268.

24. Sommers AS, Boukus ER, Carrier E. Dispelling myths about emergency department use: majority of Medicaid visits are for urgent or more serious symptoms. Res Brief. Jul 2012(23):1-10, 11-13.

25. Billings J, Raven MC. Dispelling an urban legend: frequent emergency department users have substantial burden of disease. Health Aff (Millwood). Dec 2013;32(12):2099-2108.

26. Capp R, Rosenthal MS, Desai MM, et al. Characteristics of Medicaid enrollees with frequent ED use. The American journal of emergency medicine. Sep 2013;31(9):13331337.

27. Weinick RM, Burns RM, Mehrotra A. Many emergency department visits could be managed at urgent care centers and retail clinics. Health Aff (Millwood). Sep 2010;29(9):1630-1636.

28. Rothkopf J, Brookler K, Wadhwa S, Sajovetz M. Medicaid patients seen at federally qualified health centers use hospital services less than those seen by private providers. Health Aff. 2011;30(7):1335-1342.

29. Falik M, Needleman J, Wells BL, Korb J. Ambulatory care sensitive hospitalizations and emergency visits: experiences of Medicaid patients using federally qualified health centers. Medical care. Jun 2001;39(6):551-561.

30. Cunningham PJ. What accounts for differences in the use of hospital emergency departments across U.S. communities? Health Aff (Millwood). Sep-Oct 2006;25(5):w324336.

31. Lowe RA, Fu R, Ong ET, et al. Community characteristics affecting emergency department use by Medicaid enrollees. Medical care. Jan 2009;47(1):15-22.

32. Lowe RA, Localio AR, Schwarz DF, et al. Association between primary care practice characteristics and emergency department use in a medicaid managed care organization. Medical care. Aug 2005;43(8):792-800.

33. Decker SL. Changes in Medicaid physician fees and patterns of ambulatory care. Inquiry : a journal of medical care organization, provision and financing. Fall 2009;46(3):291304.

34. Decker SL. Two-thirds of primary care physicians accepted new Medicaid patients in 2011-12: a baseline to measure future acceptance rates. Health Aff (Millwood). Jul 2013;32(7):1183-1187. 
35. Decker SL. In 2011 nearly one-third of physicians said they would not accept new Medicaid patients, but rising fees may help. Health Aff (Millwood). Aug 2012;31(8):1673-1679.

36. GAO. Medicaid: States Made Multiple Program Changes, and Beneficiaries Generally Reported Access Comparable to Private Insurance. General Accountability Office;2012.

37. Shen YC, Zuckerman S. The effect of Medicaid payment generosity on access and use among beneficiaries. Health services research. Jun 2005;40(3):723-744.

38. Zuckerman S, Williams AF, Stockley KE. Trends in Medicaid physician fees, 2003-2008. Health Aff (Millwood). May-Jun 2009;28(3):w510-519.

39. Skinner HG, Blanchard J, Elixhauser A. Trends in Emergency Department Visits, 20062011: Statistical Brief \#179. Healthcare Cost and Utilization Project (HCUP) Statistical Briefs. Rockville (MD)2006.

40. CDC. Emergency Department Visits. 2014; http://www.cdc.gov/nchs/fastats/emergencydepartment.htm. Accessed 22nd November, 2014.

41. $\mathrm{Xu} \mathrm{KT}$, Nelson BK, Berk S. The changing profile of patients who used emergency department services in the United States: 1996 to 2005. Ann Emerg Med. Dec 2009;54(6):805-810 e801-807.

42. Hasselman D. Super-Utilizer Summit Common Themes from Innovative Complex Care Management Programs. 2013; http://www.rwjf.org/content/dam/farm/reports/reports/2013/rwjf407990. Accessed 11th November, 2014.

43. O'Brien GM, Stein MD, Zierler S, Shapiro M, O'Sullivan P, Woolard R. Use of the ED as a regular source of care: associated factors beyond lack of health insurance. Ann Emerg Med. Sep 1997;30(3):286-291.

44. Sandoval E, Smith S, Walter J, et al. A comparison of frequent and infrequent visitors to an urban emergency department. J Emerg Med. Feb 2010;38(2):115-121.

45. Blank FS, Li H, Henneman PL, et al. A descriptive study of heavy emergency department users at an academic emergency department reveals heavy ED users have better access to care than average users. Journal of emergency nursing: JEN : official publication of the Emergency Department Nurses Association. Apr 2005;31(2):139-144.

46. Zuckerman S, Shen YC. Characteristics of occasional and frequent emergency department users: do insurance coverage and access to care matter? Medical care. Feb 2004;42(2):176-182.

47. Friedman BW, Serrano D, Reed M, Diamond M, Lipton RB. Use of the emergency department for severe headache. A population-based study. Headache. Jan 2009;49(1):21-30.

48. Cook LJ, Knight S, Junkins EP, Jr., Mann NC, Dean JM, Olson LM. Repeat patients to the emergency department in a statewide database. Academic emergency medicine : official journal of the Society for Academic Emergency Medicine. Mar 2004;11(3):256263.

49. Hunt KA, Weber EJ, Showstack JA, Colby DC, Callaham ML. Characteristics of frequent users of emergency departments. Ann Emerg Med. Jul 2006;48(1):1-8.

50. Mandelberg JH, Kuhn RE, Kohn MA. Epidemiologic analysis of an urban, public emergency department's frequent users. Academic emergency medicine : official journal of the Society for Academic Emergency Medicine. Jun 2000;7(6):637-646. 
51. Ruger JP, Richter CJ, Spitznagel EL, Lewis LM. Analysis of costs, length of stay, and utilization of emergency department services by frequent users: implications for health policy. Academic emergency medicine : official journal of the Society for Academic Emergency Medicine. Dec 2004;11(12):1311-1317.

52. Lucas RH, Sanford SM. An analysis of frequent users of emergency care at an urban university hospital. Ann Emerg Med. Nov 1998;32(5):563-568.

53. Genell Andren K, Rosenqvist U. Heavy users of an emergency department--a two year follow-up study. Social science \& medicine. 1987;25(7):825-831.

54. Kne T, Young R, Spillane L. Frequent ED users: patterns of use over time. The American journal of emergency medicine. Nov 1998;16(7):648-652.

55. Kennedy D, Ardagh M. Frequent attenders at Christchurch Hospital's Emergency Department: a 4-year study of attendance patterns. The New Zealand medical journal. May 7 2004;117(1193):U871.

56. Hwang AS, Liu SW, Ashburner JM, Auerbach BJ, Atlas SJ, Hong CS. Outcomes of primary care patients who are frequent and persistent users of the ED. The American journal of emergency medicine. Sep 2015;33(9):1320-1322.

57. Shapiro JS, Johnson SA, Angiollilo J, Fleischman W, Onyile A, Kuperman G. Health information exchange improves identification of frequent emergency department users. Health Aff (Millwood). Dec 2013;32(12):2193-2198.

58. Fuda KK, Immekus R. Frequent users of Massachusetts emergency departments: a statewide analysis. Ann Emerg Med. Jul 2006;48(1):9-16.

59. Weber EJ, Showstack JA, Hunt KA, Colby DC, Callaham ML. Does lack of a usual source of care or health insurance increase the likelihood of an emergency department visit? Results of a national population-based study. Ann Emerg Med. Jan 2005;45(1):412.

60. Bamezai A, Melnick G, Nawathe A. The cost of an emergency department visit and its relationship to emergency department volume. Ann Emerg Med. May 2005;45(5):483490.

61. Gill JM, Mainous AG, 3rd, Nsereko M. The effect of continuity of care on emergency department use. Archives of family medicine. Apr 2000;9(4):333-338.

62. Sun BC, Burstin HR, Brennan TA. Predictors and outcomes of frequent emergency department users. Academic emergency medicine : official journal of the Society for Academic Emergency Medicine. Apr 2003;10(4):320-328.

63. Miller JB, Brauer E, Rao H, et al. The most frequent ED patients carry insurance and a significant burden of disease. The American journal of emergency medicine. Jan 2013;31(1):16-19.

64. Doran KM, Raven MC, Rosenheck RA. What drives frequent emergency department use in an integrated health system? National data from the veterans health administration. Annals of Emergency Medicine. 2013;62(2):151-159.

65. Doupe MB, Palatnick W, Day S, et al. Frequent users of emergency departments: Developing standard definitions and defining prominent risk factors. Annals of Emergency Medicine. 2012;60(1):24-32.

66. LaCalle E, Rabin E. Frequent Users of Emergency Departments: The Myths, the Data, and the Policy Implications. Annals of Emergency Medicine. 2010;56(1):42-48.

67. Gawande A. The hot spotters: can we lower medical costs by giving the neediest patients better care? New Yorker. Jan 2011:40-51. 
68. Enard KR, Ganelin DM. Reducing preventable emergency department utilization and costs by using community health workers as patient navigators. Journal of healthcare management / American College of Healthcare Executives. Nov-Dec 2013;58(6):412427; discussion 428.

69. Schuur JD, Venkatesh AK. The growing role of emergency departments in hospital admissions. The New England journal of medicine. Aug 2 2012;367(5):391-393.

70. Finnell JT, Overhage JM, Grannis S. All health care is not local: an evaluation of the distribution of Emergency Department care delivered in Indiana. AMIA ... Annual Symposium proceedings / AMIA Symposium. AMIA Symposium. 2011;2011:409-416.

71. Andersen RM. Revisiting the behavioral model and access to medical care: does it matter? Journal of health and social behavior. 1995;36(1):1-10.

72. Andersen RM. Behavioral Model of Families Use of Health Services. Chicago, IL: Center for Health Administrtation Studies, University of Chicago; 1968.

73. Breslau N, Reeb KG. Continuity of care in a university-based practice. J Med Educ. Oct 1975;50(10):965-969.

74. Bice TW, Boxerman SB. A quantitative measure of continuity of care. Medical care. Apr 1977;15(4):347-349.

75. Steinwachs DM. Measuring provider continuity in ambulatory care: an assessment of alternative approaches. Medical care. Jun 1979;17(6):551-565.

76. Ejlertsson G, Berg S. Continuity-of-care measures. An analytic and empirical comparison. Medical care. Mar 1984;22(3):231-239.

77. Godkin M, and C. A. Rice. A measure of continuity of care for physicians in practice. Family Medicine. 1984;16(4):136-140.

78. Magill MK, Senf J. A new method for measuring continuity of care in family practice residencies. The Journal of family practice. Feb 1987;24(2):165-168.

79. Saultz JW. Defining and measuring interpersonal continuity of care. Ann Fam Med. SepOct 2003;1(3):134-143.

80. Kronick RG, Bella M, Glimer TP, Somers SA. The Faces of Medicaid II: Recognizing the Care Needs of People with Multiple Chronic Conditions. Center for Health Care Strategies, Inc.; Oct 2007.

81. Kronick RG, Bella M, Glimer TP. The Faces of Medicaid III: Refining the Portrait of People with Multiple Chronic Conditions. Center for Health Care Strategies, Inc.; Oct 2009.

82. Anderson G. Chronic Care: Making the Case for Ongoing Care. Robert Wood Johnson Foundation;2010.

83. HHS. Multiple Chronic Conditions-A Strategic Framework: Optimum Health and Quality of Life for Individuals with Multiple Chronic Conditions. Washington, DC: U.S. Department of Health and Human Services;2010.

84. NQF. Establishing a Measurement Establishing a Measurement Framework for Multiple Framework for Multiple Chronic Conditions. Washington, DC: National Quality Forum;2011.

85. AHRQ. Methods Guide for Effectiveness and Comparative Effectiveness Reviews. Agency for Healthcare Research and Quality; Jan 2014.

86. Goodman RA, Posner SF, Huang ES, Parekh AK, Koh HK. Defining and measuring chronic conditions: imperatives for research, policy, program, and practice. Preventing chronic disease. 2013;10:E66. 
87. CMS. Chronic Conditions Data Warehouse. 2015;

https://www.ccwdata.org/web/guest/condition-categories. Accessed Nov, 2015. 


\title{
CHAPTER 2
}

\section{Factors Associated with Emergency Department Visits: A Multi-State Analysis of Adult Fee-for-Service Medicaid Beneficiaries}

\begin{abstract}
OBJECTIVE: The objective of this study was to examine the association of patient- and county-level factors with the Emergency Department (ED) visits among adult fee-for-service (FFS) Medicaid beneficiaries residing in Maryland, Ohio, and West Virginia. At the visits level, the current study also analyzed type of ED visits.
\end{abstract}

METHODS: A cross-sectional design using retrospective observational data was implemented. Patient-level data were obtained from 2010 Medicaid Analytic eXtract files. Information on county-level healthcare resources was obtained from the Area Health Resource file and County Health Rankings file. Medicaid beneficiaries who were alive, continuously enrolled, had no Medicare eligibility, and not pregnant were included in the study population $(\mathrm{N}=68,882)$. Type of ED visits were classified as visits for conditions that: 1) did not require immediate ED care; 2) are treatable in primary care settings; 3 ) could have been prevented, if timely primary care was provided; and 4) required immediate ED care. Count data regression models were performed to analyze the patient- and county-level factors associated with the ED visits. Patient- and countylevel factors consisted of predisposing, enabling, need, external environment factors and personal health practices based on Andersen's Behavioral Model for healthcare services utilization. Incidence rates ratios (IRR) and 95\% confidence intervals for ED visits were estimated after accounting for the nesting of patients within counties.

RESULTS: Overall, 54\% of the study population had one or more ED visits during 2010. In adjusted analyses, the following patient-level factors were associated with higher number of ED visits: African Americans (IRR = 1.47), Hispanics (IRR = 1.63), poly-pharmacy (IRR=1.89), 
and tobacco use $(I R R=2.23)$. Patients with complex chronic illness had higher number of ED visits (IRR=3.33). The county-level factors associated with ED visits were: unemployment rate $(\mathrm{IRR}=0.94)$, and number of urgent care clinics $(\mathrm{IRR}=0.96)$. At the visit level, around $73 \% \mathrm{ED}$ visits were preventable.

CONCLUSION: Patients with complex healthcare needs had higher number of ED visits as compared to those without complex healthcare needs. Three in four ED visits were preventable suggesting that timely primary care management can reduce the frequency of ED visits. 


\section{Introduction}

The Center for Disease Control and Prevention estimated 91.1 million visits to the Emergency department (ED) in 2010 among adults aged 18-64 years. ${ }^{1}$ ED visits for healthcare are a major concern because a majority of these visits are for the care of ambulatory care sensitive conditions (ACSCs) and can be prevented with timely primary care. ${ }^{2}$ ED visits for ACSCs impose significant economic burden as costs of treating ACSCs in the EDs are higher as compared to other outpatient settings. ${ }^{3,4}$ ED visits due to ACSCs account for $\$ 38$ billion of total healthcare spending in the United States. ${ }^{5}$

There is a common misperception that almost all ED users who have preventable conditions or are frequent ED utilizers are uninsured. ${ }^{6}$ However, these ED users often have health insurance. ${ }^{6}$ For example, many individuals with Medicaid or Medicare coverage often use the ED. ${ }^{6,7}$ Overall, nearly one-third (31\%)of ED visits are attributable to Medicaid beneficiaries and $4 \%$ are attributable to dual Medicaid/Medicare eligible beneficiaries. ${ }^{1}$ ED visits by Medicaid beneficiaries accounted for about $12 \%$ of the total healthcare spending on ED services in $2012 .{ }^{8}$

ED use among Medicaid beneficiaries has received considerable policy attention and scrutiny due to provision of health insurance coverage to the uninsured by expanding Medicaid eligibility in 31 states under the Affordable Care Act (ACA). As there is some evidence of an inverse relationship between ED visits and community-level supply of primary care providers and health centers, ${ }^{9}$ it could be hypothesized that providing health insurance coverage to the uninsured without corresponding increases in primary care availability may lead to increased ED visits for non-emergent care. However, published literature reveals mixed findings. Some investigations have found little or no change in the ED utilization after provision of insurance 
coverage to the uninsured, ${ }^{10,11}$ while others found that the Medicaid expansion significantly increased both preventable and non-preventable ED utilization. ${ }^{12}$ These studies have limited ability to provide conclusive evidence because they did not include a systematic adjustment for a comprehensive set of patient- and county-level factors.

Several studies that have included a variety of patient-level factors have been conducted using a single site ${ }^{13}$ or selected ED sites in a state. ${ }^{14}$ It is important to analyze data from multiple ED sites to better capture patient history and health status. ${ }^{14}$ Studies that have captured patient history from multiple ED sites have been based on self-reported data, which has significant limitations. ${ }^{15}$ Furthermore, these studies have analyzed data at the visit-level and did not capture repeated ED visits by the same individual. ${ }^{15}$ It is important to analyze ED visits at the patientlevel because many individuals repeatedly visit the ED. In fact, $12 \%$ of the patients visit ED 4 to 38 times/year. ${ }^{13}$

The primary objective of the current study is to use patient-level administrative claims data to examine the association between the patient- and county-level factors and the ED visits. For the purposes of the study, data on ED visits by adult, fee-for-service (FFS) Medicaid beneficiaries residing in Maryland (MD), Ohio (OH), and West Virginia (WV) were selected. Andersen's behavioral model (ABM) for healthcare services utilization was adopted to provide a conceptual framework for the study. ${ }^{16}$ This model has been extensively used in healthcare services research to examine the relationship between predisposing, enabling, need, personal health practices, and external environment factors with healthcare services utilization and expenditures. The ABM model posits that the healthcare services utilization (ED visits in the 
current study) can be influenced by predisposing, enabling, need, external environment factors, and personal health practices as explained in the measures section.

Furthermore, reasons for ED visits were examined among the ED users to determine whether some of the ED visits were preventable due to ACSCs based on a published validated NYU algorithm. ${ }^{17,18}$ This algorithm has been used in healthcare services research to examine the patterns of ED visits that are preventable with the provision of timely primary care.

\section{Methods}

\section{Study Design}

This study used a retrospective cross-sectional design with observational data.

\section{Data Sources}

Medicaid Analytic Extract (MAX) Files - 2010

MAX files are prepared and released by The Centers of Medicare and Medicaid in assistance with Research Data Assistance Center. These files include: 1) Personal summary, 2) Inpatient claims, 3) Other therapy claims, and 4) Prescription drugs claims. The personal summary file included demographics, Medicaid eligibility, county federal information processing standard (FIPS) codes, Medicaid managed care enrollment, and Medicare eligibility status. The inpatient claims file included information related to hospital stays, dates of service, Medicaid payment, and the International Classification of Disease, Ninth Revision, Clinical Modification (ICD-9-CM) codes and ICD-9-CM procedure codes. The other therapy claims file included information on dates of service, types of service, Medicaid payment, ICD-9-CM codes, 
and Current Procedural Terminology (CPT) codes. The prescription drugs claims file included information on the date of prescription filled, days supplied, and national drug code (NDC). All these files can be linked using encrypted identification numbers. The current study used data on Medicaid beneficiaries residing in $\mathrm{MD}, \mathrm{OH}$, and $\mathrm{WV}$.

\section{Area Health Resources Files (AHRF)}

The AHRF files contain national, state, and county level data on approximately 6000 variables ${ }^{19}$. Examples of county-level variables are: percent with college education, health professional shortage area (HPSA), federally qualified health centers per 100,000 population and urgent care centers/100,000 population. Details on county-level variables included in the current study are provided in the Measures section.

\section{County Health Rankings Data}

The County Health Rankings data provides information on health behaviors, clinical care, social and economic factors, and physical environment for all counties in all states. ${ }^{20}$ This information is compiled from 50 different data sources.

\section{Study Population $(N=68,882)$}

The inclusion criteria were: FFS Medicaid beneficiaries, aged 22-64 years, with continuous Medicaid enrollment, not eligible for Medicare, and alive during the entire observation period. Pregnant women were excluded from the analysis because they may have unique prenatal needs. An example of selecting the final study population is summarized in Appendix A. 


\section{Dependent Variable}

Number of ED visits

ED visits were identified from inpatient and outpatient claims. To identify ED visits from the outpatient claims CPT codes (99281-85) were used. ED visits from the inpatient claims were identified using revenue codes (450-52, 456, 459, and 981).

Type of ED Visits among ED users

Based on the validated algorithm developed by Billings and colleagues known as NYU algorithm, ${ }^{17,18}$ type of ED visits were first classified into two groups: 1) those related to injuries or mental health conditions; and 2) those NOT related to injuries and mental health conditions. ED visits not related to injuries and mental health conditions were further classified into visits for conditions that: 1) did not require immediate ED care [e.g. Allergic rhinitis, cause unspecified, Spondylosis of unspecified site, without mention of myelopathy]; 2) are treatable in primary care settings [e.g. acute bronchitis, acute abdominal pain]; 3) could have been prevented, if timely primary care was provided [e.g. epilepsy, hyponatremia]; and 4) required immediate ED care [e.g. cardiac dysrhythmias, calculus of urinary track].

\section{Independent Variables}

Predisposing factors were: age (22-34, 35-44, 45-54, 55-64 years), gender (female, male), and race/ethnicity (whites, African Americans, Hispanics, other races).

Enabling factors were: patient-level Medicaid eligibility due to cash assistance/poverty (cash eligibility, no cash eligibility), county-level college education rate, primary care use (none, 
fragmented, continuous), and county-level unemployment rate. Primary care use was measured using the modified, modified continuity index developed by Magill and colleagues, ${ }^{21}$ which ranged from 0 to 1 . Poly-pharmacy was defined as concomitant use of multiple prescription drugs within a 90-day period and was based on number of prescription drugs one standard deviation above the mean. ${ }^{22}$

Need factors were: patient-level complex chronic illness (physical health conditions, mental health conditions, physical and mental health conditions, none), Medicaid eligibility due to medical need/waiver (medical eligibility, no medical eligibility), and poly-pharmacy (Yes, No). The Agency for Healthcare Research and Quality defines "a complex patient is one with two or more chronic conditions where each condition may influence the care of the other condition(s) through limitations of life expectancy, interactions between drug therapies, difficulties in establishing adequate care coordination, "and/or direct contraindications to therapy for one condition by other conditions themselves." 23 In this study, complex chronic illness was defined as those having both physical and mental health conditions. Physical health conditions consisted of: arthritis, asthma, cardiac arrhythmia, coronary artery disease, cancer, chronic heart failure, chronic kidney disease, chronic obstructive pulmonary disease (COPD), dementia, diabetes, hepatitis, hyperlipidemia, human immunodeficiency virus (HIV), hypertension, osteoporosis, and stroke. Mental health conditions consisted of anxiety, post-traumatic stress disorder, depression, bipolar disorders, psychosis, schizophrenia, and other mental illness. The selection of physical and mental health conditions was based on the framework provided by the Health and Human Services Office of the Assistant Secretary of Health. ${ }^{24}$ Both physical and mental health conditions were identified if patients had one inpatient or one outpatient claim. 
Personal health practices were: patient-level tobacco use (yes tobacco use, no tobacco use), and county-level obesity rates.

External environment factors were measured at the county-level and included metro status (metro, non-metro), health professional shortage area (HPSA - no, partial, and complete shortage areas), number of hospitals with EDs, number of hospitals with psychiatric emergency services, number of rural health clinics, number of federally qualified health centers (FQHCs), number of community mental health centers, and number of urgent care clinics per 100,000 population.

\section{Statistical Analysis}

Frequencies and percentages were used to describe the characteristics of the study population. Mean, interquartile range (IQR) and $90^{\text {th }}$ percentile were used to describe the frequency of ED visits. The frequency of ED visits can be analyzed using a variety of count data regression models. They include poisson regression, negative binomial regression (NBR), zero inflated poisson regression (ZIP), and zero inflated NBR (ZINB). After comparing the predicted and actual probabilities, and log likelihood from all four statistical models, NBR and ZINB models were deemed appropriate. The ZINB model is complex and difficult to interpret due to its two-part structure and many economists and statisticians discourage using ZINB models when NBR models fit well with the data. ${ }^{25}$ Therefore, this study used both unadjusted and adjusted NBR models to examine the patient- and county-level factors associated with the number of ED visits. 
The adjusted NBR models included predisposing, enabling, need, external environment factors, and personal health practices. The parameter estimates from the NBR models were converted to incidence rate ratios (IRRs) by exponentiating the regression coefficients and $95 \%$ confidence intervals were estimated. IRR can be interpreted as the percent change in ED visits. IRR above 1.0 implies higher number of ED visits and IRR below 1.0 implies lower number of ED visits. The data consisted of 167 counties (i.e. all counties in $\mathrm{MD}, \mathrm{OH}$, and WV) and patients nested within these counties. Therefore, the NBR models were adjusted for clustering due to counties using STATA version 14.

At the ED visit-level, the NYU algorithm was used to define visits for conditions that: 1) did not require immediate ED care; 2) are treatable in primary care settings; 3) could have been prevented, if timely primary care was provided; and 4) required immediate ED care. The algorithm uses a probabilistic approach and is based on the ICD-9-CM diagnosis codes. For each ED visit, the algorithm identifies six possible categories: 1) did not require immediate ED care; 2) are treatable in primary care settings; 3) could have been prevented, if timely primary care was provided; 4) required immediate ED care; 5) injury; and 6) psychiatric disorders. ED visits that do not fall in any of the six categories were excluded. For each of the six categories, a probability is assigned. The estimated probabilities can range from 0 to 1 . In this study, a threshold probability of 0.60 was applied to determine whether an ED visit belongs to one of the six categories. 


\section{Results}

During the calendar year 2010, $46 \%$ of the study population had zero ED visits. Around, $36 \%$ beneficiaries had less than or equal to three ED visits, $14 \%$ had 4-9 ED visits, and remaining $4 \%$ had 10 or more ED visits. Table 1 summarizes the patient-level characteristics of the study population. Majority were females (56.2\%), older adults aged 45-64 (58.1\%), whites $(85.3 \%)$, were eligible for Medicaid through cash-assistance/poverty (81.4\%), lived in counties designated as either whole/part county HPSA (79.5\%), and had fragmented/no primary care use (89.4\%). Around, $18 \%$ had poly-pharmacy, and 38\% had both physical and mental health conditions. Overall, $6.6 \%$ of the study population was tobacco user.

The following were the range of county-level factors: college education rate $4 \%$ to $42 \%$, unemployment rate $2.7 \%$ to $10.5 \%$, obesity rate $18.8 \%$ to $35.7 \%$, number of hospitals with psychiatric emergency services/100,000 population 0 to 5.9, number of EDs/100,000 population 0 to 13.1 , number of rural health clinics/100,000 population 0 to 32.9 , number of urgent care centers/100,000 population 0 to 13.1 , number of $\mathrm{FQHCs} / 100,000$ population 0 to 64.1 , and number of community mental health centers/100,000 population 0 to 3.6.

Table 2 presents mean, IQR, $90^{\text {th }}$ percentile, unadjusted IRRs, and $95 \%$ confidence intervals from the unadjusted NBR models. Overall, the mean number of ED visits were 2 with an IQR of 0,2 . Nearly, $10 \%$ of the study population had 6 or more ED visits. The frequencies of ED visits for each subgroup are presented as well. The unadjusted NBRs revealed that many subgroups of the population had higher number of ED visits: adults in the age group 35-44(IRR $=1.25)$ and 45-54 (IRR = 1.22)years; African Americans (IRR = 1.46); Medicaid eligibility due 
to poverty/cash-assistance $(I R R=1.35)$; college education rate $(I R R=1.02)$; fragmented primary care use $(I R R=1.55)$; poly-pharmacy $(I R R=2.10)$; presence of physical health conditions $(\mathrm{IRR}=2.46)$; presence of mental health conditions $(\mathrm{IRR}=1.69)$; presence of both physical and mental health conditions (IRR $=4.23)$; Medicaid eligibility due to medical needs $(I R R=1.35)$; tobacco use $(I R R=2.54)$; and number of hospitals with psychiatric emergency services $(I R R=1.21)$. Some subgroups of the population had lower number of ED visits: female $(\mathrm{IRR}=0.08)$; obesity rate $(\mathrm{IRR}=0.95)$; non-metro status $(\mathrm{IRR}=0.81)$; number of rural health centers (IRR $=0.99)$; and number of FQHCs (IRR = 0.99). No associations were observed between ED visits and the following factors: those 55-64 years old; unemployment rate; no primary care use; no/partial county HPSA; number of hospitals with EDs; number of urgent care centers; and number of community mental health centers.

The IRRs and 95\% confidence intervals from the adjusted NBR are summarized in table 3. The relationship between ED visits and the following factors remained same as observed in the unadjusted NBR models: females, African Americans, no medical eligibility, fragmented primary care use, poly-pharmacy, and presence of complex chronic illness. For example, those with poly-pharmacy had higher number of ED visits (IRR $=1.89)$ as compared to those individuals without poly-pharmacy. However, the association between ED visits and the following factors changed: age group 45-54 (IRR = 0.78), and 55-64 (IRR = 0.66); unemployment rate $(\mathrm{IRR}=0.94)$; no primary care use $(\mathrm{IRR}=0.92)$; and number of urgent care centers $(I R R=0.96)$. No associations were observed between ED visits and the following factors: 35-44 years old, Medicaid eligibility due to poverty, college education rate, obesity rate, no/partial HPSA, non-metro status of the county, number of hospitals with psychiatric 
emergency services, number of rural health centers, number of FQHCs, and number of community mental health centers.

Among ED users, the types of ED visits were examined using NYU algorithm. The results from this analysis are summarized in Table 4 . Out of 123,554 ED visits $18.11 \%$ were due to injuries, and $5.63 \%$ were due to psychiatric disorders. Around 9\% visits were unclassified. Among ED visits not related to injuries and psychiatric disorders $(\mathrm{N}=83,089), 34.65 \%$ were for conditions that did not require immediate ED care, $28.56 \%$ of ED visits were for conditions that could have been treated in primary care settings, $9.91 \%$ ED visits could have been prevented, if timely primary care was provided, and $26.9 \%$ were for conditions that required immediate ED care and could not have been prevented with ambulatory care.

\section{Discussion}

This study examined the patient- and county-level factors that were associated with the number of ED visits. It also examined ED visits that were preventable with the provision of timely primary care. With the recent implementation of ACA, it is critical to examine patientand county-level factors associated with ED visits among Medicaid beneficiaries as increased provision of health insurance coverage may result in amplified strain on payers, providers, and patients. Data for adult FFS Medicaid beneficiaries residing in $\mathrm{MD}, \mathrm{OH}$ and WV were used to derive the study findings. The study findings are particularly important for these states because they have expanded Medicaid to provide health insurance coverage for the uninsured. Earlier experiences with expanded coverage have shown mixed results for increase or decrease in the

ED utilization rates. ${ }^{10-12}$ Due to paucity of data, it is difficult to measure the real impact of the 
provision of health insurance coverage on ED utilization. However, this study aims at providing a baseline analysis for future comparisons with changes in ED use as a result of ACA implementation.

The study findings revealed that a number of patient-level and few county-level factors were associated with the ED visits among adult FFS Medicaid beneficiaries. Among predisposing factors, the current study observed that African Americans and Hispanics had higher number of ED visits as compared to whites. The findings on racial/ethnic disparities are consistent with the published literature on ED utilization. ${ }^{9,26}$

Among the enabling factors, county-level unemployment rate and primary care use were associated with the number of ED visits. A counter-intuitive finding of this study is the inverse relationship between county-level unemployment rate and number of ED visits. The reasons behind lower number of ED visits by individuals living in counties with high unemployment rate are not known. Future studies may need to examine the relationship between individual-level unemployment, poverty, and ED visits.

Findings from the current study support the published literature in which primary care use is inversely related with ED visits. ${ }^{27}$ Medicaid beneficiaries with fragmented primary care use had higher number of ED visits as compared to those with primary care continuity. At the ED visit-level, three in five ED visits were for the management of ACSCs. Taken together, these findings suggest that timely and continuous primary care in outpatient healthcare settings can reduce the frequency of ED visits among adult FFS Medicaid beneficiaries. In most 
circumstances, decision to visit the ED is usually initiated by the patient probably in consultation with their primary care providers. However, when primary care use is fragmented, the patient may choose to use ED even for non-emergency services. It has been documented that individuals without adequate primary care may delay receiving appropriate care,${ }^{28}$ which may in turn lead to increased use of ED.

All the need factors were associated with higher number of ED visits. Adult FFS Medicaid beneficiaries with complex needs (i.e. those with both physical and mental health conditions, poly-pharmacy, and were eligible for Medicaid because of their medical needs) had higher number of ED visits as compared to those without complex needs. This finding is consistent with prior studies in which ED users were found to have high medical needs, ${ }^{29-34}$ have chronic conditions, ${ }^{35}$ suffer from mental illnesses, ${ }^{36-43}$ and have greater number of psychotropic medications. ${ }^{44}$ A plausible explanation for higher ED visits by those with chronic complex illness may be due to complications of chronic conditions, side effects and adverse events due to multiple medications use ${ }^{45}$ fragmented care because of visits to multiple healthcare providers, "and/or direct contraindications to therapy for one condition by other conditions themselves."23 However, provision of care for chronic physical and mental health conditions in the ED is very expensive. ${ }^{3,4}$ Future studies need to examine whether the emerging healthcare delivery models such as medical homes, and accountable care organizations (ACO), which are specifically designed to take care of complex patients, can reduce the number of ED visits by the complex patients. Although ACO models are currently implemented for Medicare beneficiaries, Medicaid policy makers in many states are also experimenting with ACO models. Currently ACO models are being tested in Colorado, New Jersey, Oklahoma, Oregon, and Utah. These Medicaid ACO 
demonstration projects may provide evidence about whether the new delivery models can reduce the use of ED.

Among personal health practices, individuals with tobacco use had higher number of ED visits as compared to those without tobacco use. Tobacco use is a modifiable risk factor that has been linked with cardiovascular, respiratory, and cancer diseases. The prevalence of tobacco use ranged from $11.8 \%$ to $29 \%$ across all states in the US. ${ }^{46}$ The current study was conducted on states with higher tobacco use prevalence: $25.1 \%$ in $\mathrm{OH}, 19.1 \%$ in $\mathrm{MD}$, and $28.6 \%$ in WV. ${ }^{46}$ Although there is evidence of a positive association between substance abuse and ED visits ${ }^{13}$, a recently published study by Castner et al. observed a stronger association between smoking and ED use as compared to psychiatric diagnosis. ${ }^{47}$ Future research needs to focus on the underlying causes for which tobacco users are visiting the ED. It is possible that higher ED use among tobacco users is linked with the symptomatology of the pre-diagnosed clinical conditions. Future research may examine if EDs can serve as appropriate healthcare settings for the provision of smoking cessation interventions. Indeed, the results from a recently published randomized controlled trial revealed that a smoking cessation intervention offered in an ED declined smoking rates among low-income smokers significantly. ${ }^{48}$ It is plausible that ED users have limited access to other healthcare providers who can encourage them to quit tobacco use.

Some county-level external environment factors were associated with ED visits among adult FFS Medicaid beneficiaries. For example, this study noted that with higher number of urgent care centers significantly lower number of ED visits were observed. This finding is consistent with another study by Weinick et al. that observed about $13.1 \%$ to $27.1 \%$ of ED visits 
can be prevented with increased use of urgent care centers and other healthcare settings. ${ }^{49}$ Studies that have compared urgent care and ED care have found that costs of care in urgent care centers are lower as compared to EDs., ${ }^{3,4}$ Thus, the urgent care centers can be a viable substitute for EDs in providing care for acute conditions and exacerbations of chronic conditions. ${ }^{49}$

Findings of the current study need to be interpreted with consideration of some limitations. This study was conducted on alive, adult FFS Medicaid beneficiaries, aged 22-64 years old, continuously enrolled, not dually eligible, and residing in $\mathrm{MD}, \mathrm{OH}$, and WV. Considering the geographic population, policy, and resource differences typically seen across states, the results of this study represent only $\mathrm{MD}, \mathrm{OH}$, and $\mathrm{WV}$ and not generalizable to the entire Medicaid population. As Medicaid beneficiaries enrolled under managed care plans were excluded from the analytical cohort, the study suffers selection bias. The study was conducted using an observational data, therefore it is difficult to account for selection bias as ED users may have different attributes in unobserved variables compared to the non-ED users. The crosssectional design of the study does not allow causal inferences. As all the independent variables were measured in the same as year as the outcome variable, temporal relationships cannot be established. Substance abuse leads to increased ED use, however, the current study could not account for alcohol use and drug abuse because of limited sample size. Additionally, administrative claims data were used, which are created for billing purposes rather than research. This may result in misclassification of diagnosis. Although the current study examined the types of ED visits, it used a probabilistic approach and may involve some uncertainty and variations. 
Despite the limitations, the current study has several strengths. A comprehensive list of patient-level and county-level factors were used. These factors were obtained from different data sources and were linked together to provide complete information about the patient level factors and county-level healthcare resources. By relying on healthcare encounter data, the current study was able to capture services received from multiple providers, healthcare settings and geographical areas. Information on clinical diagnosis, prescription drugs and other healthcare services use were captured from claims data and do not have the shortcomings of self-reported data. The current study used patient-level data and was able to track repeated ED visits made by the same patient.

To conclude, the study is timely because many states have surveillance and other research projects to monitor the use of ED by Medicaid beneficiaries and are exploring policies and programs that can reduce preventable ED visits. ${ }^{50}$ The current study highlighted that only very few county-level factors and many patient-level factors were associated with ED visits. These findings suggest that healthcare delivery models that provide comprehensive care to complex patients may reduce the likelihood of ED visits. Implementing value-based insurance designs that provide financial incentives to promote primary care continuity may go a long way in reducing the ED visits among adult FFS Medicaid beneficiaries. 


\section{Table 1}

Description of the Study Population by Patient-level Factors

Adult Fee-for-Service Medicaid Beneficiaries

Multistate Medicaid Analytical eXtract Files - 2010

\begin{tabular}{|c|c|c|}
\hline & $\mathbf{N}$ & $(\%)$ \\
\hline ALL & 68,882 & 100.0 \\
\hline \multicolumn{3}{|c|}{ Predisposing Factors } \\
\hline \multicolumn{3}{|l|}{ Age } \\
\hline 22-34 years & 16,124 & 23.4 \\
\hline 35-44 years & 12,708 & 18.4 \\
\hline 45-54 years & 20,182 & 29.3 \\
\hline $55-64$ years & 19,868 & 28.8 \\
\hline \multicolumn{3}{|l|}{ Gender } \\
\hline Female & 38,694 & 56.2 \\
\hline Male & 30,188 & 43.8 \\
\hline \multicolumn{3}{|l|}{ Race } \\
\hline White & 58,760 & 85.3 \\
\hline African Americans & 9,023 & 13.1 \\
\hline Hispanics & 532 & 0.77 \\
\hline Other Races & 567 & 0.82 \\
\hline
\end{tabular}

\section{Medicaid Cash Eligibility}

Cash Eligibility

Enabling Factors

No cash Eligibility

$56,074 \quad 81.4$

$12,808 \quad 18.6$

Primary Care Use

None

$13,969 \quad 20.3$

Fragmented

$47,582 \quad 69.1$

Continuous

$7,331 \quad 10.6$

\section{Complex Chronic Illness}

Physical health conditions

$25,128 \quad 36.5$

Mental health conditions

$6,994 \quad 10.2$

Physical and mental health conditions

$25,867 \quad 37.5$

None

10,893

15.8

(continued)

\begin{tabular}{lrc}
\hline $\begin{array}{l}\text { Poly-pharmacy } \\
\text { Yes }\end{array}$ & 12,469 & 18.1 \\
No & 56,413 & 81.9 \\
Medicaid Medical Eligibility & & \\
Medical Eligibility & 7,064 & 10.3 \\
No medical Eligibility & 61,818 & 89.7 \\
\hline & Personal Health Practices & \\
\hline Tobacco Use & & \\
Yes Tobacco Use & 4,558 & 6.6 \\
No Tobacco Use & 64,324 & 93.4 \\
\hline
\end{tabular}

County-level External Environment Factors 


\begin{tabular}{|c|c|c|}
\hline \multicolumn{3}{|c|}{$\begin{array}{c}\text { Table 1 } \\
\text { Description of the Study Population by Patient-level Factors } \\
\text { Adult Fee-for-Service Medicaid Beneficiaries } \\
\text { Multistate Medicaid Analytical eXtract Files - 2010 }\end{array}$} \\
\hline & $\mathbf{N}$ & $(\%)$ \\
\hline ALL & 68,882 & 100.0 \\
\hline \multicolumn{3}{|l|}{ Metro } \\
\hline Metro & 41,964 & 60.9 \\
\hline Non-metro & 26,918 & 39.1 \\
\hline
\end{tabular}

Note: Based on 68,882 adult Medicaid fee-for-service beneficiaries aged 22-64 years and who are continuously enrolled for the year 2010, who are not Medicare and Medicaid eligible, who are alive and non-pregnant. County-level variables were extracted from the Area Health Resource Files and county health ranking data. 
Table 2

Mean, Inter Quartile Range, 90 $^{\text {th }}$ Percentile,

Incidence Ratios and $95 \%$ Confidence Intervals

from Negative Binomial Regressions of Number of Emergency Department Visits Adult Fee-For-Service Medicaid Beneficiaries

Multistate Medicaid Analytical eXtract Files - 2010

\begin{tabular}{|c|c|c|c|c|c|c|}
\hline & Mean & IQR & P90 & IRR & $95 \%$ CI & Sig \\
\hline \multicolumn{7}{|c|}{ Predisposing Factors } \\
\hline \multicolumn{7}{|l|}{ Age } \\
\hline 22-34 years & 2 & $(0,2)$ & 6 & & Ref & \\
\hline $35-44$ years & 2 & $(0,2)$ & 5 & 1.25 & $(1.16,1.34)$ & $* * *$ \\
\hline 45-54 years & 2 & $(0,3)$ & 6 & 1.22 & $(1.05,1.40)$ & $* *$ \\
\hline $55-64$ years & 2 & $(0,3)$ & 6 & 1.09 & $(0.94,1.24)$ & \\
\hline \multicolumn{7}{|l|}{ Gender } \\
\hline Female & 2 & $(0,3)$ & 6 & 0.08 & $(0.01,0.14)$ & $*$ \\
\hline Male & 2 & $(0,2)$ & 5 & & Ref & \\
\hline \multicolumn{7}{|l|}{ Race } \\
\hline White & 2 & $(0,2)$ & 5 & & Ref & \\
\hline African American & 3 & $(0,3)$ & 8 & 1.46 & $(1.10,1.94)$ & $* *$ \\
\hline Hispanic & 3 & $(0,2)$ & 6 & 1.30 & $(0.90,1.87)$ & \\
\hline Others & 3 & $(0,2)$ & 8 & 1.31 & $(0.78,2.22)$ & \\
\hline \multicolumn{7}{|c|}{ Enabling Factors } \\
\hline \multicolumn{7}{|l|}{ Medicaid Cash Eligibility } \\
\hline Cash eligibility & 2 & $(0,2)$ & 6 & 0.92 & $(0.87,0.98)$ & $* *$ \\
\hline No cash eligibility & 2 & $(0,3)$ & 6 & & Ref & \\
\hline \multicolumn{7}{|l|}{ County-level Education } \\
\hline Percent with college education & & & & 1.02 & $(1.01,1.03)$ & $* *$ \\
\hline \multicolumn{7}{|l|}{ County-level Unemployment } \\
\hline Percent unemployed & & & & 0.94 & $(.89,1.00)$ & \\
\hline \multicolumn{7}{|l|}{ Primary Care Use } \\
\hline None & 1 & $(0,1)$ & 3 & 0.87 & $(0.74,1.03)$ & \\
\hline Fragmented & 3 & $(0,3)$ & 7 & 1.55 & $(1.37,1.76)$ & $* * *$ \\
\hline Continuous & 2 & $(0,2)$ & 4 & & Ref & \\
\hline \multicolumn{7}{|c|}{ Need Factors } \\
\hline \multicolumn{7}{|l|}{ Complex Chronic Illness } \\
\hline Physical health conditions & 2 & $(0,2)$ & 5 & 2.46 & $(2.05,2.96)$ & $* * *$ \\
\hline Mental health conditions & 1 & $(0,2)$ & 4 & 1.69 & $(1.56,1.83)$ & $* * *$ \\
\hline Physical and mental health conditions & 3 & $(0,4)$ & 9 & 4.23 & $(3.80,4.71)$ & $* * *$ \\
\hline None & 0 & $(0,1)$ & 2 & & Ref & \\
\hline \multicolumn{7}{|l|}{ Poly-pharmacy } \\
\hline Yes & 4 & $(0,5)$ & 10 & 2.10 & $(1.96,2.26)$ & $* * *$ \\
\hline $\begin{array}{l}\text { No } \\
\text { (Continued) }\end{array}$ & 2 & $(0,2)$ & 5 & & Ref & \\
\hline
\end{tabular}


Table 2

Mean, Inter Quartile Range, 90 $^{\text {th }}$ Percentile, Incidence Ratios and $95 \%$ Confidence Intervals

from Negative Binomial Regressions of Number of Emergency Department Visits Adult Fee-For-Service Medicaid Beneficiaries Multistate Medicaid Analytical eXtract Files - 2010

\begin{tabular}{|c|c|c|c|c|c|c|}
\hline & Mean & IQR & $\mathbf{P 9 0}$ & IRR & $95 \% \mathrm{CI}$ & Sig \\
\hline \multicolumn{7}{|l|}{ Medicaid Medical Eligibility } \\
\hline Medical eligibility & 2 & $(0,3)$ & 8 & 1.35 & $(1.25,1.46)$ & $* * *$ \\
\hline No medical eligibility & 3 & $(0,2)$ & 6 & & Ref & \\
\hline \multicolumn{7}{|c|}{ Personal Health Practices } \\
\hline \multicolumn{7}{|l|}{ Tobacco Use } \\
\hline Yes Tobacco Use & 5 & $(1,6)$ & 12 & 2.54 & $(2.34,2.74)$ & $* * *$ \\
\hline No Tobacco Use & 2 & $(0,2)$ & 5 & & Ref & \\
\hline \multicolumn{7}{|l|}{ County-level Obesity } \\
\hline Obesity Rate & & & & 0.95 & $(0.91,0.99)$ & $*$ \\
\hline \multicolumn{7}{|c|}{ County-level External Environment Factors } \\
\hline \multicolumn{7}{|c|}{ Health Professional Shortage Area } \\
\hline No shortage & 2 & $(0,2)$ & 5 & 0.90 & $(0.68,1.19)$ & \\
\hline Part county shortage & 2 & $(0,2)$ & 6 & 0.95 & $(0.75,1.20)$ & \\
\hline Whole county shortage & 2 & $(0,3)$ & 6 & & Ref & \\
\hline \multicolumn{7}{|l|}{ Metro } \\
\hline Metro & 2 & $(0,3)$ & 6 & & Ref & \\
\hline Non-metro & 2 & $(0,2)$ & 5 & 0.81 & $(0.68,0.95)$ & * \\
\hline \multicolumn{7}{|l|}{ Emergency Departments } \\
\hline Number of EDs/100,000 population & & & & 0.98 & $(0.95,1.01)$ & \\
\hline \multicolumn{7}{|l|}{ Psychiatric Emergency Services } \\
\hline $\begin{array}{l}\text { Number of Psychiatric ED } / 100,000 \\
\text { population }\end{array}$ & & & & 1.21 & $(1.01,1.44)$ & * \\
\hline \multicolumn{7}{|l|}{ Rural Health Centers } \\
\hline $\begin{array}{l}\text { Number of rural health centers } / 100,000 \\
\text { population }\end{array}$ & & & & 0.99 & $(0.97,0.99)$ & * \\
\hline \multicolumn{7}{|l|}{ Urgent Care Centers } \\
\hline $\begin{array}{l}\text { Number of urgent care centers } / 100,000 \\
\text { population }\end{array}$ & & & & 0.97 & $(0.93,1.01)$ & \\
\hline \multicolumn{7}{|l|}{ FQHC } \\
\hline Number of FQHCs/100,000 population & & & & 0.99 & $(0.98,0.99)$ & * \\
\hline \multicolumn{7}{|l|}{ Community mental health centers } \\
\hline $\begin{array}{l}\text { Number of community mental health centers } \\
/ 100,000 \text { population }\end{array}$ & & & & 1.06 & $(0.90,1.23)$ & \\
\hline
\end{tabular}

Note: Based on 68,882 adult Medicaid fee-for-service beneficiaries aged 22-64 years and who are continuously enrolled for the year 2010, who are not Medicare and Medicaid eligible, who 
are alive and non-pregnant. County-level variables were extracted from the Area Health Resource Files and county health ranking data. Significant subgroup differences in number of emergency department visits were tested with negative binomial regression, which adjusted for clustering of individuals within counties.

ED: Emergency Department; FQHC: Federally Qualified Health Centers; Ref: Reference Group; IQR: Inter-Quartile Range; IRR: incidence rate ratio; CI: Confidence interval; P90: 90 ${ }^{\text {th }}$ percentile

$* * * \mathrm{p}<.001 ; * * .001<\mathrm{p}<.01 ; * .01<\mathrm{p}<.05$. 


\begin{tabular}{|c|c|c|c|}
\hline \multicolumn{4}{|c|}{$\begin{array}{c}\text { Table 3 } \\
\text { Incidence Rate Ratios and 95\% Confidence Intervals (CI) } \\
\text { from Multivariable Negative Binomial Regression of } \\
\text { Adult Fee-for-Service Medicaid Beneficiaries } \\
\text { Multistate Medicaid Analytical eXtract Files - 2010 }\end{array}$} \\
\hline & IRR & 95\% CI & Sig \\
\hline \multicolumn{4}{|c|}{ Predisposing Factors } \\
\hline \multicolumn{4}{|l|}{ Age } \\
\hline $22-34$ years & & Ref & \\
\hline $35-44$ years & 0.96 & $(0.92,1.01)$ & \\
\hline $45-54$ years & 0.78 & $(0.72,0.84)$ & $* * *$ \\
\hline $55-64$ years & 0.66 & $(0.61,0.71)$ & $* * *$ \\
\hline \multicolumn{4}{|l|}{ Gender } \\
\hline Female & 0.95 & $(0.91,0.99)$ & * \\
\hline Male & & Ref & \\
\hline \multicolumn{4}{|l|}{ Race } \\
\hline Whites & & Ref & \\
\hline African American & 1.47 & $(1.23,1.76)$ & $* * *$ \\
\hline Hispanics & 1.63 & $(1.16,2.31)$ & $* *$ \\
\hline Others & 1.36 & $(0.97,1.92)$ & \\
\hline \multicolumn{4}{|c|}{ Enabling Factors } \\
\hline \multicolumn{4}{|l|}{ Medicaid Cash Eligibility } \\
\hline Cash Eligibility & 1.07 & $(0.99,1.16)$ & \\
\hline No Cash Eligibility & & Ref & \\
\hline \multicolumn{4}{|l|}{ County-level Education } \\
\hline Percent with college education & 1.00 & $(0.99,1.02)$ & \\
\hline County-level Unemployment & & Ref & \\
\hline Percent unemployed & 0.94 & $(0.89,0.98)$ & ** \\
\hline Primary Care Use & & Ref & \\
\hline None & 0.92 & $(0.86,0.97)$ & ** \\
\hline Fragmented & 1.26 & $(1.18,1.35)$ & $* * *$ \\
\hline Continuous & & Ref & \\
\hline \multicolumn{4}{|c|}{ Need Factors } \\
\hline \multicolumn{4}{|l|}{ Complex Chronic Illness } \\
\hline Physical health conditions & 2.12 & $(1.88,2.56)$ & $* * *$ \\
\hline Mental health conditions & 1.53 & $(1.39,1.69)$ & $* * *$ \\
\hline Both physical and mental health conditions & 3.33 & $(2.96,3.75)$ & $* * *$ \\
\hline None & & Ref & \\
\hline \multicolumn{4}{|l|}{ Poly-pharmacy } \\
\hline Yes & 1.89 & $(1.80,1.99)$ & $* * *$ \\
\hline No & & Ref & \\
\hline \multicolumn{4}{|l|}{ Medicaid Medical Eligibility } \\
\hline Medical Eligibility & 1.29 & $(1.14,1.46)$ & $* * *$ \\
\hline No medical Eligibility & & Ref & \\
\hline
\end{tabular}

Tobacco Use 


\section{Table 3}

Incidence Rate Ratios and 95\% Confidence Intervals (CI)

from Multivariable Negative Binomial Regression of

Adult Fee-for-Service Medicaid Beneficiaries

Multistate Medicaid Analytical eXtract Files - 2010

\begin{tabular}{|c|c|c|c|}
\hline & IRR & $95 \% \mathrm{CI}$ & Sig \\
\hline Yes Tobacco Use & 2.23 & $(2.09,2.40)$ & **** \\
\hline No Tobacco Use & & Ref & \\
\hline \multicolumn{4}{|l|}{ County-level Obesity } \\
\hline Obesity rate & 0.96 & $(0.93,1.00)$ & \\
\hline \multicolumn{4}{|c|}{ External Environment Factors } \\
\hline \multicolumn{4}{|l|}{ Health Professional Shortage Area } \\
\hline No shortage & 1.04 & $(0.88,1.23)$ & \\
\hline Part county shortage & 1.04 & $(0.88,1.23)$ & \\
\hline Whole county shortage & & Ref & \\
\hline \multicolumn{4}{|l|}{ Metro } \\
\hline Metro & & Ref & \\
\hline Non-metro & 0.92 & $(0.82,1.03)$ & \\
\hline \multicolumn{4}{|l|}{ Emergency Departments } \\
\hline Number of ED /100,000 population & 1.03 & $(1.00,1.06)$ & $*$ \\
\hline \multicolumn{4}{|l|}{ Psychiatric Emergency Services } \\
\hline Number of Psychiatric ED/100,000 population & 1.09 & $(0.97,1.21)$ & \\
\hline \multicolumn{4}{|l|}{ Rural Health Centers } \\
\hline Number of rural health centers/100,000 population & 1.00 & $(0.99,1.02)$ & \\
\hline \multicolumn{4}{|l|}{ Urgent Care Centers } \\
\hline Number of urgent care centers $/ 100,000$ population & 0.96 & $(0.92,0.99)$ & $* *$ \\
\hline \multicolumn{4}{|l|}{ Federally Qualified Health Centers } \\
\hline Number of FQHCs/100,000 population & 1.00 & $(0.99,1.01)$ & \\
\hline \multicolumn{4}{|l|}{ Community mental health centers } \\
\hline $\begin{array}{l}\text { Number of community mental health centers } / 100,000 \\
\text { population }\end{array}$ & 0.97 & $(0.84,1.12)$ & \\
\hline
\end{tabular}

Note: Based on 68,882 adult Medicaid fee-for-service beneficiaries aged 22-64 years and who are continuously enrolled for the year 2010, who are not Medicare and Medicaid eligible, who are alive and non-pregnant. County-level variables were extracted from the Area Health Resource Files and county health ranking data. Significant subgroup differences in number of emergency department visits were tested with negative binomial regression, which adjusted for clustering of individuals within counties.

ED: Emergency Department; FQHC: Federally Qualified Health Centers; Ref: Reference Group; Sig: Significance

$* * * \mathrm{p}<.001 ; * * .001<\mathrm{p}<.01 ; * .01<\mathrm{p}<.05$. 


\begin{tabular}{|c|c|c|}
\hline \multicolumn{3}{|c|}{$\begin{array}{c}\text { Table 4 } \\
\text { NYU Algorithm Classifying ED Visits } \\
\text { Adult Fee-for-Service Medicaid Beneficiaries } \\
\text { Multistate Medicaid Analytical eXtract Files - 2010 }\end{array}$} \\
\hline & Number of ED Visits & $\%$ \\
\hline Total & 123,554 & \\
\hline No immediate ED care required & 28,789 & 23.30 \\
\hline Treatable in primary care settings & 23,734 & 19.21 \\
\hline Preventable, if timely primary care was provided & 8,230 & 6.66 \\
\hline Required immediate ED care & 22,336 & 18.08 \\
\hline Injury & 22,378 & 18.11 \\
\hline Psychiatric disorders & 6,953 & 5.63 \\
\hline Unclassified & 11,134 & 9.01 \\
\hline
\end{tabular}

Note: Based on 123,554 ED visits by adult Medicaid FFS beneficiaries aged 22-64 years and who are continuously enrolled for the year 2010, who are not Medicare and Medicaid eligible, who are alive and non-pregnant. ED visits were classified using NYU algorithm developed by New York University Center for Health and Public Service Research. Classification was based on $60 \%$ threshold and unclassified conditions were excluded. 


\section{Appendix A \\ Study Population: Adult Fee-for-Service Medicaid Beneficiaries \\ Multistate Medicaid Analytical eXtract Files - 2010 \\ (Example: West Virginia)}

- 22-64 years old

- Medicaid beneficiaries residing in WV during 2010

$$
\mathrm{N}=119,268
$$

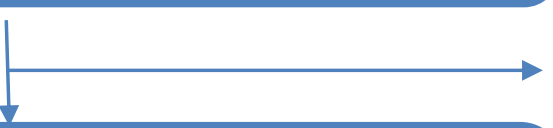

- 22-64 years old

- Medicaid beneficiaries residing in WV during 2010

- Alive

$$
\mathrm{N}=117,221
$$

- 22-64 years old

- Medicaid beneficiaries residing in WV during 2010

- Alive

- Men and non-pregnant women

$$
\mathrm{N}=107,946
$$

- 22-64 years old

- Medicaid beneficiaries residing in WV during 2010

- Alive

- Men and non-pregnant women

- Not Medicare Eligible

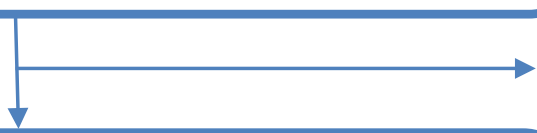

Reason for exclusion:

- $\quad$ Death $(\mathrm{N}=2,047)$

Reasons for exclusion:

- $\quad$ Pregnant women $(\mathrm{N}=9,275)$

Reasons for exclusion:

- $\quad$ Medicare eligibility $(\mathrm{N}=31,142)$

Reasons for exclusion:

- Managed care and FFS not continuous $(\mathrm{N}=32,709)$

- 22-64 years old

\section{Final Study Population:}

- Medicaid beneficiaries residing in WV during 2010

- Alive

- Men and non-pregnant women

- Not Medicare Eligible

- Fee-for-service continuous enrollment

$$
(\mathrm{N}=\mathbf{4 4 , 0 9 5})
$$




\section{References}

1. CDC. Emergency Department Visits. 2014; http://www.cdc.gov/nchs/fastats/emergencydepartment.htm. Accessed 22nd November, 2014.

2. Uscher-Pines L, Pines J, Kellermann A, Gillen E, Mehrotra A. Emergency department visits for nonurgent conditions: systematic literature review. The American journal of managed care. Jan 2013;19(1):47-59.

3. Thygeson M, Van Vorst KA, Maciosek MV, Solberg L. Use and costs of care in retail clinics versus traditional care sites. Health Aff (Millwood). Sep-Oct 2008;27(5):12831292.

4. Mehrotra A, Liu H, Adams JL, et al. Comparing costs and quality of care at retail clinics with that of other medical settings for 3 common illnesses. Annals of internal medicine. Sep 1 2009;151(5):321-328.

5. A Matter of Urgency: Reducing Emergency Department Overuse. 2010; http://www.nehi.net/writable/publication_files/file/nehi_ed_overuse_issue_brief_032610f inaledits.pdf. Accessed Aug, 2015.

6. Pitts SR, Carrier ER, Rich EC, Kellermann AL. Where Americans get acute care: increasingly, it's not at their doctor's office. Health Aff (Millwood). Sep 2010;29(9):16201629.

7. Mortensen K, Song PH. Minding the gap: a decomposition of emergency department use by Medicaid enrollees and the uninsured. Medical care. Oct 2008;46(10):1099-1107.

8. AHRQ. Emergency Room Services-Mean and Median Expenses per Person With Expense and Distribution of Expenses by Source of Payment: United States, 2012. Medical Expenditure Panel Survey Household Component Data. 2012; http://meps.ahrq.gov/mepsweb/data_stats/tables_compendia_hh_interactive.jsp?_SERVI CE=MEPSSocket0\&_PROGRAM=MEPSPGM.TC.SAS\&File=HCFY2012\&Table $=$ HCF Y2012 PLEXP E\&VAR1=AGE\&VAR2=SEX\&VAR3=RACETH5C\&VAR4=INSURC OV\&VAR5=POVCAT12\&VAR6=MSA\&VAR7=REGION\&VAR8=HEALTH\&VARO $1=4+17+44+64 \&$ VARO2=1\&VARO3=1\&VARO4=1\&VARO5=1\&VARO6=1\&VARO 7=1\&VARO8=1\&_Debug=. Accessed Aug, 2015.

9. Cunningham PJ. What accounts for differences in the use of hospital emergency departments across U.S. communities? Health Aff (Millwood). Sep-Oct 2006;25(5):w324336.

10. Miller S. The effect of the Massachusetts reform on health care utilization. Inquiry : a journal of medical care organization, provision and financing. Winter 2012;49(4):317326.

11. Smulowitz PB, O'Malley J, Yang X, Landon BE. Increased use of the emergency department after health care reform in Massachusetts. Ann Emerg Med. Aug 2014;64(2):107-115, 115 e101-103.

12. Taubman SL, Allen HL, Wright BJ, Baicker K, Finkelstein AN. Medicaid increases emergency-department use: evidence from Oregon's Health Insurance Experiment. Science. Jan 17 2014;343(6168):263-268.

13. Capp R, Rosenthal MS, Desai MM, et al. Characteristics of Medicaid enrollees with frequent ED use. The American journal of emergency medicine. Sep 2013;31(9):13331337. 
14. Finnell JT, Overhage JM, Grannis S. All health care is not local: an evaluation of the distribution of Emergency Department care delivered in Indiana. AMIA ... Annual Symposium proceedings / AMIA Symposium. AMIA Symposium. 2011;2011:409-416.

15. Tang N, Stein J, Hsia RY, Maselli JH, Gonzales R. Trends and characteristics of US emergency department visits, 1997-2007. Jama. Aug 11 2010;304(6):664-670.

16. Andersen RM. Revisiting the behavioral model and access to medical care: does it matter? Journal of health and social behavior. 1995;36(1):1-10.

17. Billings J, Parikh N, Mijanovich T. Emergency department use: the New York Story. Issue brief. Nov 2000(434):1-12.

18. Ballard DW, Price M, Fung V, et al. Validation of an algorithm for categorizing the severity of hospital emergency department visits. Medical care. Jan 2010;48(1):58-63.

19. HRSA. Area Health Resources Files (AHRF) National, State and County Health Resources Information Database. http://ahrf.hrsa.gov/download.htm. Accessed Aug, 2015.

20. County Health Rankings \& Roadmaps: Our Approach. http://www.countyhealthrankings.org/. Accessed Aug, 2015.

21. Magill MK, Senf J. A new method for measuring continuity of care in family practice residencies. The Journal of family practice. Feb 1987;24(2):165-168.

22. Goldberg JF, Brooks JO, 3rd, Kurita K, et al. Depressive illness burden associated with complex polypharmacy in patients with bipolar disorder: findings from the STEP-BD. The Journal of clinical psychiatry. Feb 2009;70(2):155-162.

23. NQF. Establishing a Measurement Establishing a Measurement Framework for Multiple Framework for Multiple Chronic Conditions. Washington, DC: National Quality Forum;2011.

24. Goodman RA, Posner SF, Huang ES, Parekh AK, Koh HK. Defining and measuring chronic conditions: imperatives for research, policy, program, and practice. Preventing chronic disease. 2013;10:E66.

25. Allison P. Do We Really Need Zero-Inflated Models? 2012; http://statisticalhorizons.com/zero-inflated-models. Accessed 15th August, 2015.

26. Ruger JP, Richter CJ, Spitznagel EL, Lewis LM. Analysis of costs, length of stay, and utilization of emergency department services by frequent users: implications for health policy. Academic emergency medicine : official journal of the Society for Academic Emergency Medicine. Dec 2004;11(12):1311-1317.

27. Gill JM, Mainous AG, 3rd, Nsereko M. The effect of continuity of care on emergency department use. Archives of family medicine. Apr 2000;9(4):333-338.

28. Medicaid and CHIP Payment and Access Commission. Report to the Congress on Medicaid and CHIP. Washington, DC: Medicaid and CHIP Payment and Access Commission; 13th June 2014.

29. O'Brien GM, Stein MD, Zierler S, Shapiro M, O'Sullivan P, Woolard R. Use of the ED as a regular source of care: associated factors beyond lack of health insurance. Ann Emerg Med. Sep 1997;30(3):286-291.

30. Sandoval E, Smith S, Walter J, et al. A comparison of frequent and infrequent visitors to an urban emergency department. J Emerg Med. Feb 2010;38(2):115-121.

31. Blank FS, Li H, Henneman PL, et al. A descriptive study of heavy emergency department users at an academic emergency department reveals heavy ED users have better access to 
care than average users. Journal of emergency nursing: JEN : official publication of the Emergency Department Nurses Association. Apr 2005;31(2):139-144.

32. Zuckerman S, Shen YC. Characteristics of occasional and frequent emergency department users: do insurance coverage and access to care matter? Medical care. Feb 2004;42(2):176-182.

33. Friedman BW, Serrano D, Reed M, Diamond M, Lipton RB. Use of the emergency department for severe headache. A population-based study. Headache. Jan 2009;49(1):21-30.

34. Cook LJ, Knight S, Junkins EP, Jr., Mann NC, Dean JM, Olson LM. Repeat patients to the emergency department in a statewide database. Academic emergency medicine : official journal of the Society for Academic Emergency Medicine. Mar 2004;11(3):256263.

35. Lowe RA, Fu R, Ong ET, et al. Community characteristics affecting emergency department use by Medicaid enrollees. Medical care. Jan 2009;47(1):15-22.

36. Mandelberg JH, Kuhn RE, Kohn MA. Epidemiologic analysis of an urban, public emergency department's frequent users. Academic emergency medicine : official journal of the Society for Academic Emergency Medicine. Jun 2000;7(6):637-646.

37. Sun BC, Burstin HR, Brennan TA. Predictors and outcomes of frequent emergency department users. Academic emergency medicine : official journal of the Society for Academic Emergency Medicine. Apr 2003;10(4):320-328.

38. D'Onofrio G. Treatment for alcohol and other drug problems: Closing the gap. Ann Emerg Med. Jun 2003;41(6):814-817.

39. Hansen GR. The drug-seeking patient in the emergency room. Emergency medicine clinics of North America. May 2005;23(2):349-365.

40. Wooden MD, Air TM, Schrader GD, Wieland B, Goldney RD. Frequent attenders with mental disorders at a general hospital emergency department. Emergency medicine Australasia : EMA. Jun 2009;21(3):191-195.

41. Rockett IR, Putnam SL, Jia H, Smith GS. Assessing substance abuse treatment need: a statewide hospital emergency department study. Ann Emerg Med. Jun 2003;41(6):802813.

42. Coley KC, Saul MI, Seybert AL. Economic burden of not recognizing panic disorder in the emergency department. J Emerg Med. Jan 2009;36(1):3-7.

43. Curran GM, Sullivan G, Williams K, Han X, Allee E, Kotrla KJ. The association of psychiatric comorbidity and use of the emergency department among persons with substance use disorders: an observational cohort study. BMC emergency medicine. 2008;8:17.

44. Doran KM, Raven MC, Rosenheck RA. What drives frequent emergency department use in an integrated health system? National data from the veterans health administration. Annals of Emergency Medicine. 2013;62(2):151-159.

45. Hafner JW, Jr., Belknap SM, Squillante MD, Bucheit KA. Adverse drug events in emergency department patients. Ann Emerg Med. Mar 2002;39(3):258-267.

46. CDC. Smoking and Tobacco Use. Highlights 2012 State Map 2012; http://www.cdc.gov/tobacco/data_statistics/state_data/state_highlights/2012/map/index.ht m. Accessed 16th Aug, 2015.

47. Castner J, Wu YW, Mehrok N, Gadre A, Hewner S. Frequent emergency department utilization and behavioral health diagnoses. Nurs Res. Jan-Feb 2015;64(1):3-12. 
48. Bernstein SL, D'Onofrio G, Rosner J, et al. Successful Tobacco Dependence Treatment in Low-Income Emergency Department Patients: A Randomized Trial. Ann Emerg Med. Aug 2015;66(2):140-147.

49. Weinick RM, Burns RM, Mehrotra A. Many emergency department visits could be managed at urgent care centers and retail clinics. Health Aff (Millwood). Sep 2010;29(9):1630-1636.

50. Mann C. Targeting Medicaid Super-Utilizers to Decrease Costs and Improve Quality Centers for Medicare \& Medicaid Services; 2013. 


\title{
CHAPTER 3
}

\section{Longitudinal Patterns of Emergency Department Visits: A Multi-state Analysis of Medicaid Beneficiaries}

\begin{abstract}
Objective: The objective of this study was to examine the longitudinal patterns of emergency department (ED) visits over a four-year period among adult fee-for-service (FFS) Medicaid beneficiaries residing in Maryland, Ohio, and West Virginia. Additionally, the rate of primary care sensitive ED visits over time was examined.
\end{abstract}

Methods: A retrospective longitudinal study design, with four observations for each individual was used. Patient-level data were obtained from the Medicaid analytic eXtract files (2006-2010). Information on time-invariant county-level factors was obtained from the area health resource and county health rankings files. ED visits were time-lagged and time-varying patient-level factors were measured for each year. Time-invariant characteristics (gender and race/ethnicity) were measured in 2006. Primary care sensitive visits were identified using a validated algorithm. The study population consisted of adult FFS Medicaid beneficiaries who were alive, continuously enrolled, eligible only for Medicaid, and non-pregnant women ( $\mathrm{N}=33,393)$. ED visits by patient- and county-level characteristics were estimated with mean, inter-quartile range and $90^{\text {th }}$ percentile based on 133,572 person years. Multivariable hurdle models with logistic (ED use versus no ED use) and negative binomial regressions (ED visits among ED users) were used to analyze the ED visits over time, after adjusting for all other independent variables. To account for correlation due to repeated observations, mixed effect models with robust standard errors were performed. Adjusted odds ratios (AOR), Incidence rate ratios (IRR) and 95\% confidence intervals (CI) for ED visits are reported. 
Results: In this study, in each time period, approximately $10 \%$ of the study population had 5 or more ED visits. In both unadjusted and adjusted analysis, the likelihood of ED use did not change from year to year(AOR $=1.00,95 \% \mathrm{CI} 0.99,1.01), \mathrm{p}=0.57$.Among ED users, the estimated number of ED visits increased over time with a small magnitude (IRR $=1.01,95 \% \mathrm{CI}$ $1.01,1.03), \mathrm{p}<0.0001$.Approximately, $55 \%$ of the ED visits were primary care sensitive in each year.

Conclusions: Over time, the rates of ED use remained stable, however, among ED users, there was a steady increase in the number of ED visits. A substantial percentage of patients had repeated ED visits over a four-year period. Visits for primary care sensitive conditions remained same over time suggesting access issues for primary care. Findings from this study can be used for actionable intelligence of state-wide planning focused on primary care resources to reduce the increased burden on the EDs. 


\section{Introduction}

During the past two decades published research has documented a steady increase in Emergency Department (ED) visits in the United States (US). ED visits increased by 32\% (from 90.3 to 119.2 million) from 1996 to $2006 .{ }^{1}$ Among older patients, ED visits increased by $25 \%$ from 2001 to 2009 based on the National Hospital Ambulatory Medical Care Survey (NHAMCS). ${ }^{2}$ The rising trend in ED visits is not unique to the elderly patients. It is evident from the literature that ED visits by younger adults, specifically those covered by Medicaid have also been increasing. Tang et al reported that the overall ED visits among those covered by Medicaid increased by $37 \%$ between 1997 and 2007. ${ }^{3}$ Furthermore, Medicaid patients had higher ED visits as compared to those with Medicare, private insurance and uninsured. ${ }^{1}$

Some of the cited reasons include the lack of primary care access, shortage of primary care providers, increased prevalence of chronic conditions, and patient complexity, ${ }^{4-8}$ although a comprehensive and systematic analysis of the reasons for increased ED visits over time is yet not available. For example, it has been reported that Medicaid beneficiaries are more likely to face access barriers to primary care as compared to individuals enrolled in other types of insurance programs and these barriers can lead to higher rates of ED use and higher number of ED visits over time. ${ }^{4,5}$ Furthermore, socio-economically disadvantaged and individuals with high medical needs sometimes use the ED repeatedly, ${ }^{7,8}$ as is the case with Medicaid beneficiaries. Such reliance on ED care may worsen chronic conditions and lead to complications that may further increase the ED use over time. Mortensen et al. also reported that poor income, self-reported poor health status and presence of chronic conditions were the major drivers of ED utilization among Medicaid beneficiaries. ${ }^{6}$

While many studies have documented growth in ED visits over time, ${ }^{1,3}$ these studies have some limitations. Many of these studies examined visit-level data and could not follow individual patients and examine the trajectory of ED visits over time. ${ }^{2,3}$ In addition, these studies 
used only two sources of data i.e. NHAMCS or Nationwide Emergency Department Sample (NEDS). ${ }^{1,9,10}$ It is important to examine ED visits over time by using patient-level data to capture repeated ED visits made by an individual. As visit-level data do not track ED visits by an individual, these data overestimate the rates of ED visits. Furthermore, visit level data are available for those who visited EDs and therefore comparisons cannot be drawn with ED nonusers. Two studies have used patient-level data and these studies have reported increase in the ED visits over time. ${ }^{5,11}$ However, these studies also have limitations because they combined a series of cross-sectional data over time and did not follow the same individual over time. It is important to understand the ED visits over time at the patient-level to identify high-risk individuals and to design policies, programs, and interventions targeting these high risk individuals.

The increase in ED visits over time by Medicaid patients is a matter of concern for the policymakers as Medicaid is an important source of health insurance coverage. In 2015,72 million individuals were enrolled in Medicaid program. ${ }^{12}$ Under the Patient Protection and Affordable Care Act (ACA), uninsured adults with income up to $138 \%$ of the federal poverty line can get health insurance coverage through Medicaid. ${ }^{13}$ Such expansion of health insurance coverage through Medicaid may affect the ED utilization. However, the effect of expanded coverage on ED utilization is yet to be determined. Furthermore, it has been documented that many of the patients who visit ED can be effectively treated in primary care settings. A policy brief from New England Healthcare Institute compared the costs of care in outpatient and ED settings and estimated the cost of ED overuse at $\$ 38$ billion. ${ }^{14}$ Therefore, it is important to analyze the type of ED visits (primary care sensitive and other) over time to formulate costcontainment strategies.

The objective of the current study is to examine ED use and visits over time after adjusting for patient and county-level factors that may influence ED use and visits among ED 
users. For the purposes of the study, longitudinal data of adult fee-for-service (FFS) Medicaid beneficiaries between 2006 and 2010 were used. A secondary objective of the study is to describe primary care sensitive ED visits at the visit-level using a published and validated NYU algorithm developed by New York University Center for Health and Public Service Research. ${ }^{15,16}$

As ED visits are influenced by both patient- and county-level factors, the current study adjusted for patient- and county-level factors in multivariable modeling. The patient- and countylevel factors were selected based on the widely-used Andersen's behavioral model (ABM) in health services research. The ABM model hypothesizes that healthcare services utilization is a function of predisposing, enabling, need, external environment factors and personal health practices. $^{17}$

\section{Methods}

\section{Study Design}

This study used a retrospective longitudinal design with observational data from Maryland (MD, Ohio (OH), and West Virginia (WV) for the years 2006-2010; only those patients who were observed for all four years were included in the analysis.

\section{Data Sources}

Medicaid Analytic eXtract (MAX) Files

Four different MAX files were used: personal summary, inpatient claims, other therapy claims, and prescription drugs claims file. The personal summary file provided information on demographics, Medicaid eligibility, county federal information processing standard (FIPS) codes, Medicaid managed care enrollment, and Medicare eligibility status. The inpatient claims file provided information on hospital stays, dates of service, Medicaid payment, and the International Classification of Disease, Ninth Revision, Clinical Modification codes (ICD-9-CM) 
and ICD-9-CM procedure codes. The outpatient claims file provided information on dates of service, types of service, Medicaid payment, ICD-9-CM, and Current Procedural Terminology (CPT) codes. The prescription drugs claims file provided information on the date of prescription filled, days supplied, and national drug code (NDC). All these files can be linked using encrypted identification numbers. The current study used data on Medicaid beneficiaries residing in MD, $\mathrm{OH}$, and WV.

\section{Area Health Resources Files (AHRF)}

The AHRF file was used to obtain county-level information explained in the Measures section. The file contains national, state, and county level data on approximately 6000 variables. $^{18}$

\section{County Health Rankings Data}

The County Health Rankings data compiled county-level information from 50 different sources on health behaviors, clinical care, social and economic factors, and physical environment. $^{19}$

\section{Study Population (N=33,393)}

The study population included FFS Medicaid beneficiaries, aged 22-64 years, with continuous Medicaid enrollment between 2006-2010, not eligible for Medicare, and alive during the entire observation period. Pregnant women were excluded from the analysis due to unique prenatal needs. An example, of the selection process of the final study population is summarized in Appendix A. Each of these individuals were followed for a period of 4 years, resulting in 133,572 person years. 


\section{Dependent Variable}

Number of ED visits

ED visits were identified from inpatient and outpatient claims using CPT (99281-85) and revenue codes (450-52, 456, 459, and 981). ED visits were identified in 2007, 2008, 2009 and 2010 - the subsequent year after the measurement of the time-varying patient-level factors.

\section{Primary Care Sensitive ED Visits}

ED visits were classified over time based on the validated algorithm developed by Billings and colleagues known as NYU algorithm. ${ }^{15,16} \mathrm{ED}$ visits were classified as the following: 1) emergent; 2) visits due to primary care sensitive conditions; 3) Mental health related; and 4) Injury related visits. ED visits due to primary care sensitive conditions included visits that 1) did not require immediate ED care [e.g. Allergic rhinitis, cause unspecified, Spondylosis of unspecified site, without mention of myelopathy];2) are treatable in primary care settings [e.g. acute bronchitis, acute abdominal pain]; 3) could have been prevented, if timely primary care was provided [e.g. hyponatremia].

\section{Independent Variables}

Key Independent Variable: Time

Time included four years: 2006-07 (Year 1), 2007-08 (Year 2), 2008-09 (Year 3), and 2009-10 (Year 4). It was used as a continuous variable and only those patients that were enrolled in all four years were included in the analysis.

\section{Other Independent Variables}

Other independent variables included both time varying and time invariant factors.

Gender and race/ethnicity, and county-level factors were time invariant factors. All other patientlevel factors were time variant and were measured each year. These independent variables were measured during the previous year (i.e. time lagged). 
Predisposing factors included age (22-34, 35-44, 45-54, 55-64 years), gender (female, male), and race/ethnicity (whites, African Americans, Hispanics, other races).

Enabling factors included patient-level Medicaid eligibility due to cash assistance/poverty (cash eligibility, no cash eligibility), county-level college education rate, primary care use (none, fragmented, continuous), and county-level unemployment rate. Modified, Modified continuity index developed by Magill et al was used to measure primary care use. $^{20}$

Need factors included patient-level health status (physical health conditions, mental health conditions, physical and mental health conditions, none), Medicaid eligibility due to medical need/waiver (medical eligibility, no medical eligibility), and poly-pharmacy (Yes, No). Physical and mental health conditions were selected on the priority basis as specified by Health and Human Services Office of the Assistant Secretary of Health. ${ }^{21}$ Physical health conditions included arthritis, asthma, cardiac arrhythmia, coronary artery disease, cancer, chronic heart failure, chronic kidney disease, chronic obstructive pulmonary disease (COPD), dementia, diabetes, hepatitis, hyperlipidemia, human immunodeficiency virus (HIV), hypertension, osteoporosis, and stroke. Mental health conditions included anxiety, post-traumatic stress disorder, depression, bipolar disorders, psychosis, schizophrenia, and other mental illness. Presence of both physical and mental health conditions was considered as complex chronic illness using the definition provided by the Agency for Healthcare Research and Quality. ${ }^{22}$ Both physical and mental health conditions were identified one inpatient or two outpatient claims. Poly-pharmacy was defined as concomitant use of multiple prescription drugs within a 90-day period and was based on number of prescription drugs one standard deviation above the mean. ${ }^{23}$

Personal health practices included patient-level tobacco use (yes tobacco use, no tobacco use), and county-level obesity rates. External environment factors included metropolitan status of 
the county (metro, non-metro), health professional shortage area (HPSA - no, partial, and complete shortage areas), number of hospitals with EDs, number of hospitals with psychiatric emergency services, number of rural health clinics, number of federally qualified health centers (FQHCs), number of community mental health centers, and number of urgent care clinics per 100,000 population.

\section{Statistical Analysis}

Frequencies and percentages were used to describe the characteristics of the study population in the baseline year i.e. 2006. Inter-quartile range (IQR) and $90^{\text {th }}$ percentile were calculated to describe the frequency of ED visits in each year. As ED visits were measured in four different years i.e. 2006-07, 2007-08, 2008-09, and 2009-10, 4 different observations were available for each subject leading to clustering within subjects. Hurdle models with mixed effects were conducted to test the relationship between ED visits and time after controlling for predisposing, enabling, need, personal health practices, and external environment factors. The hurdle model is a two-part model where the first part is the logit model with binary outcome (i.e. ED use vs. No ED use) and the second part is the negative binomial regression (i.e. ED visits by users). The first part of the model is known as "hurdle at zero" and it examined the relationship between ED use and time after adjusting for all other independent variables. The second part of the hurdle model is known as "above the hurdle" and it examined the association between the number of ED visits by users and time after adjusting for all other independent variables.

Variables were entered in the models in blocks: Model 1 - time, Model 2 - time and predisposing factors, Model 3 - time, predisposing, and enabling factors, Model 4 - time, predisposing, enabling, and need factors, Model 5 - time, predisposing, enabling, need factors, and personal health practices, and Model 6 - time, predisposing, enabling, need, personal health practices, and external environment factors. Mixed effect modeling approach adjusted for 
random intercepts and correlated error terms for repeated observations. All analyses were conducted using STATA version 14.

\section{Results}

The majority of the study population were 45-64 years old (54\%), females (58.7\%), and whites (89.3\%), and resided in a metro county (56.2\%). (Table presented in Appendix B)

Table 1 presents the time-varying characteristics of the study population for each year. More than $90 \%$ of the study population was eligible for Medicaid due to cash-assistance/poverty in each year. Approximately, $70 \%$ had fragmented primary care use in each year. The prevalence of chronic complex illness (i.e. both physical and mental health conditions) increased from $44.7 \%$ to $45.1 \%$ between Year 1 and Year 4 . Approximately, 17\% of the study population had poly-pharmacy in Year 1 and 20.9\% had poly-pharmacy in Year 4. The eligibility in Medicaid due to medical reasons declined from Year 1 to Year 4 (2.6\% to 1.4\%). The prevalence of tobacco use remained almost same in all the years.

Among ED users, IQR and $90^{\text {th }}$ percentile of the ED visits are presented in table 2 for each panel i.e. 2006-07, 2007-08, 2008-09, and 2009-10. In each panel, approximately $10 \%$ of the study population had 5 or more ED visits. Among "other" race, there was an increase in the number of ED visits by $10 \%$ of the study population i.e. 12 to 15 visits. Similar results were observed for those with poly-pharmacy where ED visits ranged from 10 to 12 for $10 \%$ of the study population in each panel year.

Table 3 summarizes the findings from the hurdle model with mixed effects. In the first model i.e. "hurdle at zero", no statistically significant relationship was observed between ED use and time after adjusting for predisposing, enabling, need, personal health practices, and external environment factors. In the second model i.e. above the hurdle", as time increased there was $1 \%$ 
increase in the number of ED visits after adjusting for predisposing, enabling, need, personal health practices, and external environment factors. Sensitivity analysis was conducted by analyzing data for each state separately. Similar results were observed for each state.

Table 4 presents the findings of Model 6 for each subgroup of the study population. In the first model i.e. "hurdle at zero" individuals aged 35-44 years were more likely to use ED as compared to those aged 22-34 years $(\mathrm{AOR}=1.10 ; 95 \% \mathrm{CI}=1.03,1.17)$. Similar results were observed for the following subgroups of the study population: females, African Americans, Hispanics, other races, cash-eligibility, fragmented primary care use, medical eligibility, physical health conditions, mental health conditions, physical and mental health conditions, polypharmacy, tobacco use, part county health professional shortage area, number of EDs/100,000 population, and number of psychiatric EDs/100,000 population. As compared to those aged 2234 years, individuals aged 45-54 years were less likely to use $\mathrm{ED}(\mathrm{AOR}=0.83 ; 95 \% \mathrm{CI}=0.78$, 0.89). Similar results were observed for the following subgroups of the study population: 55-64 years old, percent with college education, percent unemployed, no primary care use, county-level obesity rate, and urgent care centers/100,000 population.

In the second model i.e. "above the hurdle" following subgroups of the study population had higher number of ED visits: females, African Americans, Hispanics, other races, fragmented primary care use, presence of physical health conditions, presence of mental health conditions, presence of both physical and mental health conditions, poly-pharmacy, tobacco use, and number of hospitals with psychiatric emergency services/100,000 population. Following subgroups of the study population had lower number of ED visits: 35-64 years old, county-level percent unemployed, county-level obesity rate, non-metro counties, and number of urgent care centers/100,000 population. 
Table 5 presents the findings after the application of NYU algorithm on ED visits for each year. In each year more than half of the ED visits were due to primary care sensitive conditions. For each year following were the rate of primary care sensitive ED visits per 1,000 of the total ED visits: Year 1 - 553/1000; Year 2 - 542/1000; Year 3 - 539/1000; Year 4 $539 / 1000$.

\section{Discussion}

In the current study, the use and number of ED visits over time were analyzed. This study provided the pre-ACA estimates of ED use and number of ED visits for adult FFS Medicaid beneficiaries who were followed for a period of 4 years. The percentage of ED users did not increase over time. The stability of ED use over time was an unexpected finding because published studies that have evaluated ED use longitudinally using patient-level data reported an increase in ED use over time. ${ }^{11}$ The difference in findings could be due to the study design (longitudinal versus pooled cross-sectional data over a number of years). The findings from the current study suggest that identifying and profiling individuals using an indicator i.e. presence or absence of ED use may not provide a complete picture of ED use over time.

In the current study, it was observed that number of ED visits increased over time with a small magnitude among ED users. The findings of the current study are consistent with the study conducted by Tang et al that reported an increase in the rate of ED visits among Medicaid patients over time using visit level data. ${ }^{3}$ However, a report on the ED use by California Medicaid participants concluded that increase in ED visits is a temporary phenomenon. ${ }^{24}$ Differences in findings could be attributed to the study design; the current study examined ED visits over time by following the same individual and repeatedly measuring ED visits. During the four-year period, primary care use remained the same with more than $70 \%$ of the study population having fragmented primary care use. It was also observed that the counties with higher number of urgent care centers per 100,000 population had lower number of ED visits. 
Additionally, it was observed in the current study that more than half of the ED visits in each year were due to primary care sensitive conditions. Taken together these findings suggest that the increase in the intensity of ED use may be due to increasing complexity and lack of access to primary care for extended periods of time.

Previous literature suggests that Medicaid beneficiaries face many barriers that include: access to primary care providers, limited physician office hours, increased wait time, limited availability of immediate diagnostic services, lack of transportation and usual source of care. ${ }^{1,25}$ To mitigate the effect of these barriers, it is important to explore ways to triage patients with non-emergent care needs to other healthcare settings (e.g. primary care doctors, clinics, and urgent care facilities).Given that a majority of ED visits occur after business hours, ${ }^{26}$ improving the infrastructure to provide after hour care, extended primary care office hours, and increasing the supply of urgent care centers can go a long way in reducing the frequency of ED visits. ${ }^{27}$ In fact, almost $30 \%$ of all ED visits can be managed at urgent care centers and other healthcare settings. ${ }^{28}$ Additionally, when patients received proper guidance about the appropriate settings for healthcare through public education, ED visits have declined with consequent annualized cost-savings of approximately $\$ 31$ million..$^{29,30}$

It is documented in the literature that the factors such as access to primary care providers and patient complexity accounted for higher number of ED visits. ${ }^{4,6}$ The current study had findings consistent with the previous literature. Individuals with fragmented primary care use and complex healthcare needs were more likely to use ED and had higher number of ED visits. It was observed that the percentage of individuals with complex chronic illness increased from $44.7 \%$ in 2006 to $45.1 \%$ in 2009; similarly the rates of polypharmacy also increased from $17 \%$ in 2006 to $20.9 \%$ in 2009 . These findings highlight the role of patient complexity in increased visits to the ED over time. Therefore, healthcare providers may adopt interventions and treatment strategies designed to provide better management of the patient complexities. In Washington 
State by formulating a policy named "ER is for Emergencies" of tracking the ED use of Medicaid beneficiaries over a period of time, the policy makers were able to identify high-risk adults, target interventions for these individuals and reduce ED use, that resulted in costsavings. ${ }^{29,30}$

The current study was conducted on alive, adult FFS Medicaid beneficiaries, aged 22-64 years old, continuously enrolled, not dually eligible, and residing in $\mathrm{MD}, \mathrm{OH}$, and WV from 2006-2010. The results of this study are not generalizable to Medicaid population of other states because wide difference exist across states in terms of the geographic population, policy, and resources. Due to the exclusion of managed care population from the study population there is a possibility of selection bias. Due to limited sample size, the study could not control for alcohol consumption and drug abuse. Use of administrative claims data may result in misclassification of diagnosis. The study did not control for unobserved differences that may affect ED visits over time. These differences may be due to factors such as patient's preferences and knowledge, perceived health status of the patient, and disease severity.

Despite the limitations, the current study has several strengths. A comprehensive list of patient- and county-level factors were used from different data sources to perform longitudinal analysis. By relying on healthcare encounter data, the current study was able to capture services received from multiple providers, healthcare settings and geographical areas. Information on clinical diagnosis, prescription drugs and other healthcare services use were captured from claims data and do not have the shortcomings of self-reported data. The current study used patient-level data and was able to track repeated ED visits made by the same patient.

To conclude, ED use among Medicaid patients remained stable, however, the intensity of ED use, measured by the number of ED visits increased over time. These findings suggest that ED overcrowding may remain even after the provision of health insurance to the uninsured under 
the ACA. Provision of health insurance coverage alone without corresponding improvements in primary care access may increase the burden on EDs and escalate costs. A multi-pronged approach with both infrastructure improvements and public education may be necessary to reduce the burden on EDs. 


\begin{tabular}{|c|c|c|c|c|c|c|c|c|}
\hline \multicolumn{9}{|c|}{$\begin{array}{c}\text { Table 1 } \\
\text { Descriptive of the Study Population } \\
\text { Time Varying Patient-Level Factors Each Year } \\
\text { Adult Fee-for-Service Medicaid Beneficiaries } \\
\text { Multistate Medicaid Analytical eXtract Files - 2006-2010 }\end{array}$} \\
\hline & \multicolumn{2}{|c|}{ Year 1} & \multicolumn{2}{|c|}{ Year 2} & \multicolumn{2}{|c|}{ Year 3} & \multicolumn{2}{|c|}{ Year 4} \\
\hline All & $\begin{array}{c}\mathbf{N} \\
\mathbf{3 3 , 3 9 3}\end{array}$ & $\%$ & $\begin{array}{c}\mathbf{N} \\
\mathbf{3 3 , 3 9 3}\end{array}$ & $\%$ & $\begin{array}{c}\mathbf{N} \\
\mathbf{3 3 , 3 9 3}\end{array}$ & $\%$ & $\begin{array}{c}\mathbf{N} \\
\mathbf{3 3 , 3 9 3}\end{array}$ & $\%$ \\
\hline \multicolumn{9}{|c|}{ Enabling Factors } \\
\hline \multicolumn{9}{|l|}{ Medicaid Eligibility } \\
\hline Cash Eligibility & 31,239 & 93.6 & 31,566 & 94.5 & 31,561 & 94.5 & 31,564 & 94.5 \\
\hline No Cash Eligibility & 2,154 & 6.5 & 1,827 & 5.5 & 1,832 & 5.5 & 1,829 & 5.5 \\
\hline \multicolumn{9}{|l|}{ Primary Care Use } \\
\hline None & 6,236 & 18.7 & 6,187 & 18.5 & 6,057 & 18.1 & 5,497 & 16.5 \\
\hline Fragmented & 23,747 & 71.1 & 23,777 & 71.2 & 23,965 & 71.8 & 24,623 & 73.7 \\
\hline Continuous & 3,410 & 10.2 & 3,429 & 10.3 & 3,371 & 10.1 & 3,273 & 9.8 \\
\hline \multicolumn{9}{|c|}{ Need Factors } \\
\hline \multicolumn{9}{|l|}{ Complex Chronic Illness } \\
\hline Physical Health Conditions & 9,260 & 27.7 & 9,609 & 28.8 & 9,805 & 29.4 & 9,914 & 29.7 \\
\hline Mental Health Conditions & 4,684 & 14.0 & 4,467 & 13.4 & 4,366 & 13.1 & 4,219 & 12.6 \\
\hline Physical and Mental Health & & & & & & & & \\
\hline Conditions & 14,910 & 44.7 & 14,935 & 44.7 & 14,979 & 44.9 & 15,071 & 45.1 \\
\hline None & 4,539 & 13.6 & 4,382 & 13.1 & 4,243 & 12.7 & 4,189 & 12.5 \\
\hline \multicolumn{9}{|l|}{ Poly-Pharmacy } \\
\hline Yes & 5,560 & 16.7 & 5,980 & 17.9 & 6,637 & 19.9 & 6,983 & 20.9 \\
\hline No & 27,833 & 83.4 & 27,413 & 82.1 & 26,756 & 80.1 & 26,410 & 79.1 \\
\hline \multicolumn{9}{|l|}{ Medicaid Medical Eligibility } \\
\hline Medical Eligibility & 852 & 2.6 & 745 & 2.2 & 533 & 1.6 & 482 & 1.4 \\
\hline No Medical Eligibility & 32,541 & 97.5 & 32,648 & 97.8 & 32,860 & 98.4 & 32,911 & 98.6 \\
\hline \multicolumn{9}{|c|}{ Personal Health Practices } \\
\hline Tobacco Use & & & & & & & & \\
\hline Yes Tobacco Use & 1,825 & 5.5 & 1,950 & 5.8 & 1,730 & 5.2 & 1,886 & 5.7 \\
\hline No Tobacco Use & 31,568 & 94.5 & 31,443 & 94.2 & 31,663 & 94.8 & 31,507 & 94.4 \\
\hline
\end{tabular}

Note: Based on 33,393 adult Medicaid fee-for-service beneficiaries aged 22-64 years and who are continuously enrolled, who are not Medicare and Medicaid eligible, who are alive and nonpregnant for the years 2006-2010. County-level variables were extracted from the Area Health Resource Files and county health ranking data. Information on time-varying baseline characteristics was extracted from the base period of the panels i.e. Year 1: 2006 in 2006-07 panel; Year 2: 2007 in 2007-08 panel, Year 3: 2008 in 2008-09 panel, and Year 4: 2009 in 200910 panel. 


\section{Table 2}

Inter-Quartile Range \& 90th Percentile of Emergency Department Visits Among Emergency Department Users

Adult Fee-for-Service Medicaid Beneficiaries

Multistate Medicaid Analytical eXtract Files - 2006-2010

\begin{tabular}{|c|c|c|c|c|c|c|c|c|}
\hline \multirow[t]{2}{*}{$\begin{array}{l}\text { Panels } \\
\text { Emergency Department users (N) }\end{array}$} & \multicolumn{2}{|c|}{$\begin{array}{c}\text { Year 1 } \\
17,079\end{array}$} & \multicolumn{2}{|c|}{$\begin{array}{l}\text { Year } 2 \\
17,135\end{array}$} & \multicolumn{2}{|c|}{$\begin{array}{c}\text { Year 3 } \\
17,163\end{array}$} & \multicolumn{2}{|c|}{$\begin{array}{l}\text { Year } 4 \\
17,008\end{array}$} \\
\hline & IQR & P90 & IQR & P90 & IQR & P90 & IQR & $\mathbf{P 9 0}$ \\
\hline All & $(1,4)$ & 8 & $(1,4)$ & 8 & $(1,4)$ & 8 & $(1,4)$ & 8 \\
\hline \multicolumn{9}{|c|}{ Predisposing Factors } \\
\hline \multicolumn{9}{|l|}{ Age } \\
\hline 22-34 years & $(1,4)$ & 8 & $(1,4)$ & 8 & $(1,4)$ & 8 & $(1,4)$ & 8 \\
\hline $35-44$ years & $(1,4)$ & 8 & $(1,4)$ & 8 & $(1,4)$ & 8 & $(1,4)$ & 9 \\
\hline 45-54 years & $(1,4)$ & 7 & $(1,4)$ & 7 & $(1,4)$ & 8 & $(1,4)$ & 9 \\
\hline 55-64 years & $(1,4)$ & 7 & $(1,4)$ & 8 & $(1,4)$ & 8 & $(1,4)$ & 8 \\
\hline \multicolumn{9}{|l|}{ Gender } \\
\hline Female & $(1,4)$ & 8 & $(1,4)$ & 8 & $(1,4)$ & 8 & $(1,4)$ & 9 \\
\hline Male & $(1,4)$ & 7 & $(1,4)$ & 7 & $(1,4)$ & 7 & $(1,4)$ & 8 \\
\hline \multicolumn{9}{|l|}{ Race } \\
\hline White & $(1,4)$ & 7 & $(1,4)$ & 7 & $(1,4)$ & 8 & $(1,4)$ & 8 \\
\hline African Americans & $(1,5)$ & 9 & $(1,5)$ & 9 & $(1,5)$ & 10 & $(1,6)$ & 11 \\
\hline Hispanics & $(1,5)$ & 11 & $(1,5)$ & 10 & $(1,5)$ & 10 & $(1,4)$ & 7 \\
\hline Other Races & $(1,4)$ & 12 & $(2,7)$ & 13 & $(1,6)$ & 15 & $(2,8)$ & 15 \\
\hline \multicolumn{9}{|c|}{ Enabling Factors } \\
\hline \multicolumn{9}{|l|}{ Medicaid Eligibility } \\
\hline Cash Eligibility & $(1,4)$ & 8 & $(1,4)$ & 8 & $(1,4)$ & 8 & $(1,4)$ & 8 \\
\hline No Cash Eligibility & $(1,4)$ & 8 & $(1,4)$ & 7 & $(1,4)$ & 7 & $(1,4)$ & 8 \\
\hline \multicolumn{9}{|l|}{ Primary Care Use } \\
\hline None & $(1,3)$ & 6 & $(1,4)$ & 6 & $(1,4)$ & 6 & $(1,4)$ & 7 \\
\hline Fragmented & $(1,4)$ & 8 & $(1,4)$ & 8 & $(1,4)$ & 8 & $(1,5)$ & 9 \\
\hline Continuous & $(1,4)$ & 7 & $(1,4)$ & 6 & $(1,4)$ & 7 & $(1,4)$ & 7 \\
\hline \multicolumn{9}{|c|}{ Need Factors } \\
\hline \multicolumn{9}{|l|}{ Complex Chronic Illness } \\
\hline Physical Health Conditions & $(1,4)$ & 6 & $(1,4)$ & 6 & $(1,4)$ & 7 & $(1,4)$ & 7 \\
\hline Mental Health Conditions & $(1,4)$ & 6 & $(1,4)$ & 6 & $(1,4)$ & 6 & $(1,4)$ & 6 \\
\hline Physical and Mental Health Conditions & $(1,5)$ & 9 & $(1,5)$ & 9 & $(1,5)$ & 9 & $(1,5)$ & 10 \\
\hline None & $(1,3)$ & 5 & $(1,3)$ & 5 & $(1,3)$ & 5 & $(1,3)$ & 5 \\
\hline \multicolumn{9}{|l|}{ Poly-Pharmacy } \\
\hline Yes & $(1,6)$ & 10 & $(1,6)$ & 10 & $(1,6)$ & 11 & $(1,6)$ & 12 \\
\hline No & $(1,4)$ & 7 & $(1,4)$ & 7 & $(1,4)$ & 7 & $(1,4)$ & 7 \\
\hline \multicolumn{9}{|l|}{ Medicaid Medical Eligibility } \\
\hline Medical Eligibility & $(1,4)$ & 10 & $(1,4)$ & 8 & $(1,4)$ & 7 & $(1,5)$ & 10 \\
\hline No Medical Eligibility & $(1,4)$ & 8 & $(1,4)$ & 8 & $(1,4)$ & 8 & $(1,4)$ & 8 \\
\hline
\end{tabular}




\section{Table 2}

Inter-Quartile Range \& 90th Percentile of Emergency Department Visits Among Emergency Department Users

Adult Fee-for-Service Medicaid Beneficiaries

Multistate Medicaid Analytical eXtract Files - 2006-2010

\begin{tabular}{|c|c|c|c|c|c|c|c|c|}
\hline \multirow{2}{*}{$\begin{array}{l}\text { Panels } \\
\text { Emergency Department users (N) }\end{array}$} & \multirow{2}{*}{\multicolumn{2}{|c|}{$\begin{array}{l}\text { Year 1 } \\
17,079\end{array}$}} & \multirow{2}{*}{\multicolumn{2}{|c|}{$\begin{array}{l}\text { Year 2 } \\
17,135\end{array}$}} & \multirow{2}{*}{\multicolumn{2}{|c|}{$\begin{array}{l}\text { Year 3 } \\
17,163\end{array}$}} & \multirow{2}{*}{\multicolumn{2}{|c|}{$\begin{array}{l}\text { Year } 4 \\
17,008\end{array}$}} \\
\hline & & & & & & & & \\
\hline All & $(1,4)$ & 8 & $(1,4)$ & 8 & $(1,4)$ & 8 & $(1,4)$ & 8 \\
\hline \multicolumn{9}{|c|}{ Personal Health Practices } \\
\hline \multicolumn{9}{|l|}{ Tobacco Use } \\
\hline Yes Tobacco Use & $(1,6)$ & 12 & $(1,6)$ & 11 & $(1,6)$ & 13 & $(1,6)$ & 13 \\
\hline No Tobacco Use & $(1,4)$ & 7 & $(1,4)$ & 7 & $(1,4)$ & 8 & $(1,4)$ & 8 \\
\hline \multicolumn{9}{|c|}{ External Environment Factors } \\
\hline \multicolumn{9}{|l|}{ Health Professional Shortage Area } \\
\hline No Shortage & $(1,4)$ & 7 & $(1,4)$ & 7 & $(1,4)$ & 8 & $(1,4)$ & 8 \\
\hline Whole County Shortage & $(1,4)$ & 8 & $(1,4)$ & 8 & $(1,4)$ & 8 & $(1,4)$ & 8 \\
\hline Part County Shortage & $(1,4)$ & 8 & $(1,4)$ & 8 & $(1,4)$ & 8 & $(1,4)$ & 9 \\
\hline \multicolumn{9}{|l|}{ Metro } \\
\hline Metro & $(1,4)$ & 8 & $(1,4)$ & 8 & $(1,5)$ & 8 & $(1,5)$ & 9 \\
\hline Non-Metro & $(1,4)$ & 7 & $(1,4)$ & 7 & $(1,4)$ & 7 & $(1,4)$ & 7 \\
\hline
\end{tabular}

Note: Based on 33,393 adult Medicaid fee-for-service beneficiaries aged 22-64 years and who are continuously enrolled, who are not Medicare and Medicaid eligible, who are alive, nonpregnant and are ED users for the years 2006-2010. County-level variables were extracted from the Area Health Resource Files and county health ranking data.

IQR: Inter-Quartile Range; P90: $90^{\text {th }}$ percentile 
Table 3

Parameter Estimates of Time from

Adjusted Mixed-Effects Hurdle Models of

Emergency Department Use and Emergency Department Visits

Adult Fee-for-Service Medicaid Beneficiaries $(N=133,572)$

Multistate Medicaid Analytical eXtract Files - 2006-2010

AOR $95 \%$ CI $\quad$ Sig IRR $\quad 95 \%$ CI $\quad$ Sig

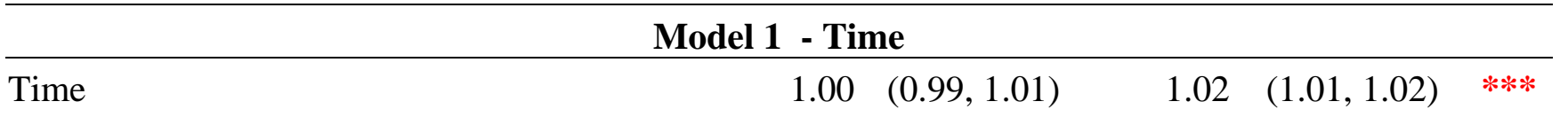

Model 2 - Time + Predisposing Factors

\begin{tabular}{llllll}
\hline Time & 1.00 & $(0.99,1.01)$ & 1.02 & $(1.01,1.02)$ & $* * * *$
\end{tabular}

Model 3 - Time + Predisposing + Enabling Factors

Time $\quad 1.00 \quad(0.99,1.01) \quad 1.02 \quad(1.01,1.02) \quad * * *$

Model 4 - Time + Predisposing + Enabling + Need Factors

\begin{tabular}{llllll}
\hline Time & 1.00 & $(0.98,1.01)$ & 1.01 & $(1.01,1.02)$ & $* * *$
\end{tabular}

\begin{tabular}{llllll}
\hline \multicolumn{5}{c}{ Model 5 - Time + Predisposing + Enabling + Need Factors +Personal Health Practices } \\
\hline Time & 1.00 & $(0.98,1.01)$ & 1.01 & $(1.01,1.02)$ & $* * *$
\end{tabular}

Model 6 - Time + Predisposing + Enabling + Need Factors + Personal Health Practices + External Environment Factors

Time $\quad 1.00 \quad(0.98,1.01) \quad 1.01 \quad(1.01,1.02) \quad * * *$

Note: Based on 133,572 person years of adult Medicaid fee-for-service beneficiaries aged 22-64 years and who are continuously enrolled, who are not Medicare and Medicaid eligible, who are alive, non-pregnant and are ED users for the years 2006-2010. County-level variables were extracted from the Area Health Resource Files and county health ranking data.

Predisposing factors include age, race and gender. Enabling factors include Medicaid cash eligibility, rate of college education, unemployment rate, and primary care use. Need factors include presence of physical health conditions, presence of mental health conditions, presence of both physical and mental health conditions and none. Personal health practices include tobacco use and obesity rate. External environment factors included metro status of the county, health professional shortage area, number of EDs/100,000 of the population, number of hospitals with psychiatric EDs/100,000 of the population, number of rural health centers/100,000 of the 
population, number of urgent care centers/100,000 of the population, number of federally qualified health centers/100,000 of the population and number of community mental health centers/100,000 of the population.

AOR: Adjusted Odds Ratios; IRR: Incidence Rate Ratios; CI: Confidence interval; Sig: Significance

$* * * \mathrm{p}<.001 ; * * .001<\mathrm{p}<.01 ; * .01<\mathrm{p}<.05$ 


\section{Table 4}

Parameter Estimates from

Adjusted Mixed-Effects Hurdle Models of

Emergency Department Use and Emergency Department Visits

Adult Fee-for-Service Medicaid Beneficiaries $(N=133,572)$

Multistate Medicaid Analytical eXtract Files - 2006-2010

\begin{tabular}{|c|c|c|c|c|c|c|}
\hline & AOR & 95\% CI & Sig & IRR & 95\% CI & Sig \\
\hline Time & 1.00 & $(0.98,1.01)$ & & 1.01 & $(1.01,1.02)$ & $* * * *$ \\
\hline \multicolumn{7}{|c|}{ Predisposing Factors } \\
\hline \multicolumn{7}{|l|}{ Age } \\
\hline \multicolumn{7}{|l|}{$22-34$ years } \\
\hline $35-44$ years & 1.10 & $(1.03,1.17)$ & $*$ & 0.97 & $(0.94,0.99)$ & $*$ \\
\hline $45-54$ years & 0.83 & $(0.78,0.89)$ & $* * *$ & 0.90 & $(0.88,0.93)$ & $* * *$ \\
\hline 55-64 years & 0.73 & $(0.68,0.78)$ & $* * *$ & 0.88 & $(0.85,0.90)$ & *** \\
\hline \multicolumn{7}{|l|}{ Gender } \\
\hline Female & 1.27 & $(1.21,1.33)$ & $* * *$ & 1.03 & $(1.01,1.05)$ & $*$ \\
\hline \multicolumn{7}{|l|}{ Male } \\
\hline \multicolumn{7}{|l|}{ Race } \\
\hline \multicolumn{7}{|l|}{ White } \\
\hline African Americans & 1.40 & $(1.29,1.51)$ & $* * *$ & 1.14 & $(1.10,1.18)$ & $* * *$ \\
\hline Hispanics & 1.77 & $(1.24,1.54)$ & $* *$ & 1.11 & $(0.92,1.35)$ & \\
\hline Other Races & 1.58 & $(1.04,2.41)$ & * & 1.31 & $(1.05,1.64)$ & $*$ \\
\hline \multicolumn{7}{|c|}{ Enabling Factors } \\
\hline \multicolumn{7}{|l|}{ Medicaid Eligibility } \\
\hline Cash Eligibility & 1.14 & $(1.08,1.49)$ & $*$ & 1.03 & $(0.99,1.07)$ & \\
\hline \multicolumn{7}{|l|}{ No Cash Eligibility } \\
\hline \multicolumn{7}{|l|}{ County-level Education } \\
\hline Percent with college education & 0.99 & $(0.98,1.00)$ & & 1.00 & $(1.00,1.01)$ & \\
\hline \multicolumn{7}{|l|}{ County-level Unemployment } \\
\hline Percent unemployed & 0.90 & $(0.88,0.92)$ & $* * *$ & 0.99 & $(0.98,0.99)$ & $* *$ \\
\hline \multicolumn{7}{|l|}{ Primary Care Use } \\
\hline None & 0.93 & $(0.87,0.98)$ & $*$ & 0.99 & $(0.96,1.02)$ & \\
\hline Fragmented & 1.17 & $(1.11,1.23)$ & $* * *$ & 1.04 & $(1.01,1.06)$ & *** \\
\hline \multicolumn{7}{|l|}{ Continuous } \\
\hline \multicolumn{7}{|c|}{ Need Factors } \\
\hline \multicolumn{7}{|l|}{ Medical Eligibility } \\
\hline Medical Eligibility & 1.27 & $(1.08,1.49)$ & ** & 1.05 & $(0.98,1.13)$ & \\
\hline No Medical Eligibility & & & & & & \\
\hline \multicolumn{7}{|l|}{ Complex Chronic Illness } \\
\hline Physical Health Conditions & 1.43 & $(1.34,1.52)$ & $* * *$ & 1.15 & $(1.12,1.18)$ & $* * *$ \\
\hline Mental Health Conditions & 1.41 & $(1.32,1.52)$ & $* * *$ & 1.13 & $(1.09,1.16)$ & $* * *$ \\
\hline \multicolumn{7}{|l|}{ Physical and Mental Health } \\
\hline Conditions & 2.13 & $(1.99,2.27)$ & $* * *$ & 1.33 & $(1.29,1.37)$ & $* * *$ \\
\hline None & & & & & & \\
\hline
\end{tabular}




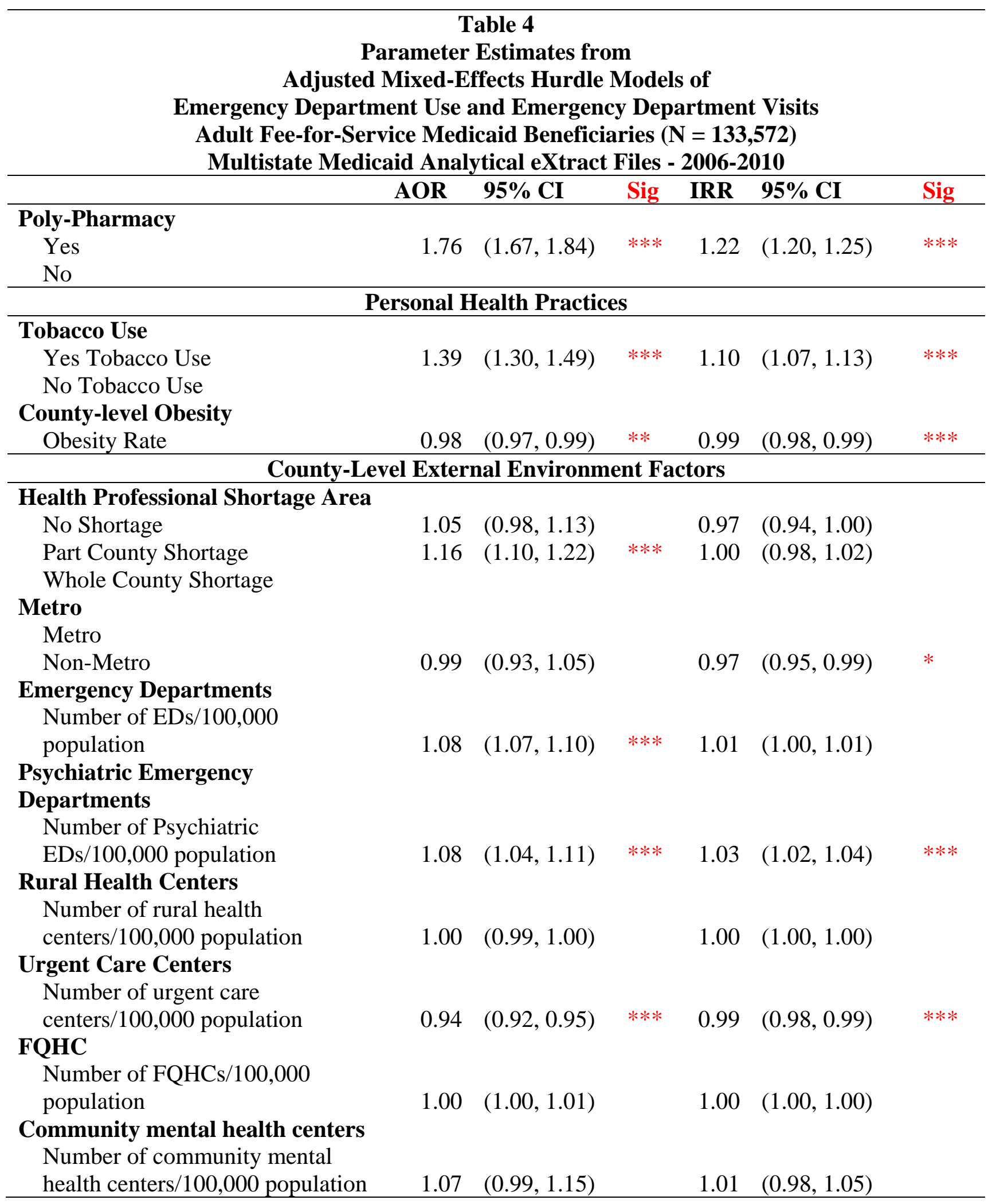


Note: Based on 133,572 person years of adult Medicaid fee-for-service beneficiaries aged 22-64 years and who are continuously enrolled, who are not Medicare and Medicaid eligible, who are alive, non-pregnant and are ED users for the years 2006-2010. County-level variables were extracted from the Area Health Resource Files and county health ranking data.

AOR: Adjusted Odds Ratios; IRR: Incidence Rate Ratios; CI: Confidence interval; Sig: Significance; ED: Emergency Department; FQHC: Federally Qualified Health Centers

$* * * \mathrm{p}<.001 ; * * .001<\mathrm{p}<.01 ; * .01<\mathrm{p}<.05$. 


\section{Table 5}

Visit-Level Analysis Among Emergency Department Users

NYU Algorithm Classifying Emergency Department Visits each Year

Adult Fee-for-Service Medicaid Beneficiaries

Multistate Medicaid Analytical Extract Files -2006-2010

\begin{tabular}{lrrrr}
\hline & Year 1 & $\begin{array}{r}\text { Year 2 } \\
(\boldsymbol{\%})\end{array}$ & $\begin{array}{r}\text { Year 3 } \\
(\boldsymbol{\%})\end{array}$ & $\begin{array}{r}\text { Year 4 } \\
(\boldsymbol{\%})\end{array}$ \\
\hline $\begin{array}{l}\text { Total Emergency Department visits }(\mathbf{n}) \\
\text { Emergent (Not avoidable) }\end{array}$ & 52,588 & 44,830 & 44,802 & 53,948 \\
Primary care sensitive & 19.11 & 19.27 & 19.40 & 20.25 \\
• Non-emergent & & & & \\
• Emergent - Primary care treatable & 21.22 & 21.28 & 21.05 & 20.65 \\
• Emergent - Preventable/Avoidable & 7.19 & 7.67 & 7.25 & 7.89 \\
Mental Health Related & 6.09 & 5.97 & 6.18 & 6.18 \\
Injury & 19.54 & 20.57 & 20.55 & 19.64 \\
\hline
\end{tabular}

Note: Based on emergency department visits in each year by adult Medicaid FFS beneficiaries aged 22-64 years and who are continuously enrolled for the year 2006-2010, who are not Medicare and Medicaid eligible, who are alive and non-pregnant. Emergency department visits were classified using NYU algorithm developed by New York University Center for Health and Public Service Research. Classification was based on 60\% threshold and unclassified conditions were excluded. Year1: ED visits in 2007; Year2: ED visits in 2008; Year 3: ED visits in 2009: Year 4: ED visits in 2010. 


\section{Appendix A \\ Study Population: Adult Fee-for-Service Medicaid Beneficiaries \\ Multistate Medicaid Analytical Extract Files - Year 4 \\ (Example: West Virginia)}

- 22-64 years old

- Medicaid beneficiaries residing in WV during 2009

$$
\mathrm{N}=89,951
$$

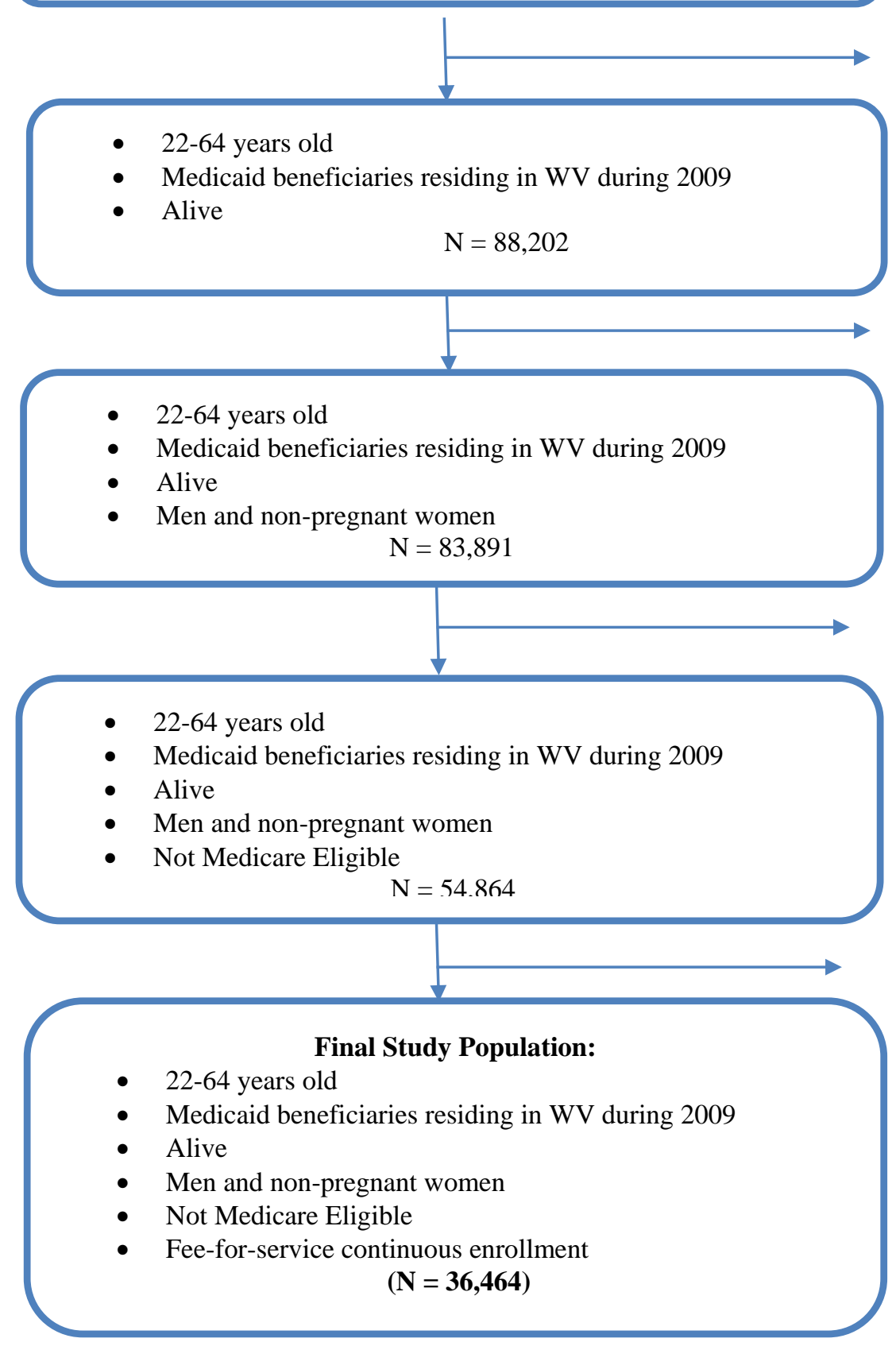

Reason for exclusion:

- $\quad$ Death in 2009 and $2010(N=1,749)$

Reasons for exclusion:

- $\quad$ Pregnant women in 2009 and $2010(N=4,311)$

Reasons for exclusion:

- Medicare eligibility in 2009 and $2010(N=29,027)$

Reasons for exclusion:

- Managed care and FFS not continuous in 2009 and $2010(\mathrm{~N}=$ 18,400) 


\section{Appendix B}

\section{Table 1}

Baseline Descriptive of the Study Population Patient-Level Factors Only

Adult Fee-for-Service Medicaid Beneficiaries

Multistate Medicaid Analytical eXtract Files - 2006

\begin{tabular}{|c|c|c|}
\hline \multirow[b]{2}{*}{ All } & $\mathbf{N}$ & $\%$ \\
\hline & \multicolumn{2}{|l|}{33,393} \\
\hline \multicolumn{3}{|l|}{ Predisposing Factors } \\
\hline \multicolumn{3}{|l|}{ Age } \\
\hline 22-34 years & 7,356 & 22.0 \\
\hline $35-44$ years & 7,887 & 23.6 \\
\hline 45-54 years & 11,492 & 34.4 \\
\hline 55-64 years & 6,658 & 19.9 \\
\hline \multicolumn{3}{|l|}{ Gender } \\
\hline Female & 19,595 & 58.7 \\
\hline Male & 13,798 & 41.3 \\
\hline \multicolumn{3}{|l|}{ Race } \\
\hline White & 29,822 & 89.3 \\
\hline African Americans & 3,351 & 10.0 \\
\hline Hispanics & 126 & 0.4 \\
\hline Other Races & 94 & 0.3 \\
\hline \multicolumn{3}{|l|}{ Enabling Factors } \\
\hline \multicolumn{3}{|l|}{ Medicaid Eligibility } \\
\hline Cash Eligibility & 31,239 & 93.5 \\
\hline No Cash Eligibility & 2,154 & 6.5 \\
\hline \multicolumn{3}{|l|}{ Primary Care Use } \\
\hline None & 6,236 & 18.7 \\
\hline Fragmented & 23,747 & 71.1 \\
\hline Continuous & 3,410 & 10.2 \\
\hline \multicolumn{3}{|l|}{ Need Factors } \\
\hline \multicolumn{3}{|l|}{ Complex Chronic Illness } \\
\hline Physical Health Conditions & 9,260 & 27.7 \\
\hline Mental Health Conditions & 4,684 & 14.0 \\
\hline Physical and Mental Health Conditions & 14,910 & 44.7 \\
\hline None & 4,539 & 13.6 \\
\hline \multicolumn{3}{|l|}{ Poly-Pharmacy } \\
\hline Yes & 5,560 & 16.7 \\
\hline No & 27,833 & 83.3 \\
\hline \multicolumn{3}{|l|}{ Medicaid Medical Eligibility } \\
\hline Medical Eligibility & 852 & 2.6 \\
\hline No Medical Eligibility & 32,541 & 97.4 \\
\hline
\end{tabular}




\begin{tabular}{|c|c|c|}
\hline \multicolumn{3}{|c|}{$\begin{array}{c}\text { Table 1 } \\
\text { Baseline Descriptive of the Study Population } \\
\text { Patient-Level Factors Only } \\
\text { Adult Fee-for-Service Medicaid Beneficiaries } \\
\text { Multistate Medicaid Analytical eXtract Files - 2006 }\end{array}$} \\
\hline & $\mathbf{N}$ & $\%$ \\
\hline All & 33,393 & \\
\hline \multicolumn{3}{|c|}{ Personal Health Practices } \\
\hline \multicolumn{3}{|l|}{ Tobacco Use } \\
\hline Yes Tobacco Use & 1,825 & 5.5 \\
\hline No Tobacco Use & 31,568 & 94.5 \\
\hline \multicolumn{3}{|c|}{ External Environment Factors } \\
\hline \multicolumn{3}{|c|}{ Health Professional Shortage Area } \\
\hline No Shortage & 6,925 & 20.7 \\
\hline Whole County Shortage & 11,333 & 33.9 \\
\hline Part County Shortage & 15,135 & 45.3 \\
\hline \multicolumn{3}{|l|}{ Metro } \\
\hline Metro & 18,751 & 56.2 \\
\hline Non-Metro & 14,642 & 43.8 \\
\hline
\end{tabular}

Note: Based on 33,393 adult Medicaid fee-for-service beneficiaries aged 22-64 years and who are continuously enrolled, who are not Medicare and Medicaid eligible, who are alive and nonpregnant for the years 2006-2010. County-level variables were extracted from the Area Health Resource Files and county health ranking data. Information on baseline characteristics was extracted from the base period of the panels i.e. 2006 in 2006-07 panel, 2007 in 2007-08 panel, 2008 in 2008-09 panel, and 2009 in 2009-10 panel. 


\section{References}

1. Pitts SR, Niska RW, Xu J, Burt CW. National Hospital Ambulatory Medical Care Survey: 2006 emergency department summary. Natl Health Stat Report. 2008(7):1-38.

2. Pines JM, Mullins PM, Cooper JK, Feng LB, Roth KE. National trends in emergency department use, care patterns, and quality of care of older adults in the United States. $J$ Am Geriatr Soc. Jan 2013;61(1):12-17.

3. Tang N, Stein J, Hsia RY, Maselli JH, Gonzales R. Trends and characteristics of US emergency department visits, 1997-2007. Jama. Aug 11 2010;304(6):664-670.

4. Cunningham PJ. What accounts for differences in the use of hospital emergency departments across U.S. communities? Health Aff (Millwood). Sep-Oct 2006;25(5):w324336.

5. Cheung PT, Wiler JL, Lowe RA, Ginde AA. National study of barriers to timely primary care and emergency department utilization among Medicaid beneficiaries. Ann Emerg Med. Jul 2012;60(1):4-10 e12.

6. Mortensen K, Song PH. Minding the gap: a decomposition of emergency department use by Medicaid enrollees and the uninsured. Medical care. Oct 2008;46(10):1099-1107.

7. Mandelberg JH, Kuhn RE, Kohn MA. Epidemiologic analysis of an urban, public emergency department's frequent users. Academic emergency medicine : official journal of the Society for Academic Emergency Medicine. Jun 2000;7(6):637-646.

8. Gawande A. The hot spotters: can we lower medical costs by giving the neediest patients better care? New Yorker. Jan 2011:40-51.

9. Skinner HG, Blanchard J, Elixhauser A. Trends in Emergency Department Visits, 20062011: Statistical Brief \#179. Healthcare Cost and Utilization Project (HCUP) Statistical Briefs. Rockville (MD)2006.

10. Weiss AJ, Wier LM, Stocks C, Blanchard J. Overview of Emergency Department Visits in the United States, 2011: Statistical Brief \#174. Healthcare Cost and Utilization Project (HCUP) Statistical Briefs. Rockville (MD)2006.

11. $\mathrm{Xu} \mathrm{KT,} \mathrm{Nelson} \mathrm{BK,} \mathrm{Berk} \mathrm{S.} \mathrm{The} \mathrm{changing} \mathrm{profile} \mathrm{of} \mathrm{patients} \mathrm{who} \mathrm{used} \mathrm{emergency}$ department services in the United States: 1996 to 2005. Ann Emerg Med. Dec 2009;54(6):805-810 e801-807.

12. CMS. Medicaid \& CHIP: April 2015 Monthly Applications, Eligibility Determinations and Enrollment Report. MD: Department of Health and Human Services Centers for Medicare \& Medicaid Services; 30th Sept 2015.

13. Centers for M, Medicaid Services HHS. Medicaid program; eligibility changes under the Affordable Care Act of 2010. Final rule, Interim final rule. Federal register. 2012;77(57):17144-17217.

14. A Matter of Urgency: Reducing Emergency Department Overuse. 2010; http://www.nehi.net/writable/publication_files/file/nehi_ed_overuse_issue_brief_032610f inaledits.pdf. Accessed Aug, 2015.

15. Billings J, Parikh N, Mijanovich T. Emergency department use: the New York Story. Issue brief. Nov 2000(434):1-12.

16. Ballard DW, Price M, Fung V, et al. Validation of an algorithm for categorizing the severity of hospital emergency department visits. Medical care. Jan 2010;48(1):58-63.

17. Andersen RM. Revisiting the behavioral model and access to medical care: does it matter? Journal of health and social behavior. 1995;36(1):1-10. 
18. HRSA. Area Health Resources Files (AHRF) National, State and County Health Resources Information Database. http://ahrf.hrsa.gov/download.htm. Accessed Aug, 2015.

19. County Health Rankings \& Roadmaps: Our Approach. http://www.countyhealthrankings.org/. Accessed Aug, 2015.

20. Magill MK, Senf J. A new method for measuring continuity of care in family practice residencies. The Journal of family practice. Feb 1987;24(2):165-168.

21. Goodman RA, Posner SF, Huang ES, Parekh AK, Koh HK. Defining and measuring chronic conditions: imperatives for research, policy, program, and practice. Preventing chronic disease. 2013;10:E66.

22. NQF. Establishing a Measurement Establishing a Measurement Framework for Multiple Framework for Multiple Chronic Conditions. Washington, DC: National Quality Forum;2011.

23. Goldberg JF, Brooks JO, 3rd, Kurita K, et al. Depressive illness burden associated with complex polypharmacy in patients with bipolar disorder: findings from the STEP-BD. The Journal of clinical psychiatry. Feb 2009;70(2):155-162.

24. Lo N, Roby DH, Padilla J, et al. Increased service use following Medicaid expansion is mostly temporary: evidence from California's low income health program. Policy brief. Oct 2014(PB2014-7):1-8.

25. Gindi RM CR, Kirzinger WK. Emergency room use among adults aged 18-64: Early release of estimates from the National Health Interview Survey, January-June 2011. National Center for Health Statistics;2012.

26. Pitts SR, Carrier ER, Rich EC, Kellermann AL. Where Americans get acute care: increasingly, it's not at their doctor's office. Health Aff (Millwood). Sep 2010;29(9):16201629.

27. Mason D. JAMA Forum: The Affordable Care Act and Emergency Care Visits: Why Choose the Emergency Department? 2014; http://newsatjama.jama.com/2014/02/26/jama-forum-the-affordable-care-act-andemergency-care-visits-why-choose-the-emergency-department/. Accessed 11th Novermeber, 2014.

28. Weinick RM, Burns RM, Mehrotra A. Many emergency department visits could be managed at urgent care centers and retail clinics. Health Aff (Millwood). Sep 2010;29(9):1630-1636.

29. Busch J. ER is for emergencies: how washington turned bad public policy into good healthcare. EMS world. Mar 2014;43(3):25.

30. Kellermann AL, Weinick RM. Emergency departments, Medicaid costs, and access to primary care--understanding the link. The New England journal of medicine. Jun 7 2012;366(23):2141-2143. 


\title{
CHAPTER 4
}

\section{Healthcare Expenditures Associated with Persistent Emergency Department Use: A Multi-state Analysis of Medicaid Beneficiaries}

\begin{abstract}
Objective: The objective of the current study is to determine the patient- and county-level factors associated with persistent emergency department (ED) use and estimate the excess healthcare expenditures associated with persistent ED use among fee-for-service (FFS) Medicaid beneficiaries.
\end{abstract}

Methods: A retrospective observational study design with index (calendar year 2009) and follow-up periods (calendar year 2010) was used. Patient-level data were obtained from the Medicaid analytic eXtract files (2009-2010). Information on county-level factors was obtained from the area health resource and county health rankings files. The study population consisted of non-elderly adult (22-64 years) FFS Medicaid beneficiaries who were alive, continuously enrolled, eligible only for Medicaid, and non-pregnant women through all 24 months of the study period. Individuals with persistent ED use were defined as those with 4 or more ED visits during the index and the follow-up years. Individuals with no ED use (non-users) were defined as those not having any ED visits in the index and the follow-up years. Chi-square tests were conducted to examine subgroup differences between persistent ED users and non-users. Logistic regression was conducted to examine the patient- and county-level factors associated with persistent ED use. Total expenditures in the follow-up period were derived using Medicaid payments and included outpatient, inpatient, and prescription drug expenditures. ED-related payments were excluded. Mean expenditures were compared between persistent ED users and non-users. Inverse Probability Treatment Weights (IPTWs) were derived to adjust for the observed selection bias among persistent ED users and non-users. The association between persistent ED use and 
healthcare expenditures was tested with generalized linear models (GLM) with log link function and gamma distribution with IPTWs. Multivariable models accounted for clustering of the individuals within counties.

Results: Among the Medicaid beneficiaries who were observed in both years $9.6 \%(\mathrm{~N}=5,145)$ were persistent ED users; there were significant differences between persistent ED users and non-users in patient- and county-level characteristics. Persistent ED users were more likely to have complex chronic illnesses ( $\mathrm{AOR}=7.65 ; 95 \% \mathrm{CI}=6.66,8.77)$ and poly-pharmacy ( $\mathrm{AOR}=$ 4.36; $95 \% \mathrm{CI}=3.99,4.77)$. In multivariable regression, persistent ED users had significantly higher total healthcare expenditures as compared to non-users ( $\$ 5,900$ vs $\$ 2,902)$.

Conclusion: One in 10 Medicaid beneficiaries had persistent ED use over a period of two years. Persistent ED users had higher healthcare needs and had higher healthcare expenditures as compared to non-users. Cost containment strategies may need to focus on reducing the risk of persistent ED use. 


\section{Introduction}

Frequent Emergency Department (ED) use is a longstanding problem in the United States (US) as these visits are associated with higher healthcare expenditures, ${ }^{1}$ as well as fragmented ${ }^{2,3}$ and reduced quality of care. ${ }^{2}$ Frequent ED users have "complex physical, behavioral, and social needs" that were not met "by the current fragmented health care system" ; are often medically high-need individuals, ${ }^{5-10}$ with chronic physical and/or mental health conditions, ${ }^{4,11,17-23}$ have higher healthcare utilization, ${ }^{11,12}$ incur higher expenditures, ${ }^{13}$ and have higher rates of mortality ${ }^{14}$ as compared to less frequent ED users.

There is some evidence that frequent ED use may be persistent with some individuals visiting EDs frequently every year (i.e. persistent ED users). Among all ED users, the percentage of persistent ED users ranged from $0.5 \%$ to $38 \%$ depending on the definition of frequent ED use, settings, and region. ${ }^{10,15-18}$ There is no consensus on the annual number of visits that define frequent $\mathrm{ED}$ use and the definition ranges from 3 to $10 \mathrm{ED}$ visits annually. ${ }^{16,18-20} \mathrm{In}$ a recently published study, Hwang et al. defined individuals who had $\geq 4$ ED visits every year (for a period of two years) as persistent ED users using data from a primary academic center and found that $0.5 \%$ had persistent ED use. ${ }^{18}$ Knee et at defined individuals who had $\geq 10$ ED visits every year (over a period of 4 years) and found that $17 \%$ had persistent ED use. ${ }^{16}$ Fuda et al. defined individuals who $\geq 5$ ED visits every year (for a period of two years) using data from acute-care hospital and found that $28 \%$ had persistent ED use. ${ }^{20}$

Studying persistent ED use is important because they account for a larger portion of ED visits annually. ${ }^{21}$ Additionally, frequent ED users are often covered by public insurance such as Medicaid $^{22,23}$; they have complex healthcare needs and higher healthcare expenditures. ${ }^{24}$ However, except for one study, ${ }^{18}$ comprehensive research on subgroup differences in persistent ED users is lacking. To date no study has examined the association between persistent ED use and healthcare expenditures. It is known that frequent ED visits lead to increased ED healthcare 
expenditures. ${ }^{13,25,26}$ Some of the reasons for increased expenditures among ED users can be attributed to the care of Ambulatory Care Sensitive Conditions (ACSC) in the EDs ${ }^{27}$, patients' complex chronic illnesses ${ }^{5-7}$ and use of inpatient services. ${ }^{18}$ ED visits due to ACSCs account for $\$ 38$ billion of total healthcare spending in the United States. ${ }^{28}$ As costs of providing treatment in the ED are higher compared to treatment in other healthcare settings, ${ }^{29,30}$ persistent ED users may have higher healthcare expenditures compared to other ED users and non-users.

Examining the healthcare expenditures associated with persistent ED use among Medicaid enrollees is important because current healthcare spending in US has almost reached $\$ 2.9$ trillion out of which $\$ 449.4$ billion are attributable to Medicaid. ${ }^{31}$ The Medicaid enrollees utilize ED frequently due to lack of primary care access, shortage of primary care providers, increased prevalence of chronic conditions, and patient complexity. ${ }^{12,32-35}$ If primary care access issues continue over time, many individuals may have persistent ED use. Analyzing the association between healthcare expenditures and persistent ED use may highlight the need for cost containment strategies and programs focused on persistent ED users.

The objective of the current study is to examine the patient- and county-level factors associated with persistent ED use and estimate the excess expenditures associated with persistent ED use among adult fee-for-service (FFS) Medicaid beneficiaries.

\section{Methods}

\section{Study Design}

A retrospective observational study design with index (calendar year 2009) and follow-up period (calendar year 2010) was used with data from administrative claims of Medicaid beneficiaries residing in Maryland (MD), Ohio (OH), and West Virginia (WV). 


\section{Data Sources}

Medicaid Analytic eXtract (MAX) Files - 2009-2010

MAX files include personal summary file, inpatient claims, other therapy claims, and prescription drugs claims. These files can be linked using encrypted identification numbers and include following information on Medicaid enrollees: demographics, Medicaid eligibility, county federal information processing standard (FIPS) codes, Medicaid managed care enrollment, Medicare eligibility status, information related to hospital stays, dates of service, Medicaid payment, the International Classification of Disease, Ninth Revision, Clinical Modification codes (ICD-9-CM), ICD-9-CM procedure codes, dates of service, types of service, Medicaid payment, ICD-9-CM, and Current Procedural Terminology (CPT) codes, date of prescription filled, days supplied, and national drug code (NDC).

\section{Area Health Resources Files (AHRF)}

The AHRF data are released by Health Resources and Services Administration division of U.S. Department of Health and Human Services. These file contain national, state, and county

level data on various measures. ${ }^{36}$ Variables used in the current from AHRF data are explained in the measures section.

\section{County Health Rankings Data}

The County Health Rankings data compiles information on health behaviors, clinical care, social and economic factors, and physical environment from different data sources. ${ }^{37}$

\section{Study Population}

The study population included FFS Medicaid beneficiaries, aged 22-64 years, with continuous Medicaid enrollment, not eligible for Medicare, and alive during index (calendar year 2009) and follow-up period (calendar year 2010). Pregnant women were excluded from the analysis. An example of selecting the final study population is summarized in Appendix A. The 
final study population included 53,729 Medicaid enrollees. The primary analysis focuses on 22,252 Medicaid enrollees with either frequent ED use in both years $(n=5,145)$ or no ED use in both years $(n=17,107)$.

\section{Measures}

Dependent Variable

\section{Total Healthcare Expenditures}

Payments made by Medicaid for outpatient, inpatient, and prescription drugs utilization services were used to derive healthcare expenditures. Types of healthcare expenditures included outpatient, inpatient, and prescription drug expenditures. These expenditures were summed to derive total expenditures. ED related expenditures were excluded from total expenditures and outpatient expenditures. All expenditures were adjusted using the US consumer price index for medical services and are expressed in 2010 US dollars. ${ }^{38}$

Key Variable: Persistent ED users versus Non-users

ED visits were identified from inpatient (revenue codes: 450-52, 456, 459, and 981) and outpatient claims (CPT codes: 99281-85). The number of ED visits were estimated for both index and follow-up year. As there is no consensus on the number of ED visits that define frequent ED users, we used the commonly used definition (i.e. 4 or more ED visits annually). Therefore, for each year ED users were categorized as: 1) frequent ED users ( $\geq 4$ visits), 2) Infrequent ED users ( $1-3$ visits), and non-users (0 visits). Using these categories, persistent ED use was defined as following: 1) no ED use in both years (non-users); 2) No ED use in the index and ED use in the follow-up year; 3) ED use in the index and no ED use in the follow-up year; 4) persistent ED use ( $\geq 4$ visits in index and follow-up years); and 5) other ED users.

Based on these categories, it was estimated that $31.8 \%$ were non-users; $15.2 \%$ were nonusers in the index but used EDs in the follow-up year; $15.9 \%$ were users in the index but did not 
use ED during the follow-up period; $9.6 \%$ were persistent ED users and $27.5 \%$ were classified as other ED users.

\section{Independent Variables}

Other independent variables were measured during the index year; they were: age (22-34, 35-44, 45-54, 55-64 years), gender (female, male), and race/ethnicity (whites, African Americans, Hispanics, other races), patient-level Medicaid eligibility due to cash assistance/poverty (cash eligibility, no cash eligibility), county-level college education rate, primary care use (none, fragmented, continuous), and county-level unemployment rate, patientlevel complex chronic illness (physical health conditions, mental health conditions, physical and mental health conditions, none), Medicaid eligibility due to medical need/waiver (medical eligibility, no medical eligibility), and poly-pharmacy (Yes, No), patient-level tobacco use (yes tobacco use, no tobacco use), and county-level obesity rates, metro status (metro, non-metro), health professional shortage area (HPSA - no, partial, and complete shortage areas), number of hospitals with EDs, number of hospitals with psychiatric emergency services, number of rural health clinics, number of federally qualified health centers (FQHCs), number of community mental health centers, number of urgent care clinics per 100,000 population, and inpatient use (yes, no).

Primary care use was measured using the modified, modified continuity index (MMCI) developed by Magill and colleagues, ${ }^{39}$ which ranged from 0 to 1 . Poly-pharmacy was defined as concomitant use of multiple prescription drugs within a 90-day period and was based on number of prescription drugs one standard deviation above the mean. ${ }^{40}$ Patient-level complex chronic illness was defined using the AHRQ definition: "a complex patient is one with two or more chronic conditions where each condition may influence the care of the other condition(s) through limitations of life expectancy, interactions between drug therapies, difficulties in establishing adequate care coordination, and/or direct contraindications to therapy for one condition by other 
conditions themselves". ${ }^{41}$ In this study, complex chronic illness was defined as those having both physical and mental health conditions. Physical health conditions consisted of: arthritis, asthma, cardiac arrhythmia, coronary artery disease, cancer, chronic heart failure, chronic kidney disease, chronic obstructive pulmonary disease (COPD), dementia, diabetes, hepatitis, hyperlipidemia, human immunodeficiency virus (HIV), hypertension, osteoporosis, and stroke. Mental health conditions consisted of generalized anxiety, post-traumatic stress disorder, depression, bipolar disorders, psychosis, schizophrenia, and other mental illness. The selection of physical and mental health conditions was based on the framework provided by the Health and Human Services Office of the Assistant Secretary of Health. ${ }^{42}$ Each physical and mental health condition was identified using one inpatient or two outpatient claims for every patient.

\section{Statistical Analysis}

Frequencies and percentages were used to describe the characteristics of the study population. Chi-square tests were conducted to examine subgroup differences in the characteristics of persistent ED users as compared to non-users. Logistic regression was conducted to examine the patient- and county-level factors that were associated with persistent ED use as compared to no use. Mean expenditures for each subgroup of the study population were calculated to compare expenditures by persistent ED use as compared to no ED use.

\section{Inverse Probability of Treatment Weights (IPTW) to control for observed selection bias:}

Persistent ED users and non-users were significantly different in observed characteristics. Therefore, IPTW approach was used to control for selection bias due to observed differences in baseline characteristics of persistent ED users and non-users. IPTWs are the inverse probability of persistent ED use (i.e. exposure in a nonrandomized study) conditional on the observed independent variables that affect persistent ED use. The predicted probabilities obtained from either logistic or probit regression can be used to calculate the IPTWs. IPTWs creates a balance in terms of distribution of potential confounders across treatment levels. 
In this logistic regression on persistent ED use the following independent variables were used: age, gender, race/ethnicity, Medicaid eligibility due to cash-assistance and medical needs, county-level college education percent and unemployment rate, primary care use, presence of complex chronic illness, poly-pharmacy, tobacco use, county-level obesity rates, number of EDs/100,000 population, number of hospitals with psychiatric EDs/100,000 population, metro status of the county, health professional shortage area, number of rural health centers/100,000 population, number of urgent care centers/100,000 population, number of federally qualified health centers/100,000 population, and number of community mental health centers/100,000 population.

Unadjusted generalized linear models (GLM) with log-link and gamma distribution were conducted to examine the association between persistent ED use and total healthcare expenditures. Modified park test and pregibon link test were conducted to select the log-link and gamma family distribution. Adjusted GLM model was conducted to examine the association between persistent ED use and total healthcare expenditures after controlling for other independent variables. For adjusted GLM, different models were conducted by entering the independent variables in block: 1) persistent ED use (Model 1), 2) persistent ED use and patientlevel factors (Model 2), and 3) persistent ED use, patient- and county-level factors (Model 3). Expenditures associated with persistent ED use were estimated by adding and exponentiating the intercept and the coefficient for persistent ED use. Expenditures associated with non-use were estimated by exponentiating the intercepts. The differences in the expenditures of persistent ED users and non-users were reported as average change in expenditures associated with persistent ED use.

\section{Results}


Among Medicaid beneficiaries with persistent ED use or no use $(\mathrm{N}=22,252)$, a majority of the study population were: $45-64$ years old $(56.1 \%)$, females $(56.4 \%)$, whites $(85.8 \%)$, those eligible for Medicaid due to cash assistance/poverty (86.9\%), with fragmented primary care use (66.8\%), those living in a county with partial/whole health professional shortage (80\%), and those living in a metro county (61.3\%). Approximately, $6 \%$ of Medicaid beneficiaries were eligible for Medicaid due to medical needs, $16 \%$ had poly-pharmacy, and $6 \%$ had tobacco use. Approximately, one-third of the study population had complex chronic illness i.e. the presence of both mental and physical health conditions. (Results presented in Appendix B)

Findings from chi-square tests to examine subgroup differences in the characteristics of those with persistent ED use as compared to individuals with no ED use are summarized in table 1. Approximately, one-fourth of the study population were persistent ED user i.e. they had 4 or more visits both in index and follow-up years. Chi-square tests revealed significant subgroup differences in the characteristics of the two groups for all the variables except Medicaid eligibility due to cash-assistance/poverty $(\mathrm{p}<0.05)$. For example, a higher proportion of African Americans (32\%) were persistent ED users as compared to whites (21.8\%). It was also observed that among persistent ED users, 55.6\% had inpatient hospitalizations, however among non-users only $2 \%$ had inpatient hospitalizations (data not presented in table).

AORs and 95\% CIs from logistic regression on persistent ED users are summarized in Table 2. As compared to males, females were more likely to be persistent ED users (AOR = $1.17,95 \% \mathrm{CI}=1.08,1.26)$. Similar results were observed for the following factors: African Americans, Hispanics, other race/ethnicity groups, Medicaid eligibility due to cash-assistance, fragmented primary care use, presence of physical health conditions, presence of mental health conditions, presence of both physical and mental health conditions, poly-pharmacy, Medicaid eligibility due to medical needs, tobacco use, number of hospitals with psychiatric emergency services/100,000 population, and number of EDs/100,000 population. As compared to 
individuals aged 22-34 years, those aged 35-44 years were less likely to be persistent ED users $(\mathrm{AOR}=0.84,95 \% \mathrm{CI}=0.75,0.94)$. Similar results were observed for the following factors: individuals aged 45-64 years, county-level unemployment rate, no primary care use, county-level obesity rate, non-metro status of the county, and number of urgent care centers $/ 100,000$ population. The following factors were not statistically significant: county-level college education rate, health professional shortage area, number of rural health centers $/ 100,000$ population, number of FQHCs/100,000 population, and number of community mental health centers/100,000 population.

IPTW-adjusted mean total, outpatient and prescription expenditures by persistent ED use are presented in Table 3. Persistent ED users had 2 times higher total healthcare expenditures as compared to non-users. Similar results were observed for outpatient and prescription drug expenditures. Among, users as well prescription and inpatient expenditures were higher among persistent ED users as compared to non-users.

The findings from GLM models with log link function are presented in table 4. Again, these models are adjusted for IPTWs. After adjusting for patient-characteristics, persistent ED users had \$6,621 higher total expenditures than non-users (Full model is presented in appendix C). After adjusting for county-level factors persistent ED users had $\$ 3,088$ higher total expenditures than non-users. Similar results were observed for outpatient and prescription drug expenditures.

\section{Secondary Analysis:}

Expenditures were also compared between persistent ED users and other ED users by using the entire study population $(\mathrm{N}=53,729)$. As explained in the methods section, ED use over time consisted of 5 categories, which were: 1) no ED use in both years (non-users); 2) No ED use in the index and ED use in the follow-up year; 3) ED use in the index and no ED use in the 
follow-up year; 4) persistent ED use ( $\geq 4$ visits in index and follow-up years); and 5) other ED users. Medicaid beneficiaries who had no ED use in the index year and had ED use in the followup year had $\$ 3,753$ lower expenditures as compared to those with persistent ED use. Similar results were observed for other categories as well. These results indicated that persistent ED users had significantly higher expenditures compared to other ED users (Results presented in appendix D).

Further, quantile regressions were also conducted to examine whether the distribution of total healthcare expenditures changed the relationship between persistent ED use and total healthcare expenditures. In the $50^{\text {th }}$ quantile, it was observed that persistent ED users had $\$ 7,190$ higher expenditures as compared to non-users. Similar results were observed for other quantiles as well (Results presented in appendix E).

\section{Discussion}

The current study examined the patient- and county-level factors associated with persistent ED use. Furthermore, the excess healthcare expenditures associated with persistent ED use were also estimated. In the total study population $(n=53,729), 9.6 \%$ were persistent ED users and $31.8 \%$ were non-users. When the study population was restricted to only persistent ED users and non-users $(n=22,252), 23.1 \%$ were persistent ED users. In this study, one in ten Medicaid enrollee was a persistent ED user. Other studies have reported that the percentage of persistent ED users varied from $0.5 \%$ to $38 \% \cdot{ }^{10,15-18}$ It is difficult to compare the proportion of persistent ED users because studies used different definitions to describe them. However, it can be concluded that a subgroup of the Medicaid population needs special attention from the policymakers and healthcare providers to design policies and healthcare management plans specific to their needs. 
The current study observed that patient-level factors were associated with persistent ED use. For example, individuals with complex chronic illnesses, poly-pharmacy, and poor lifestyle practices such as tobacco use were more likely to visit ED persistently. Additionally, among those with persistent ED use, approximately $83 \%$ had fragmented primary care use. Hwang et al. reported similar findings and found that a greater proportion of persistent ED users had physical and mental health conditions as compared to frequent ED users. ${ }^{18}$ As compared to frequent ED users, a greater proportion of persistent ED users had alcohol and drug abuse disorders. ${ }^{18}$ Additionally, a greater proportion of persistent ED users missed primary care appointments as compared to frequent and infrequent ED users. ${ }^{18}$

In the current study, residents of counties with high density of urgent care centers were less likely to have persistent ED use as compared to non-users. Published studies suggest that urgent care centers may prevent ED visits and can manage care at lower costs. ${ }^{29,30,43}$ As many ED visits tend to happen after business hours, ${ }^{22}$ facilitating after-hour care, extending primary care office hours, and increasing the supply of urgent care centers may help in reducing the frequency of ED visits ${ }^{44}$ and may lead to reduction in expenditures.

It was observed that the total healthcare expenditures (non-ED related expenditures) were two times higher among persistent users as compared to non-users. Similar findings were observed for prescription and outpatient expenditures. It is plausible that persistent ED users have greater unmet needs and may be utilizing other services at a higher rate. For example, Hwang et al. observed that persistent ED users had greater primary care visits as compared to both frequent and infrequent ED users. ${ }^{18}$ However, the author also noted that these visits were made to different primary care providers resulting in fragmented care. The current study also found that persistent ED users were more likely to have chronic complex illnesses, polypharmacy, tobacco use, and fragmented primary care. Taken together, these findings may explain 
why persistent ED users also have higher expenditures of other services (i.e. prescription drugs, and outpatient).

In the current study, it was also observed that among persistent ED users $55 \%$ had inpatient hospitalizations and among non-users only $2 \%$ had inpatient hospitalizations. This highlights that persistent ED users have complex healthcare needs. Even after having higher number of ED visits, persistent ED users were hospitalized at a greater rate. The findings from the current study are similar to the evidence provided in the literature. The Center for Disease Control and Prevention (CDC) estimated that out of 129.8 million ED visits in 2010, 13.3\% resulted in a hospital admission. ${ }^{45}$ Mandelberg et al. reported that approximately $50 \%$ of the frequent users are hospitalized in the same year of their ED visit. ${ }^{12}$ It is possible that higher prevalence of complex chronic illnesses, poly-pharmacy, and fragmented primary care use may be leading to higher inpatient use among these individuals.

The study findings highlight the need for policies, programs, and interventions that can meet the healthcare needs of persistent ED users, which may lead to reduction in healthcare expenditures. Many states have set up Health Information Exchanges (HIEs) that facilitate exchanging health related information not only within the state, but also across the states. ${ }^{46}$ HIEs are effective in identifying frequent ED users, reducing hospital readmissions and decreasing duplicate lab tests. ${ }^{19,47-49}$ For example, after implementation of HIEs in 2005 several healthcare organizations in Memphis, Tennessee reduced the overall healthcare expenditures by $\$ 1.9$ million among ED users. ${ }^{47}$ However, the effect of using statewide HIE data rather than sitespecific data on frequent visits to ED settings is yet to be seen. ${ }^{19,49}$

Findings of the current study need to be interpreted with consideration of some limitations. This study was conducted on alive, adult FFS Medicaid beneficiaries, aged 22-64 years old, continuously enrolled, not dually eligible, and residing in $\mathrm{MD}, \mathrm{OH}$, and WV. As 
demographic and resource differences exist across states, the results of this study are not generalizable to the entire Medicaid population. Substance abuse leads to increased ED use, however, the current study could not account for alcohol use and drug abuse because of limited sample size. Additionally, administrative claims data were used, which are created for billing purposes rather than research. This may result in misclassification of diagnosis. Furthermore, due to use of administrative claims data, the study did not control for factors such as education, and distance from the usual source of care. Due to variation in ED use and visits a large proportion of individuals visiting ED were excluded from the analysis.

Despite the limitations, the current study has several strengths. A comprehensive list of patient-level and county-level factors were used. These factors were obtained from different data sources and were linked together to provide complete information about the patient level factors and county-level healthcare resources. By relying on healthcare encounter data, the current study was able to capture services received from multiple providers, healthcare settings and geographical areas. Information on clinical diagnosis, prescription drugs and other healthcare services use were captured from claims data and do not have the shortcomings of self-reported data. The current study used patient-level data and was able to track repeated ED visits made by the same patient.

To conclude, one in 10 adult Medicaid beneficiaries had persistent ED use over a period of two years. Persistent ED users had complex medical needs and higher healthcare expenditures as compared to non-users. Identifying persistent ED users and providing targeted interventions to this sub-group may reduce the cost burden for Medicaid. 


\begin{tabular}{|c|c|c|c|c|c|}
\hline \multicolumn{6}{|c|}{$\begin{array}{c}\text { Table } 1 \\
\text { Description of the Study Population by Patient-Level Factors } \\
\text { Adult Fee-for-Service Medicaid Beneficiaries }(\mathrm{N}=\mathbf{2 2 , 2 5 2}) \\
\text { Multistate Medicaid Analytical Extract Files - 2009-10 }\end{array}$} \\
\hline & \multicolumn{2}{|c|}{ Non-Users } & \multicolumn{2}{|c|}{$\begin{array}{l}\text { Persistent } \\
\text { ED Users }\end{array}$} & \\
\hline & $\mathrm{N}$ & $\%$ & $\mathrm{~N}$ & $\%$ & Sig \\
\hline Total & 17,107 & $76.9 \%$ & 5,145 & 23.1 & \\
\hline Age & & & & & $* * *$ \\
\hline $22-34$ years & 4,595 & 80.5 & 1,114 & 19.5 & \\
\hline $35-44$ years & 2,931 & 72.4 & 1,116 & 27.6 & \\
\hline $45-54$ years & 4,823 & 74.7 & 1,637 & 25.3 & \\
\hline $55-64$ years & 4,758 & 78.8 & 1,278 & 21.2 & \\
\hline Gender & & & & & $* * *$ \\
\hline Female & 9,282 & 74.0 & 3,266 & 26.0 & \\
\hline Male & 7,825 & 80.6 & 1,879 & 19.4 & \\
\hline Race/Ethnicity & & & & & $* * *$ \\
\hline White & 14,939 & 78.2 & 4,160 & 21.8 & \\
\hline African American & 1,922 & 68.0 & 904 & 32.0 & \\
\hline Hispanic & 136 & 80.5 & 33 & 19.5 & \\
\hline Others & 110 & 69.6 & 48 & 30.4 & \\
\hline \multicolumn{6}{|l|}{ Medicaid Eligibility } \\
\hline Cash Eligibility & 14,857 & 76.8 & 4,485 & 23.2 & \\
\hline No Cash Eligibility & 2,250 & 77.3 & 660 & 22.7 & \\
\hline Primary care Use & & & & & $* * *$ \\
\hline None & 4,287 & 88.9 & 535 & 11.1 & \\
\hline Fragmented & 10,600 & 71.3 & 4,273 & 28.7 & \\
\hline Continuous & 2,220 & 86.8 & 337 & 13.2 & \\
\hline Complex Chronic Illness & & & & & $* * *$ \\
\hline Physical health conditions & 5,278 & 79.9 & 1,326 & 20.1 & \\
\hline Mental health conditions & 2,926 & 82.4 & 626 & 17.6 & \\
\hline $\begin{array}{l}\text { Physical and mental health } \\
\text { conditions }\end{array}$ & 3,960 & 58.3 & 2,837 & 41.7 & \\
\hline None & 4,943 & 93.3 & 356 & 6.7 & \\
\hline Poly-Pharmacy & & & & & $* * *$ \\
\hline Yes & 1,697 & 46.6 & 1,942 & 53.4 & \\
\hline No & 15,410 & 82.8 & 3,203 & 17.2 & \\
\hline Medicaid Medical Eligibility & & & & & $* * *$ \\
\hline Medical Eligibility & 974 & 68.6 & 445 & 31.4 & \\
\hline No Medical Eligibility & 16,133 & 77.4 & 4,700 & 22.6 & \\
\hline Tobacco Use & & & & & $* * *$ \\
\hline Yes Tobacco Use & 559 & 44.9 & 687 & 55.1 & \\
\hline No Tobacco Use & 16,548 & 78.8 & 4,458 & 21.2 & \\
\hline Metro & & & & & $* * *$ \\
\hline Metro & 10,306 & 75.6 & 3,324 & 24.4 & \\
\hline Non-metro & 6,801 & 78.9 & 1,821 & 21.1 & \\
\hline
\end{tabular}


Note: Based on 22,252 adult Medicaid fee-for-service beneficiaries aged 22-64 years and who are continuously enrolled for the year 2009 and 2010, who are not Medicare and Medicaid eligible, who are alive and non-pregnant and were either persistent ED users or non-users.

ED: Emergency Department; Sig: Significance

$* * * \mathrm{p}<.001 ; * * .001<\mathrm{p}<.01 ; * .01<\mathrm{p}<.05$. 


\begin{tabular}{|c|c|c|c|}
\hline \multicolumn{4}{|c|}{$\begin{array}{c}\text { Table } 2 \\
\text { Adjusted Odds Ratios and 95\% Confidence Intervals (CI) } \\
\text { from Logistic Regression of Persistent Emergency Department Users } \\
\text { Adult Fee-for-Service Medicaid Beneficiaries } \\
\text { Multistate Medicaid Analytical Extract Files - 2009-2010 }\end{array}$} \\
\hline & AOR & $95 \% \mathrm{CI}$ & Sig \\
\hline \multicolumn{4}{|l|}{ Age } \\
\hline 22-34 years & & Ref & \\
\hline $35-44$ years & 0.84 & {$[0.75,0.94]$} & $* *$ \\
\hline $45-54$ years & 0.50 & {$[0.45,0.55]$} & $* * *$ \\
\hline $55-64$ years & 0.36 & {$[0.32,0.40]$} & $* * *$ \\
\hline \multicolumn{4}{|l|}{ Gender } \\
\hline Female & 1.17 & {$[1.08,1.26]$} & $* * *$ \\
\hline Male & & Ref & \\
\hline \multicolumn{4}{|l|}{ Race/Ethnicity } \\
\hline Whites & & Ref & \\
\hline African American & 1.96 & {$[1.75,2.19]$} & $* * *$ \\
\hline Hispanics & 1.65 & {$[1.08,2.53]$} & $*$ \\
\hline Others & 2.48 & {$[1.68,3.67]$} & $* * *$ \\
\hline \multicolumn{4}{|l|}{ Medicaid Cash Eligibility } \\
\hline Cash Eligibility & 1.32 & {$[1.14,1.53]$} & $* * *$ \\
\hline No Cash Eligibility & & Ref & \\
\hline \multicolumn{4}{|l|}{ County-level Education } \\
\hline Percent with college education & 1.00 & {$[0.99,1.01]$} & \\
\hline County-level Unemployment & & Ref & \\
\hline Percent unemployed & 0.85 & {$[0.83,0.88]$} & $* * *$ \\
\hline Primary Care Use & & Ref & \\
\hline None & 0.79 & {$[0.67,0.92]$} & $* *$ \\
\hline Fragmented & 1.67 & {$[1.46,1.91]$} & $* * *$ \\
\hline Continuous & & Ref & \\
\hline \multicolumn{4}{|l|}{ Complex Chronic Illness } \\
\hline Physical health conditions & 3.30 & {$[2.86,3.81]$} & $* * *$ \\
\hline Mental health conditions & 2.81 & {$[2.43,3.26]$} & $* * *$ \\
\hline Both physical and mental health conditions & 7.65 & {$[6.66,8.77]$} & $* * *$ \\
\hline None & & Ref & \\
\hline \multicolumn{4}{|l|}{ Poly-pharmacy } \\
\hline Yes & 4.36 & {$[3.99,4.77]$} & $* * *$ \\
\hline No & & Ref & \\
\hline \multicolumn{4}{|l|}{ Medicaid Medical Eligibility } \\
\hline Medical Eligibility & 2.01 & {$[1.67,2.43]$} & $* * *$ \\
\hline No medical Eligibility & & Ref & \\
\hline \multicolumn{4}{|l|}{ Tobacco Use } \\
\hline Yes Tobacco Use & 3.97 & {$[3.48,4.54]$} & $* * *$ \\
\hline No Tobacco Use & & Ref & \\
\hline \multicolumn{4}{|l|}{ County-level Obesity } \\
\hline Obesity rate & 0.91 & {$[0.90,0.93]$} & $* * *$ \\
\hline
\end{tabular}




\begin{tabular}{|c|c|c|c|}
\hline \multicolumn{4}{|c|}{$\begin{array}{c}\text { Table } 2 \\
\text { Adjusted Odds Ratios and 95\% Confidence Intervals (CI) } \\
\text { from Logistic Regression of Persistent Emergency Department Users } \\
\text { Adult Fee-for-Service Medicaid Beneficiaries } \\
\text { Multistate Medicaid Analytical Extract Files - 2009-2010 }\end{array}$} \\
\hline & AOR & $95 \% \mathrm{CI}$ & Sig \\
\hline \multicolumn{4}{|l|}{ Health Professional Shortage Area } \\
\hline No shortage & 1.01 & {$[0.90,1.13]$} & \\
\hline Part county shortage & 1.09 & {$[1.00,1.19]$} & \\
\hline Whole county shortage & & Ref & \\
\hline \multicolumn{4}{|l|}{ Metro } \\
\hline Metro & & Ref & \\
\hline Non-metro & 0.90 & {$[0.81,1.00]$} & $*$ \\
\hline \multicolumn{4}{|l|}{ Emergency Departments } \\
\hline Number of ED /100,000 population & 1.08 & {$[1.05,1.10]$} & $* * *$ \\
\hline \multicolumn{4}{|l|}{ Psychiatric Emergency Services } \\
\hline Number of Psychiatric ED/100,000 population & 1.20 & {$[1.14,1.26]$} & $* * *$ \\
\hline \multicolumn{4}{|l|}{ Rural Health Centers } \\
\hline Number of rural health centers/100,000 population & 1.01 & {$[1.00,1.02]$} & $*$ \\
\hline \multicolumn{4}{|l|}{ Urgent Care Centers } \\
\hline Number of urgent care centers/100,000 population & 0.90 & {$[0.87,0.93]$} & $* * *$ \\
\hline \multicolumn{4}{|l|}{ Federally Qualified Health Centers } \\
\hline Number of FQHCs/100,000 population & 1.00 & {$[1.00,1.01]$} & \\
\hline \multicolumn{4}{|l|}{ Community mental health centers } \\
\hline $\begin{array}{l}\text { Number of community mental health centers } / 100,000 \\
\text { population }\end{array}$ & 1.07 & {$[0.95,1.21]$} & \\
\hline
\end{tabular}

Note: Based on 22,252 adult Medicaid fee-for-service beneficiaries aged 22-64 years and who are continuously enrolled for the year 2009 and 2010, who are not Medicare and Medicaid eligible, who are alive and non-pregnant and were either persistent ED users or non-users.

ED: Emergency Department; FQHC: Federally Qualified Health Centers; Ref: Reference Group; Sig: Significance; AOR: Adjusted Odds Ratios

$* * * \mathrm{p}<.001 ; * * .001<\mathrm{p}<.01 ; * .01<\mathrm{p}<.05$. 


\begin{tabular}{|c|c|c|c|c|c|}
\hline \multicolumn{6}{|c|}{$\begin{array}{c}\text { Table 3 } \\
\text { IPTW-Adjusted Mean Expenditures and Ratio of Means } \\
\text { by Type of Healthcare Expenditures } \\
\text { Adult Fee-for-Service Medicaid Beneficiaries } \\
\text { Multistate Medicaid Analytical Extract Files - 2009-2010 }\end{array}$} \\
\hline \multirow[t]{2}{*}{$\begin{array}{l}\text { Type of } \\
\text { Expenditures }\end{array}$} & \multicolumn{2}{|c|}{$\begin{array}{c}\text { Non-users } \\
(\mathbf{N}=17,107)\end{array}$} & \multicolumn{2}{|c|}{$\begin{array}{c}\text { Persistent ED users } \\
(\mathrm{N}=5,145)\end{array}$} & \\
\hline & Mean (\$) & SE & Mean (\$) & SE & $\begin{array}{r}\text { Ratio of } \\
\text { means }\end{array}$ \\
\hline Total $* * *$ & $15,846.4$ & 205.2 & $32,685.5$ & 695.3 & 2.1 \\
\hline $\begin{array}{l}\text { Outpatient**** } \\
\text { Prescription }\end{array}$ & $12,814.1$ & 198.7 & $16,978.4$ & 416.9 & 1.3 \\
\hline Drugs $* * * *$ & $2,869.3$ & 37.1 & $6,058.2$ & 195.6 & 2.1 \\
\hline \multicolumn{6}{|c|}{ In Users } \\
\hline $\begin{array}{l}\text { Prescription } \\
\text { Drugs*** }\end{array}$ & $3,215.1$ & 39.6 & $6,133.3$ & 197.1 & 1.9 \\
\hline Inpatient**** & $11,167.8$ & 791.6 & $19,926.7$ & 676.2 & 1.8 \\
\hline
\end{tabular}

Note: Based on 22,252 adult Medicaid fee-for-service beneficiaries aged 22-64 years and who are continuously enrolled for the year 2009 and 2010, who are not Medicare and Medicaid eligible, who are alive and non-pregnant and were either persistent ED users or non-users. Asterisks represent significant group differences between persistent ED users and non-users based on IPTW adjusted t-tests. Prescription drug expenditures among users were based on 16,105 non-users and 5,119 persistent ED users. Inpatient expenditures among users were based on 348 non-users and 2,940 persistent ED users.

$* * * \mathrm{p}<.001 ; * * .001<\mathrm{p}<.01 ; * .01<\mathrm{p}<.05$. 


\begin{tabular}{|c|c|c|c|}
\hline \multicolumn{4}{|c|}{$\begin{array}{c}\text { Table } 4 \\
\text { Intercept and Beta Coefficient for Persistent ED Use and Standard } \\
\text { Errors from } \\
\text { Generalized Linear Models with Log Link Function } \\
\text { By Type of Expenditures } \\
\text { Using Inverse Probability Treatment Weights } \\
\text { Adult Fee-for-Service Medicaid Beneficiaries } \\
\text { Multistate Medicaid Analytical Extract Files - 2009-10 } \\
\end{array}$} \\
\hline $\begin{array}{l}\text { Type of } \\
\text { Expenditures }\end{array}$ & $\begin{array}{l}\text { Intercept } \\
\text { (SE) }\end{array}$ & $\begin{array}{c}\text { Persistent ED Use -Beta } \\
\text { (SE) }\end{array}$ & $\begin{array}{c}\text { Change } \\
(\$)\end{array}$ \\
\hline \multicolumn{4}{|c|}{ Model 1} \\
\hline Total & $\begin{array}{r}9.67 * * * \\
(0.10) \\
9.46 * * *\end{array}$ & $\begin{array}{r}0.73^{* * * *} \\
(0.07) \\
0.29 * * *\end{array}$ & $17,002.09$ \\
\hline Outpatient & $\begin{array}{r}(0.13) \\
8.08^{* * * *}\end{array}$ & $\begin{aligned}(0.08) \\
0.65 * * *\end{aligned}$ & $4,248.95$ \\
\hline Prescription Drugs\# & $(0.03)$ & $(0.07)$ & $2,918.21$ \\
\hline & & & Model 2 \\
\hline Total & $\begin{array}{r}8.77 \text { *** } \\
(0.16) \\
8.13^{* * * *}\end{array}$ & $\begin{array}{r}0.71 * * * \\
(0.07) \\
0.61 * * *\end{array}$ & $6,621.99$ \\
\hline Outpatient & $\begin{array}{r}(0.21) \\
7.23^{* * * *}\end{array}$ & $\begin{array}{r}(0.07) \\
0.20^{* * * * *}\end{array}$ & $2,871.66$ \\
\hline Prescription Drugs\# & $(0.13)$ & $(0.12)$ & 308.07 \\
\hline & & & Model 3 \\
\hline Total & $\begin{array}{r}7.97 \text { *** } \\
(0.64) \\
7.47 * * *\end{array}$ & $\begin{array}{r}0.72 * * * \\
(0.07) \\
0.70^{* * * *}\end{array}$ & $3,088.04$ \\
\hline Outpatient & $\begin{array}{r}(0.86) \\
6.87 * * *\end{array}$ & $\begin{aligned}(0.07) \\
0.20^{* * * *}\end{aligned}$ & $1,781.37$ \\
\hline Prescription Drugs\# & $(0.46)$ & $(0.11)$ & 211.54 \\
\hline
\end{tabular}

Note: Based on 22,252 adult Medicaid fee-for-service beneficiaries aged 22-64 years and who are continuously enrolled for the year 2009 and 2010, who are not Medicare and Medicaid eligible, who are alive and non-pregnant. Independent variables in each model are: Model 1 persistent ED use; Model 2 persistent ED use and patient-level factors; Model 3 persistent ED use, patient- and county-level factors.

\# based on those with positive prescription drug expenditures $(\mathrm{N}=21,224)$.

ED: Emergency Department; SE: Standard error

$* * * \mathrm{p}<.001 ; * * .001<\mathrm{p}<.01 ; * .01<\mathrm{p}<.05$. 


\section{Appendix A \\ Study Population: Adult Fee-for-Service Medicaid Beneficiaries \\ Multistate Medicaid Analytical Extract Files - 2009-2010 \\ (Example: West Virginia)}

- 22-64 years old

- Medicaid beneficiaries residing in WV during 2009

$$
\mathrm{N}=89,951
$$

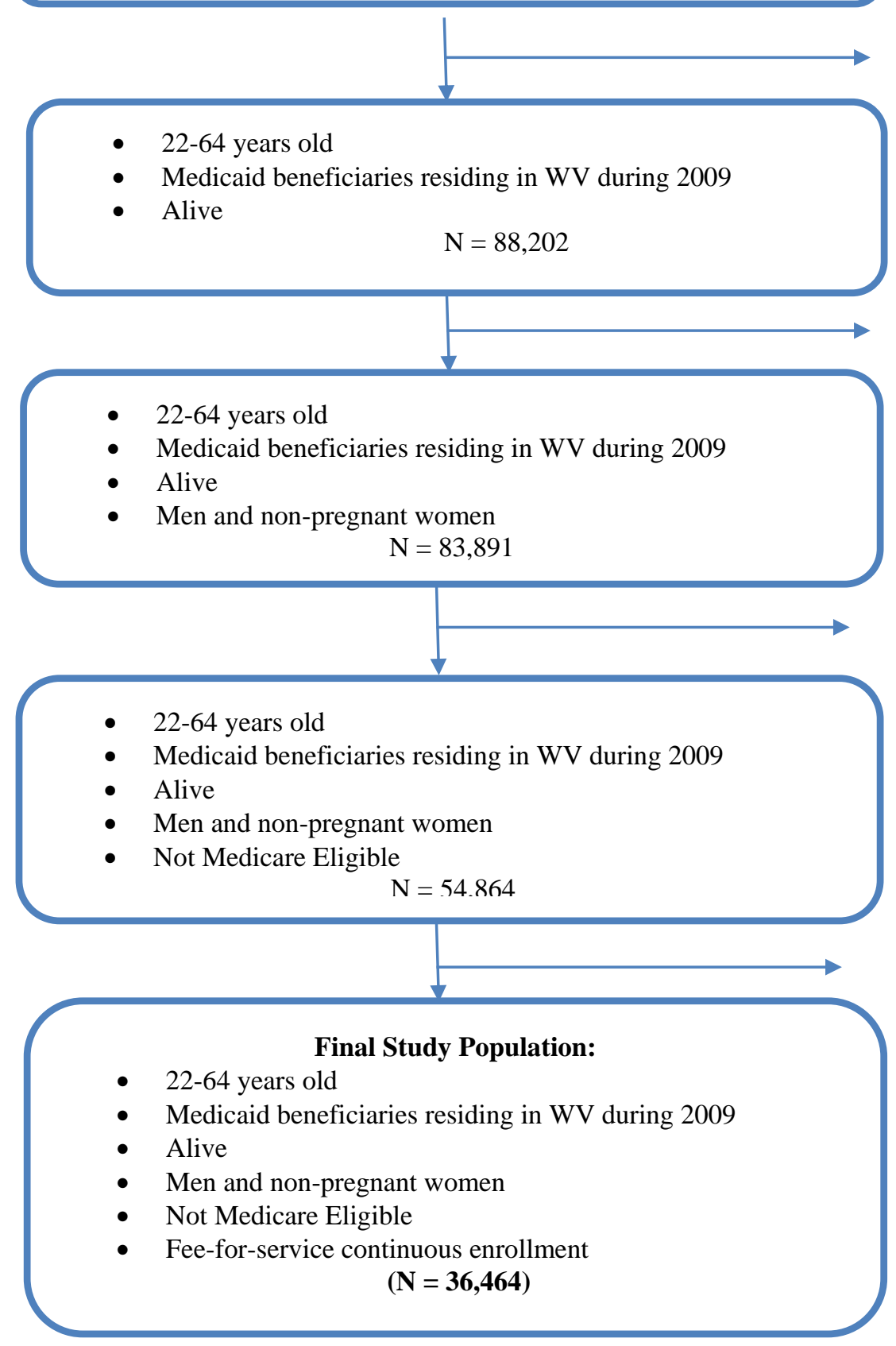

Reason for exclusion:

- $\quad$ Death in 2009 and $2010(N=1,749)$

Reasons for exclusion:

- Pregnant women in 2009 and $2010(N=4,311)$

Reasons for exclusion:

- Medicare eligibility in 2009 and $2010(N=29,027)$

Reasons for exclusion:

- Managed care and FFS not continuous in 2009 and $2010(\mathrm{~N}=$ $18,400)$ 


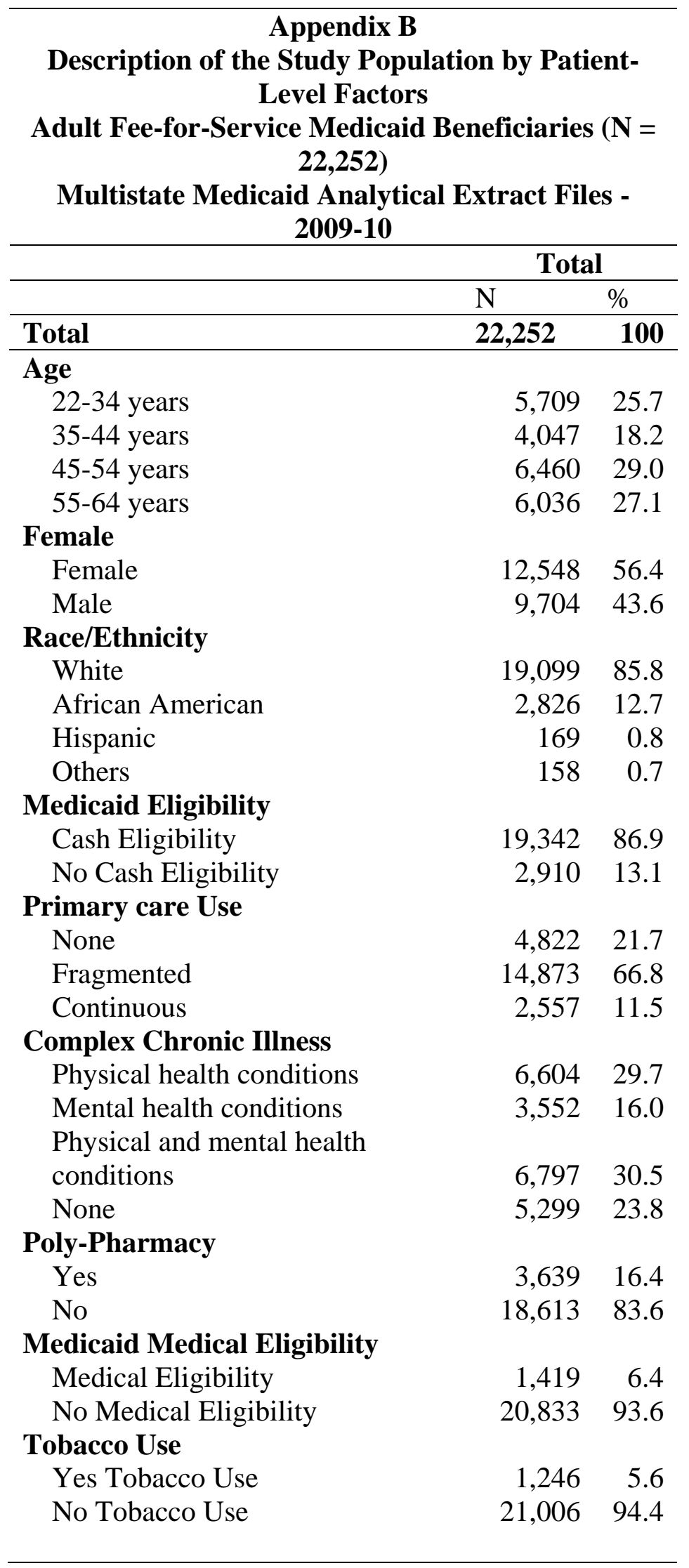




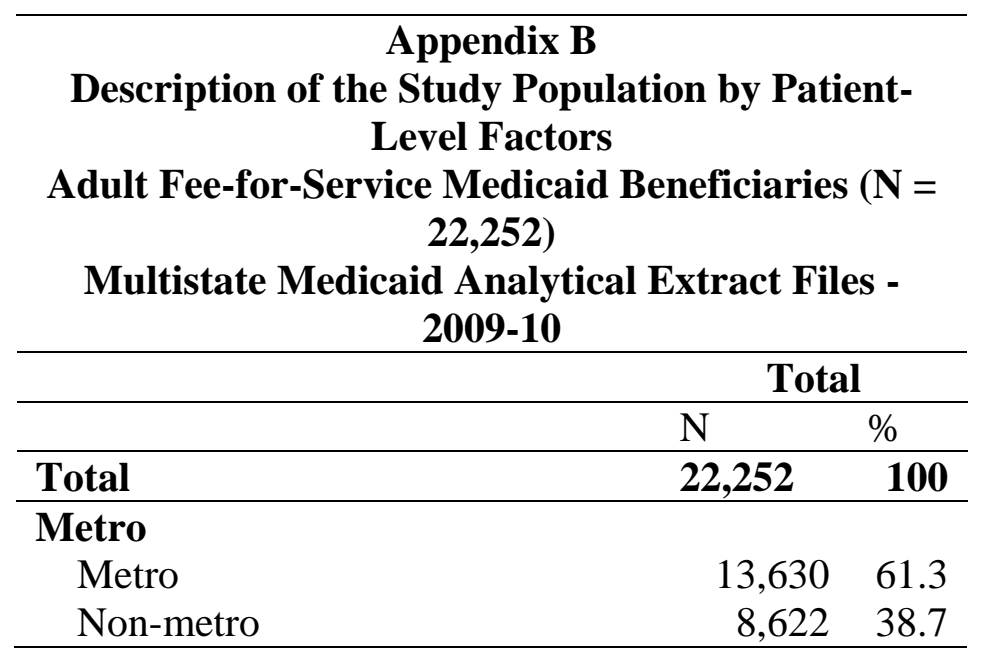

Note: Based on 22,252 adult Medicaid fee-for-service beneficiaries aged 22-64 years and who are continuously enrolled for the year 2009 and 2010, who are not Medicare and Medicaid eligible, who are alive and non-pregnant and were either persistent ED users or non-users. 


\begin{tabular}{|c|c|c|c|c|}
\hline \multicolumn{5}{|c|}{$\begin{array}{c}\text { Appendix C } \\
\text { Total Expenditures and Beta Coefficients from } \\
\text { Adjusted Generalized Linear Models with Log Link Function } \\
\text { by Persistent Emergency Department Use } \\
\text { Adult Fee-for-Service Medicaid Beneficiaries } \\
\text { Multistate Medicaid Analytical Extract Files - 2009-10 }\end{array}$} \\
\hline & Beta & $95 \% \mathrm{CI}$ & Change (\$) & Sig \\
\hline \multicolumn{5}{|l|}{ Persistent Emergency Department } \\
\hline $\begin{array}{l}\text { Persistent ED users } \\
\text { Non-Users }\end{array}$ & 0.72 & $(0.58,0.87)$ & $3,088.04$ & $* * *$ \\
\hline \multicolumn{5}{|l|}{ Age } \\
\hline \multicolumn{5}{|l|}{$22-34$ years } \\
\hline $35-44$ years & -0.51 & $(-0.66,-0.37)$ & $-1,168.11$ & $* * *$ \\
\hline $45-54$ years & -0.89 & $(-1.02,-0.75)$ & $-1,704.80$ & $* * *$ \\
\hline $55-64$ years & -1.01 & $(-1.12,-0.89)$ & $-1,840.65$ & $* * *$ \\
\hline \multicolumn{5}{|l|}{ Gender } \\
\hline $\begin{array}{l}\text { Female } \\
\text { Male }\end{array}$ & \multicolumn{3}{|c|}{ Male } & \\
\hline \multicolumn{4}{|l|}{ Race/Ethnicity } & White \\
\hline African American & 0.01 & $(-0.10,0.13)$ & 39.91 & \\
\hline Hispanic & -0.39 & $(-1.13,0.35)$ & -936.72 & \\
\hline Others & 0.21 & $(-0.21,0.63)$ & 675.28 & \\
\hline \multicolumn{4}{|l|}{ Medicaid Eligibility } & Cash Eligibility \\
\hline No Cash Eligibility & -0.15 & $(-0.30,0.00)$ & -400.45 & $*$ \\
\hline \multicolumn{5}{|l|}{ County-level Education } \\
\hline Percent with college education & 0.04 & $(0.03,0.06)$ & 128.94 & $* * *$ \\
\hline \multicolumn{5}{|l|}{ County-level Unemployment } \\
\hline Percent unemployed & 0.25 & $(0.20,0.30)$ & 831.96 & $* * *$ \\
\hline \multicolumn{5}{|l|}{ Primary Care Use } \\
\hline None & -0.18 & $(-0.27,-0.08)$ & -470.98 & $* * *$ \\
\hline \multicolumn{5}{|l|}{ Continuous } \\
\hline \multicolumn{5}{|l|}{ Complex Chronic Illness } \\
\hline Physical health conditions & 0.27 & $(0.13,0.40)$ & 885.00 & $* * *$ \\
\hline Mental health conditions & 0.27 & $(0.13,0.41)$ & 899.95 & $* * *$ \\
\hline $\begin{array}{l}\text { Physical and mental health conditions } \\
\text { None }\end{array}$ & 0.39 & $(0.26,0.52)$ & $1,385.83$ & $* * *$ \\
\hline \multicolumn{5}{|l|}{ Poly-Pharmacy } \\
\hline $\begin{array}{l}\text { Yes } \\
\text { No }\end{array}$ & 0.61 & $(0.54,0.69)$ & $2,457.06$ & $* * *$ \\
\hline
\end{tabular}




\begin{tabular}{|c|c|c|c|c|}
\hline \multicolumn{5}{|c|}{$\begin{array}{c}\text { Appendix C } \\
\text { Total Expenditures and Beta Coefficients from } \\
\text { Adjusted Generalized Linear Models with Log Link Function } \\
\text { by Persistent Emergency Department Use } \\
\text { Adult Fee-for-Service Medicaid Beneficiaries } \\
\text { Multistate Medicaid Analytical Extract Files - 2009-10 }\end{array}$} \\
\hline & Beta & $95 \% \mathrm{CI}$ & Change (\$) & Sig \\
\hline $\begin{array}{l}\text { Medicaid Medical Eligibility } \\
\text { Medical Eligibility }\end{array}$ & & & & \\
\hline No Medical Eligibility & 0.98 & $(0.68,1.28)$ & $4,820.65$ & $* * *$ \\
\hline $\begin{array}{l}\text { Tobacco Use } \\
\text { Yes Tobacco Use } \\
\text { No Tobacco Use }\end{array}$ & -0.20 & $(-0.33,-0.07)$ & -531.53 & $* *$ \\
\hline $\begin{array}{l}\text { County-level Obesity } \\
\text { Obesity Rate }\end{array}$ & -0.03 & $(-0.06,0.00)$ & -80.60 & \\
\hline $\begin{array}{l}\text { Health Professional Shortage Area } \\
\text { No shortage } \\
\text { Part county shortage } \\
\text { Whole county shortage }\end{array}$ & $\begin{array}{r}-0.10 \\
0.10\end{array}$ & $\begin{array}{l}(-0.27,0.08) \\
(-0.04,0.24)\end{array}$ & $\begin{array}{r}-264.38 \\
308.30\end{array}$ & \\
\hline $\begin{array}{l}\text { Metro Status } \\
\text { Metro } \\
\text { Non-metro }\end{array}$ & -0.13 & $(-0.28,0.01)$ & -364.65 & \\
\hline $\begin{array}{l}\text { Emergency Departments } \\
\text { Number of ED /100,000 population }\end{array}$ & 0.00 & $(-0.04,0.04)$ & -1.27 & \\
\hline $\begin{array}{l}\text { Psychiatric Emergency Services } \\
\text { Number of Psychiatric ED/100,000 } \\
\text { population }\end{array}$ & 0.01 & $(-0.08,0.09)$ & 25.33 & \\
\hline $\begin{array}{l}\text { Rural Health Centers } \\
\text { Number of rural health centers/100,000 } \\
\text { population }\end{array}$ & -0.01 & $(-0.02,0.00)$ & -22.38 & \\
\hline $\begin{array}{l}\text { Urgent Care Centers } \\
\text { Number of urgent care centers/100,000 } \\
\text { population }\end{array}$ & -0.06 & $(-0.10,-0.03)$ & -182.02 & $* * *$ \\
\hline $\begin{array}{l}\text { Federally Qualified Health Centers } \\
\text { Number of FQHCs/100,000 population }\end{array}$ & -0.01 & $(-0.01,0.00)$ & -19.49 & $*$ \\
\hline $\begin{array}{l}\text { Community mental health centers } \\
\text { Number of community mental health } \\
\text { centers } / 100,000 \text { population }\end{array}$ & 0.02 & $(-0.22,0.26)$ & 52.96 & \\
\hline
\end{tabular}

Note: Based on 22,252 adult Medicaid fee-for-service beneficiaries aged 22-64 years and who are continuously enrolled for the year 2009 and 2010, who are not Medicare and Medicaid eligible, who are alive and non-pregnant. Beta coefficients are from the IPTW-adjusted generalized linear models. 
ED: Emergency Department; Sig: Significance $* * * \mathrm{p}<.001 ; * * .001<\mathrm{p}<.01 ; * .01<\mathrm{p}<.05$. 


\begin{tabular}{lcrr}
\hline \multicolumn{4}{c}{$\begin{array}{c}\text { Appendix D } \\
\text { Total Expenditures and Beta Coefficients from }\end{array}$} \\
Adjusted Generalized Linear Models with Log Link Function \\
by Persistent Emergency Department Use \\
Adult Fee-for-Service Medicaid Beneficiaries \\
Multistate Medicaid Analytical Extract Files - 2009-10 & \\
\hline \multicolumn{4}{r}{} \\
Non-users & Beta & Change (\$) & Sig \\
Non-user --user & -0.67 & $5,545.46$ & $* * *$ \\
User--Non-user & -0.40 & $3,752.94$ & $* * *$ \\
Others & -0.67 & $5,560.79$ & $* * *$ \\
\hline
\end{tabular}

Note: Based on 22,252 adult Medicaid fee-for-service beneficiaries aged 22-64 years and who are continuously enrolled for the year 2009 and 2010, who are not Medicare and Medicaid eligible, who are alive and non-pregnant. Beta coefficients are from the IPTW-adjusted generalized linear models. Beta coefficients were adjusted for both patient- and county-level factors. ED use overtime consisted of 5 categories, which were: 1) no ED use in both years (nonusers); 2) No ED use in the index and ED use in the follow-up year; 3) ED use in the index and no ED use in the follow-up year; 4) persistent ED use ( $\geq 4$ visits in index and follow-up years); and 5) other ED users.

ED: Emergency Department; Sig: Significance

$* * * \mathrm{p}<.001 ; * * .001<\mathrm{p}<.01 ; * .01<\mathrm{p}<.05$. 


\begin{tabular}{|c|c|c|c|c|}
\hline \multicolumn{5}{|c|}{$\begin{array}{c}\text { Appendix E } \\
\text { Beta Coefficients from } \\
\text { Adjusted Quantile Regressions } \\
\text { by Persistent Emergency Department Use } \\
\text { Adult Fee-for-Service Medicaid Beneficiaries } \\
\text { Multistate Medicaid Analytical Extract Files - 2009-10 }\end{array}$} \\
\hline & \multicolumn{4}{|c|}{ Quantile Coefficients } \\
\hline & 0.25 & 0.50 & 0.75 & 0.90 \\
\hline $\begin{array}{l}\text { Persistent ED users } \\
\text { Non-users }\end{array}$ & $3,073.85^{* * *}$ & $7,189.94 * * *$ & $16,201.68 * * *$ & $34,372.94 * * *$ \\
\hline
\end{tabular}

Note: Based on 22,252 adult Medicaid fee-for-service beneficiaries aged 22-64 years and who are continuously enrolled for the year 2009 and 2010, who are not Medicare and Medicaid eligible, who are alive and non-pregnant. Beta coefficients are from the IPTW-adjusted Quantile Regressions. Beta coefficients were adjusted for both patient- and county-level factors.

ED: Emergency Department; Sig: Significance

$* * * \mathrm{p}<.001 ; * * .001<\mathrm{p}<.01 ; * .01<\mathrm{p}<.05$. 


\section{References}

1. National Association of Community Health Centers 2006 Data on Community Health Centers Summary of Findings National Association of Community Health Centers;2006.

2. Hospital-Based Emergency Care: At the Breaking Point. Washington, DC: The National Academies Press; 2007.

3. Finnell JT, Overhage JM, Grannis S. All health care is not local: an evaluation of the distribution of Emergency Department care delivered in Indiana. AMIA ... Annual Symposium proceedings / AMIA Symposium. AMIA Symposium. 2011;2011:409-416.

4. Hasselman D. Super-Utilizer Summit Common Themes from Innovative Complex Care Management Programs. 2013; http://www.rwjf.org/content/dam/farm/reports/reports/2013/rwjf407990. Accessed 11th November, 2014.

5. O'Brien GM, Stein MD, Zierler S, Shapiro M, O'Sullivan P, Woolard R. Use of the ED as a regular source of care: associated factors beyond lack of health insurance. Ann Emerg Med. Sep 1997;30(3):286-291.

6. Sandoval E, Smith S, Walter J, et al. A comparison of frequent and infrequent visitors to an urban emergency department. J Emerg Med. Feb 2010;38(2):115-121.

7. Blank FS, Li H, Henneman PL, et al. A descriptive study of heavy emergency department users at an academic emergency department reveals heavy ED users have better access to care than average users. Journal of emergency nursing: JEN : official publication of the Emergency Department Nurses Association. Apr 2005;31(2):139-144.

8. Zuckerman S, Shen YC. Characteristics of occasional and frequent emergency department users: do insurance coverage and access to care matter? Medical care. Feb 2004;42(2):176-182.

9. Friedman BW, Serrano D, Reed M, Diamond M, Lipton RB. Use of the emergency department for severe headache. A population-based study. Headache. Jan 2009;49(1):21-30.

10. Cook LJ, Knight S, Junkins EP, Jr., Mann NC, Dean JM, Olson LM. Repeat patients to the emergency department in a statewide database. Academic emergency medicine : official journal of the Society for Academic Emergency Medicine. Mar 2004;11(3):256263.

11. Hunt KA, Weber EJ, Showstack JA, Colby DC, Callaham ML. Characteristics of frequent users of emergency departments. Ann Emerg Med. Jul 2006;48(1):1-8.

12. Mandelberg JH, Kuhn RE, Kohn MA. Epidemiologic analysis of an urban, public emergency department's frequent users. Academic emergency medicine : official journal of the Society for Academic Emergency Medicine. Jun 2000;7(6):637-646.

13. Ruger JP, Richter CJ, Spitznagel EL, Lewis LM. Analysis of costs, length of stay, and utilization of emergency department services by frequent users: implications for health policy. Academic emergency medicine : official journal of the Society for Academic Emergency Medicine. Dec 2004;11(12):1311-1317.

14. Lucas RH, Sanford SM. An analysis of frequent users of emergency care at an urban university hospital. Ann Emerg Med. Nov 1998;32(5):563-568.

15. Genell Andren K, Rosenqvist U. Heavy users of an emergency department--a two year follow-up study. Social science \& medicine. 1987;25(7):825-831.

16. Kne T, Young R, Spillane L. Frequent ED users: patterns of use over time. The American journal of emergency medicine. Nov 1998;16(7):648-652. 
17. Kennedy D, Ardagh M. Frequent attenders at Christchurch Hospital's Emergency Department: a 4-year study of attendance patterns. The New Zealand medical journal. May 7 2004;117(1193):U871.

18. Hwang AS, Liu SW, Ashburner JM, Auerbach BJ, Atlas SJ, Hong CS. Outcomes of primary care patients who are frequent and persistent users of the ED. The American journal of emergency medicine. Sep 2015;33(9):1320-1322.

19. Shapiro JS, Johnson SA, Angiollilo J, Fleischman W, Onyile A, Kuperman G. Health information exchange improves identification of frequent emergency department users. Health Aff (Millwood). Dec 2013;32(12):2193-2198.

20. Fuda KK, Immekus R. Frequent users of Massachusetts emergency departments: a statewide analysis. Ann Emerg Med. Jul 2006;48(1):9-16.

21. Capp R, Rosenthal MS, Desai MM, et al. Characteristics of Medicaid enrollees with frequent ED use. The American journal of emergency medicine. Sep 2013;31(9):13331337.

22. Pitts SR, Carrier ER, Rich EC, Kellermann AL. Where Americans get acute care: increasingly, it's not at their doctor's office. Health Aff (Millwood). Sep 2010;29(9):16201629.

23. Weber EJ, Showstack JA, Hunt KA, Colby DC, Callaham ML. Does lack of a usual source of care or health insurance increase the likelihood of an emergency department visit? Results of a national population-based study. Ann Emerg Med. Jan 2005;45(1):412.

24. Billings J, Raven MC. Dispelling an urban legend: frequent emergency department users have substantial burden of disease. Health Aff (Millwood). Dec 2013;32(12):2099-2108.

25. Bamezai A, Melnick G, Nawathe A. The cost of an emergency department visit and its relationship to emergency department volume. Ann Emerg Med. May 2005;45(5):483490.

26. Gill JM, Mainous AG, 3rd, Nsereko M. The effect of continuity of care on emergency department use. Archives of family medicine. Apr 2000;9(4):333-338.

27. McWilliams A, Tapp H, Barker J, Dulin M. Cost analysis of the use of emergency departments for primary care services in Charlotte, North Carolina. North Carolina medical journal. Jul-Aug 2011;72(4):265-271.

28. A Matter of Urgency: Reducing Emergency Department Overuse. 2010; http://www.nehi.net/writable/publication_files/file/nehi_ed_overuse_issue_brief_032610f inaledits.pdf. Accessed Aug, 2015.

29. Thygeson M, Van Vorst KA, Maciosek MV, Solberg L. Use and costs of care in retail clinics versus traditional care sites. Health Aff (Millwood). Sep-Oct 2008;27(5):12831292.

30. Mehrotra A, Liu H, Adams JL, et al. Comparing costs and quality of care at retail clinics with that of other medical settings for 3 common illnesses. Annals of internal medicine.

Sep 1 2009;151(5):321-328.

31. NHE Fact Sheet. 2015; https://www.cms.gov/research-statistics-data-andsystems/statistics-trends-and-reports/nationalhealthexpenddata/nhe-fact-sheet.html.

Accessed Oct, 2015.

32. Cunningham PJ. What accounts for differences in the use of hospital emergency departments across U.S. communities? Health Aff (Millwood). Sep-Oct 2006;25(5):w324336. 
33. Cheung PT, Wiler JL, Lowe RA, Ginde AA. National study of barriers to timely primary care and emergency department utilization among Medicaid beneficiaries. Ann Emerg Med. Jul 2012;60(1):4-10 e12.

34. Mortensen K, Song PH. Minding the gap: a decomposition of emergency department use by Medicaid enrollees and the uninsured. Medical care. Oct 2008;46(10):1099-1107.

35. Gawande A. The hot spotters: can we lower medical costs by giving the neediest patients better care? New Yorker. Jan 2011:40-51.

36. HRSA. Area Health Resources Files (AHRF) National, State and County Health Resources Information Database. http://ahrf.hrsa.gov/download.htm. Accessed Aug, 2015.

37. County Health Rankings \& Roadmaps: Our Approach. http://www.countyhealthrankings.org/. Accessed Aug, 2015.

38. BLS. Consumer Price Index. Bureau of Labor Statistics: United States Department of Labor.

39. Magill MK, Senf J. A new method for measuring continuity of care in family practice residencies. The Journal of family practice. Feb 1987;24(2):165-168.

40. Goldberg JF, Brooks JO, 3rd, Kurita K, et al. Depressive illness burden associated with complex polypharmacy in patients with bipolar disorder: findings from the STEP-BD. The Journal of clinical psychiatry. Feb 2009;70(2):155-162.

41. NQF. Establishing a Measurement Establishing a Measurement Framework for Multiple Framework for Multiple Chronic Conditions. Washington, DC: National Quality Forum;2011.

42. Goodman RA, Posner SF, Huang ES, Parekh AK, Koh HK. Defining and measuring chronic conditions: imperatives for research, policy, program, and practice. Preventing chronic disease. 2013;10:E66.

43. Weinick RM, Burns RM, Mehrotra A. Many emergency department visits could be managed at urgent care centers and retail clinics. Health Aff (Millwood). Sep 2010;29(9):1630-1636.

44. Mason D. JAMA Forum: The Affordable Care Act and Emergency Care Visits: Why Choose the Emergency Department? 2014;

http://newsatjama.jama.com/2014/02/26/jama-forum-the-affordable-care-act-andemergency-care-visits-why-choose-the-emergency-department/. Accessed 11th Novermeber, 2014.

45. CDC. Emergency Department Visits. 2014; http://www.cdc.gov/nchs/fastats/emergencydepartment.htm. Accessed 22nd November, 2014.

46. HealthIT.gov. State Health Information Exchange. State Health Information Exchange Cooperative Agreement Program 2014; http://www.healthit.gov/policy-researchersimplementers/state-health-information-exchange. Accessed 24th November, 2014.

47. Frisse ME, Johnson KB, Nian H, et al. The financial impact of health information exchange on emergency department care. Journal of the American Medical Informatics Association : JAMIA. May-Jun 2012;19(3):328-333.

48. Sridhar S, Brennan PF, Wright SJ, Robinson SM. Optimizing financial effects of HIE: a multi-party linear programming approach. Journal of the American Medical Informatics Association : JAMIA. Nov-Dec 2012;19(6):1082-1088.

49. Castillo EM, Brennan JJ, Killeen JP, Chan TC. Identifying frequent users of emergency department resources. Journal of Emergency Medicine.47(3):343-347. 


\section{CHAPTER 5}

\section{Summary of Findings, Discussion and Conclusions}

The purpose of this dissertation was to provide a comprehensive understanding of the ED use and ED visits among adult fee-for-service Medicaid beneficiaries. To accomplish the purpose, three-related objectives were formed. These were to: 1) examine patient- and countylevel characteristics associated with the number of ED visits among adult fee-for-service (FFS) Medicaid beneficiaries; examine the reasons for ED visits among ED users; 2) analyze the variation in the number of ED visits over time among adult FFS Medicaid beneficiaries; describe primary care sensitive ED visits over time at the visit-level; and investigate the patient- and county-level factors associated with persistent ED use and its impact on healthcare expenditures. Reasons for ED visits were described with the following classification of visits for conditions that: 1) did not require immediate ED care;2) are treatable in primary care settings; 3) could have been prevented, if timely primary care was provided; 4) required immediate ED care; 5) injury; and 6) psychiatric disorders. To achieve the objectives of this dissertation, Medicaid feefor-service claims data for years 2006 through 2010 for residents of MD, OH, and WV were selected.

\section{Overall Findings}

\section{Cross-sectional Analyses}

\section{Patient- and County-Level Factors associated with Number of ED Visits}

Cross-sectional analyses of data, revealed that out of 68,882 individuals, more than half had one or more ED visit during 2010. Both patient- and county-level factors were associated with ED visits. Following sub-groups of the study population had higher number of ED visits: African Americans, Hispanics, those with fragmented primary care use, those with physical health conditions, those with mental health conditions, those with both physical and mental 
health conditions, those with poly-pharmacy, those eligible for Medicaid due to medical needs, and those with tobacco use.

Following county-level factors were associated with higher number of ED visits: number of EDs/100,000 population. Following factors were associated with lower number of ED visits: county-level unemployment rate, those who had no primary care use, and number of urgent care centers/100,000 population. Urgent care centers are less expensive settings for provision of healthcare as compared to EDs. It is evident from published literature that urgent care centers can prevent approximately one-fourth of the ED visits. ${ }^{1}$ The reasons behind low rates of ED visits by individuals living in counties with high unemployment rate are not known. Future studies may need to examine the relationship between ED visits and patient-level unemployment and poverty status.

\section{Type of ED visits among ED users}

At the ED visit-level, three in five ED visits were for the management of ACSCs. Out of 123,554 ED visits in 2010, 23.3\% did not require immediate ED care, $19.21 \%$ were treatable in primary care settings, $6.7 \%$ were preventable if timely primary care was provided, $18.08 \%$ required immediate ED care, $18.11 \%$ were due to injury, $5.63 \%$ were due to psychiatric disorders, and $9.01 \%$ were unclassified. These findings suggest that timely and continuous primary care in outpatient healthcare settings can reduce the frequency of ED visits among adult FFS Medicaid beneficiaries.

\section{Longitudinal Analyses}

\section{ED Use over Time}

Nearly $50 \%$ of the study population had ED use every year from 2007 through 2010. In multivariable analyses, ED use did not change from year to year. Those with fragmented primary care use, presence of complex chronic illnesses, poly-pharmacy, and tobacco were more likely to 
use ED. Residents in the counties with higher number of urgent care centers were less likely to use ED.

\section{Number of ED Visits over Time among ED Users}

Among ED users, the number of ED visits increased over time. But the increase was of a very small magnitude. Those with fragmented primary care use, presence of complex chronic illnesses, poly-pharmacy, and tobacco had higher number of ED visits. Residents in counties with higher number of urgent care centers had lower number of ED visits. The increase in the intensity of ED use may be due to increasing complexity and fragmented primary care use for extended period of time. Policy-makers may implement policies to identify these high-need individuals. Further, programs and interventions may be implemented to reduce the number of ED visits among ED users.

\section{Type of ED Visits among ED Users}

Similar to cross-sectional analyses findings, at the ED-visit level, approximately, $55 \%$ of the ED visits were primary care sensitive in each year. To reduce the number of ED visits, it is important to explore ways to triage patients with non-emergent care needs to other healthcare settings.

\section{Persistent ED Use over Time}

One in ten adults with fee-for-service Medicaid were persistent ED users, defined as greater than or equal to $4 \mathrm{ED}$ visits for two consecutive years. Persistent ED users were significantly different from non-users. Persistent ED users were more likely to have fragmented primary care use, complex chronic illness, poly-pharmacy and poor lifestyle practices such as tobacco use. Medicaid beneficiaries residing in counties with higher number of urgent care centers were less likely to have persistent ED use. A higher proportion of persistent ED users had inpatient use as compared to non-users. 


\section{Persistent ED Use and its Impact on Healthcare Expenditures}

Persistent ED users had twice as much total healthcare expenditures (that did not include ED expenditures) as non ED users. Similar findings were observed for prescription drugs and outpatient expenditures. After controlling for patient- and county-level factors, persistent ED users had significantly higher total, prescription drugs, and outpatient expenditures.

\section{Implications of Study Findings}

Across all three studies, it was observed that Medicaid beneficiaries with complex chronic illness (i.e. presence of both physical and mental health conditions) were more likely to use ED, use ED persistently, and have higher number of ED visits. Similar findings were observed for those with poly-pharmacy, and poor lifestyle practices such as tobacco use. A plausible explanation for higher ED visits by those with chronic complex illness may be due to complications of chronic conditions, side effects and adverse events due to multiple prescription drugs use, ${ }^{2}$ fragmented care because of visits to multiple healthcare providers, "and/or direct contraindications to therapy for one condition by other conditions themselves." ${ }^{3}$ These findings highlight the need to design interventions and programs tailored to the needs of this particular subgroup of the population. It is challenging to manage conditions that co-occur and indeed, it was noted across all three studies that adult FFS Medicaid beneficiaries had higher rates of cooccurring physical and mental health conditions. This implies that this subgroup of the population has very different healthcare needs and there may be a need to improve the connectivity between ambulatory care settings and other healthcare services such as care management. Indeed, in a systematic review that examined the effectiveness of various interventions implemented on frequent ED users, it was noted that case management was the most effective intervention in reducing healthcare costs and improving clinical outcomes. ${ }^{4}$

It was also observed those with fragmented primary care were more likely to use ED, use ED persistently and have higher number of ED visits. At the visit-level approximately half of the 
ED visits were due to primary care sensitive conditions. Taken together, these findings suggest that timely and continuous primary care in outpatient healthcare settings can reduce the frequency of ED visits among adult FFS Medicaid beneficiaries.

Presence of complex chronic illness was also associated with persistent ED use and higher healthcare expenditures among persistent ED users. Therefore, healthcare delivery models that provide comprehensive care to patients with complex healthcare needs may reduce the intensity of ED visits and reduce healthcare expenditures. Further research is required to study the effectiveness of these healthcare delivery models on the number of ED visits and persistent ED use.

The study findings also highlight the need for the conduct of longitudinal studies of ED visits. For example, in the cross-sectional analysis, it was observed that females had lower number of ED visits as compared to males. However, in the longitudinal analyses it was noted that females had significantly higher number of ED visits as compared to males and females were more likely to be persistent ED users as compared to males. This finding highlights the need for conducting longitudinal studies i.e. following patients over time to identify their characteristics. Future studies need to examine the underlying reasons behind gender disparities that are associated with increased ED use. Identification of the characteristics may contribute in reducing the number of ED visits and associated healthcare expenditures.

Both in the cross-sectional and longitudinal analysis it was observed that adults aged 2234 years had higher number of ED visits. It was also observed that adults in this particular age group were more likely to be persistent ED users. This finding is inconsistent with the findings of Skinner et al. who noted an increase in ED visits among adults aged 45-64 years. ${ }^{5}$ The differences in the findings may be due to type of data used as findings from this study were based on visit level data. Moreover, the study lacked any robust analysis i.e. controlling for other 
factors which may be attribute to a different finding. Tang et al. also observed a significant increase in the ED visits among adult ED users using visit level data. ${ }^{6}$ This again highlights the need for conducting more longitudinal studies to identify the characteristics of the ED users.

Across all three studies it was observed that residents in counties with higher number of urgent care centers/100,000 population had lower number of ED visits and residents in counties with higher number of urgent care centers were less likely to be persistent ED user. Published studies suggest that urgent care centers may prevent ED visits and can manage care at lower costs. ${ }^{1,7,8}$ As many ED visits tend to happen after business hours, ${ }^{9}$ facilitating after-hour care, extending primary care office hours, and increasing the supply of urgent care centers can go a long way in reducing the frequency of ED visits ${ }^{10}$ and may lead to reduction in total healthcare expenditures. A study by Weinick et al. observed about $13.1 \%$ to $27.1 \%$ of ED visits can be prevented with increased use of urgent care centers and other healthcare settings. ${ }^{1}$ Studies that compared urgent center care and ED found that costs of care in urgent care centers are lower as compared to EDs. ${ }^{7,8}$ Thus, the urgent care centers can be a viable substitute for EDs in providing care for acute conditions and exacerbations of chronic conditions. ${ }^{1}$

These findings are important because currently there is an increased attention towards identifying frequent users of healthcare services as they exert a pressure on already overburdened healthcare system and are attributable to increased healthcare expenditures. These findings underscore the fact that county-level resources may impact ED use and policy-makers may determine the need to invest in additional healthcare resources to reduce the number of ED visits. With the implementation of the Affordable Care Act (ACA), policy-makers are concerned that the increased coverage may affect the utilization of healthcare services. There is an increased emphasis to provide coordinated care through patient centered medical homes, health homes and accountable care organizations. This stimulates the need to identify the characteristics of 
persistent users of healthcare services to design policies, interventions and programs for improvement of the healthcare delivery system.

Although, it was observed that primary care use was fragmented among ED users, however, no statistically significant relationship was observed between health professional shortage areas (HPSA) and the number of ED visits in all the studies. This finding needs to be interpreted with caution because the HPSA designations were formed in 1978 and several reports have been issued by the Government Accountability Office criticizing the ineffectiveness of these designations to identify the shortage areas. ${ }^{11,12}$

\section{Significance of Study Findings:}

\section{Healthcare Policy}

With the implementation of ACA, there is an increased focus on identifying the characteristics of the individuals who are persistent users of healthcare services such as EDs. Current research suggests that the provision of health insurance may affect the demand for healthcare services. ACA primarily aimed at increasing primary care access to the uninsured and reduce ED utilization. Earlier experiences with expanded coverage have shown mixed results for increase or decrease in the ED utilization rates. Due to paucity of data, it is difficult to examine the impact of the provision of health insurance coverage on ED utilization. However, this dissertation aimed at providing a baseline analysis that can be used to compare potential changes as a result of ACA implementation. Findings were derived using Medicaid claims data for the states that have expanded for Medicaid. Additionally, it is documented in the literature that Medicaid beneficiaries visiting ED repeatedly are those with unmet medical needs and may lead to higher healthcare spending for the payers. ${ }^{13}$ With Medicaid expansion under the ACA, these costs may increase creating an extra burden on this state funded program.

\section{Medicaid}


Medicaid is an important source of health insurance coverage in the US for low-income families and children and disabled Medicare beneficiaries. Under the ACA, due to Medicaid expansion, Medicaid's importance has increased as more low-income individuals are getting enrolled into Medicaid with income up to $138 \%$ of the federal poverty line. ${ }^{14}$ The impact of the Medicaid expansion on ED utilization is yet to be seen. States plan to monitor individuals who visit ED repeatedly very closely and implement policies to reduce preventable ED visits and consequent hospitalizations. ${ }^{13}$ This initiative is undertaken to reduce the economic burden and provide better healthcare management to individuals with high medical needs. As most studies in the literature report that the ED users are covered through Medicaid, it is critical to identify these users using Medicaid administrative claims data. ${ }^{9,15}$

\section{County-level Resources}

Medicaid beneficiaries residing in the counties with urgent care centers had lower ED visits. This finding was observed across all three studies. It is evident from previous research that urgent care centers may reduce the ED visits and they are less expensive settings as compared to EDs. ${ }^{1}$ This highlights the need to increase the access to other healthcare resources to optimally distribute the higher number of ED visits.

\section{Administrative Claims Data}

Use of administrative claims data across all three studies allowed to follow Medicaid beneficiaries over the years and capture repeated ED visits. Majority of the studies in literature on ED visits are conducted using visit-level or national survey data. These databases may under/over-estimate the number of ED visits. Often, disease conditions and other information are self-reported in these databases which may lead to recall bias. Administrative claims data have their own limitation but they provide real-world evidence on patient's health history and allows longitudinal analysis of the healthcare services utilization. Further, administrative claims data have variety of information including other healthcare services use, and expenditures. 


\section{$\underline{\text { Strengths and Limitations }}$}

This dissertation has several strengths. A comprehensive list of patient-level and countylevel factors were used. These factors were obtained from different data sources and were linked together to provide complete information about the patient level factors and county-level healthcare resources. By relying on healthcare encounter data, the current study was able to capture services received from multiple providers, healthcare settings and geographical areas. Information on clinical diagnosis, prescription drugs and other healthcare services use were captured from claims data and do not have the shortcomings of self-reported data. The current study used patient-level data and was able to track repeated ED visits made by the same patient.

Findings of the dissertation need to be interpreted with consideration of some limitations. This study was conducted on alive, adult FFS Medicaid beneficiaries, aged 22-64 years old, continuously enrolled, not dually eligible, and residing in $\mathrm{MD}, \mathrm{OH}$, and WV. Considering the geographic population, policy, and resource differences typically seen across states, the results of this dissertation represent only $\mathrm{MD}, \mathrm{OH}$, and $\mathrm{WV}$ and not generalizable to the entire Medicaid population. As Medicaid beneficiaries enrolled under managed care plans were excluded from the analytical cohort, the dissertation suffers selection bias. The dissertation was conducted using an observational data, therefore it is difficult to account for selection bias as ED users may have different attributes in unobserved variables compared to the non-ED users. Substance abuse leads to increased ED use, however, the current study could not account for alcohol use and drug abuse because of limited sample size. Additionally, administrative claims data were used, which are created for billing purposes rather than research. This may result in misclassification of diagnosis.

In this dissertation, Medicaid claims data were combined with area health resource file (AHRF) that has some important limitations. Longitudinal Medicaid data were not combined 
with longitudinal AHRF data. Only single year AHRF data were used across all three studies. Although, all information on all variables was consistently collected for one year, however, if the information was not available data on year for which information was available were used. In this dissertation, although only obesity rates were used from the county health rankings, however in general these files have state average data for the counties which have low sample size.

\section{Future Research}

This dissertation reveals important findings specifically due to changing healthcare environment at this time. Data paucity restricts to study the current impact of ACA on healthcare services utilization. However, findings from this dissertation can be used in future to compare the ED utilization among Medicaid beneficiaries post-ACA. Additionally, this dissertation was conducted on states that have expanded for Medicaid. Findings from the current research may be used to study the impact of Medicaid expansion on ED utilization in these particular states. With the implementation of new payments models such as accountable care organizations, bundled payments, and episode-based payments there will be an increased focused on provision of value based care in EDs. Future research may focus on studying the impact of new payment models on the care provided in the EDs. In this dissertation, it was observed that adult FFS Medicaid beneficiaries had high rates of complex chronic illness, poly-pharmacy, and fragmented use of primary care. Future research may focus on examining whether care provided under collaborative care models impacts the health of Medicaid beneficiaries with complex healthcare needs. 


\section{References}

1. Weinick RM, Burns RM, Mehrotra A. Many emergency department visits could be managed at urgent care centers and retail clinics. Health Aff (Millwood). Sep 2010;29(9):1630-1636.

2. Hafner JW, Jr., Belknap SM, Squillante MD, Bucheit KA. Adverse drug events in emergency department patients. Ann Emerg Med. Mar 2002;39(3):258-267.

3. NQF. Establishing a Measurement Establishing a Measurement Framework for Multiple Framework for Multiple Chronic Conditions. Washington, DC: National Quality Forum;2011.

4. Althaus F, Paroz S, Hugli O, et al. Effectiveness of interventions targeting frequent users of emergency departments: A systematic review. Annals of Emergency Medicine. 2011;58(1):41-52.

5. Skinner HG, Blanchard J, Elixhauser A. Trends in Emergency Department Visits, 20062011: Statistical Brief \#179. Healthcare Cost and Utilization Project (HCUP) Statistical Briefs. Rockville (MD)2006.

6. Tang N, Stein J, Hsia RY, Maselli JH, Gonzales R. Trends and characteristics of US emergency department visits, 1997-2007. Jama. Aug 11 2010;304(6):664-670.

7. Thygeson M, Van Vorst KA, Maciosek MV, Solberg L. Use and costs of care in retail clinics versus traditional care sites. Health Aff (Millwood). Sep-Oct 2008;27(5):12831292.

8. Mehrotra A, Liu H, Adams JL, et al. Comparing costs and quality of care at retail clinics with that of other medical settings for 3 common illnesses. Annals of internal medicine. Sep 1 2009;151(5):321-328.

9. Pitts SR, Carrier ER, Rich EC, Kellermann AL. Where Americans get acute care: increasingly, it's not at their doctor's office. Health Aff (Millwood). Sep 2010;29(9):16201629.

10. Mason D. JAMA Forum: The Affordable Care Act and Emergency Care Visits: Why Choose the Emergency Department? 2014; http://newsatjama.jama.com/2014/02/26/jama-forum-the-affordable-care-act-andemergency-care-visits-why-choose-the-emergency-department/. Accessed 11th Novermeber, 2014.

11. GAO. HEALTH CARE SHORTAGE AREAS: Designations Not a Useful Tool for Directing Resources to the Underserved. U.S. Government Accountability Office; 8th Sept 1995.

12. GAO. HEALTH PROFESSIONAL SHORTAGE AREAS: Problems Remain with Primary Care Shortage Area Designation System. U.S. Government Accountability Office; 24th Oct 2006.

13. Mann C. Targeting Medicaid Super-Utilizers to Decrease Costs and Improve Quality Centers for Medicare \& Medicaid Services; 2013.

14. Centers for M, Medicaid Services HHS. Medicaid program; eligibility changes under the Affordable Care Act of 2010. Final rule, Interim final rule. Federal register. 2012;77(57):17144-17217.

15. Weber EJ, Showstack JA, Hunt KA, Colby DC, Callaham ML. Does lack of a usual source of care or health insurance increase the likelihood of an emergency department visit? Results of a national population-based study. Ann Emerg Med. Jan 2005;45(1):412. 